\title{
NIF Periscope Wall Modal Study Comparison of Results for 2 FEA Models with 2 Modal Tests
}

M. W. Eli, M. A. Gerhard, C. L. Lee, S. C. Sommer, T. G. Woehrle

October 26, 2000 


\section{DISCLAIMER}

This document was prepared as an account of work sponsored by an agency of the United States Government. Neither the United States Government nor the University of California nor any of their employees, makes any warranty, express or implied, or assumes any legal liability or responsibility for the accuracy, completeness, or usefulness of any information, apparatus, product, or process disclosed, or represents that its use would not infringe privately owned rights. Reference herein to any specific commercial product, process, or service by trade name, trademark, manufacturer, or otherwise, does not necessarily constitute or imply its endorsement, recommendation, or favoring by the United States Government or the University of California. The views and opinions of authors expressed herein do not necessarily state or reflect those of the United States Government or the University of California, and shall not be used for advertising or product endorsement purposes.

This work was performed under the auspices of the U. S. Department of Energy by the University of California, Lawrence Livermore National Laboratory under Contract No. W-7405-Eng-48.

This report has been reproduced directly from the best available copy.

Available electronically at http://www.doc.gov/bridge

Available for a processing fee to U.S. Department of Energy

And its contractors in paper from

U.S. Department of Energy

Office of Scientific and Technical Information

P.O. Box 62

Oak Ridge, TN 37831-0062

Telephone: (865) 576-8401

Facsimile: (865) 576-5728

E-mail: reports@adonis.osti.gov

Available for the sale to the public from

U.S. Department of Commerce

National Technical Information Service

5285 Port Royal Road

Springfield, VA 22161

Telephone: (800) 553-6847

Facsimile: (703) 605-6900

E-mail: orders@ntis.fedworld.gov

Online ordering: http://www.ntis.gov/ordering.htm

OR

Lawrence Livermore National Laboratory

Technical Information Department's Digital Library

http:/ / www.llnl.gov/tid/Library.html 


\title{
NIF - 0054932-OA \\ NIF Periscope Wall \\ Modal Study
}

Comparison of Results for

2 FEA Models with 2 Modal Tests

\section{Draft}

October 26, 2000

\author{
Prepared by:
}

Mark W. Eli

Structural and Applied Mechanics Group (SAMG)

New Technologies Engineering Div (NTED)

Mechanical Engineering (ME) Dept

\section{Michael A. Gerhard}

SAMG/NTED/ME

Christopher L. Lee

SAMG/NTED/ME

Stanley C. Sommer

NIF Systems Engineering

Thomas G. Woehrle

SAMG/NTED/ME 



\section{Table of Contents}

$\underline{\text { Section }} \quad \underline{\text { Page }}$

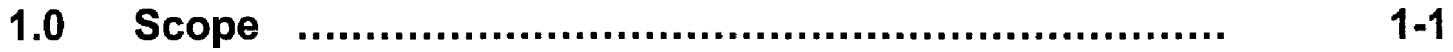

1.1 Purpose of Modal Tests for NIF Periscope $\quad \ldots . . . . . . . . . . . \quad 1-2$

1.2 NIF Criteria - The NIF Stability Budget $\ldots . . . \ldots \ldots \ldots . . . . . . .1-1$

2.0 Analytical Predictions Using Periscope Wall

Finite Element Model $\quad$............................................ $\quad 2-1$

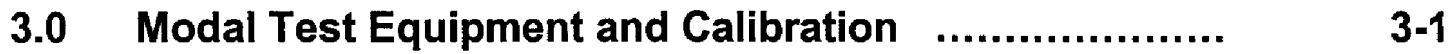

4.0 Experimental Modal Testing \& Analysis for Periscope Wall 4-1

5.0 Comparison of Analytical and Experimental Modal

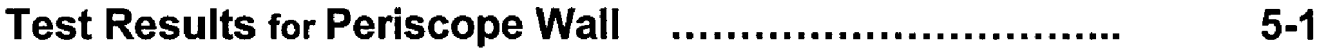

6.0 Modal Test Damping Results for Periscope Wall ............ 6-1

7.0 Verification of "Beta" Factor for SSI effects $\ldots \ldots \ldots \ldots . . . . . . .7$

8.0 Future Modal Test Plans for "Full" Periscope Assembly

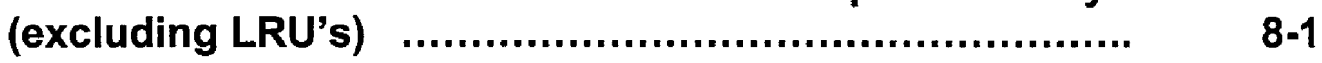

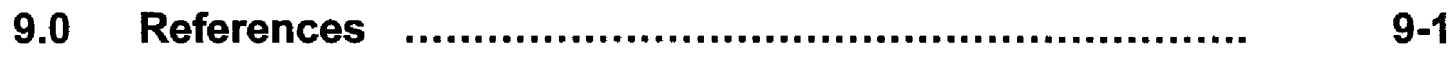

Appendix A

A.0 Modal Test of Periscope LM3/Polarizer LRU ......... A-1

Appendix B

B.0 Modal Damping Estimates for Global Modes 1 \& 2 of Instrumented Hammer Impulse ................... B-1

Appendix C

C.0 Modal Assurance Criteria (MAC) $\quad \ldots \ldots \ldots \ldots \ldots \ldots \ldots . . . \ldots \ldots$

Appendix D

D.0 Modal Test of Periscope LM3/Polarizer LRU $\ldots . . . \quad$ D-1 



\subsection{Scope}

This report summarizes experimentally and numerically determined modal properties for one of the reinforced concrete end walls of the NIF Periscope Support Structure in Laser Bay 1 (Figure 1-1). Two methods were used to determine these modal properties:

1. Computational finite-element analyses (modal extraction process).

2. Experimental modal analysis based on measured test data.

This report also includes experimentally determined modal properties for a prototype LM3/Polarizer line-replaceable unit (LRU) (Figure 1-2) and a prototype PEPC LRU (Figure 1-3).

Two important parameters, used during the design phase, are validated through testing [ref 1]. These parameters are the natural frequencies and modal damping (of the system in question) for the first several global modes of vibration. Experimental modal testing provides these modal values, along with the corresponding mode shapes.

Another important parameter, the input excitation (expected during normal operation of the NIF laser system) [ref 1], can be verified by performing a series of ambient vibration measurements in the vicinity of the particular system (or subsystem) of interest. The topic of ambient input excitation will be covered in a separate report.

Due to the large mass of the Periscope Pedestal, it is difficult to excite the entire series of Periscope Pedestal Walls all at once. It was decided that the experimental modal tests would be performed on just one Periscope End Wall in Laser Bay 1. Experimental modal properties for the Periscope End Wall have been used to validate and update the FE analyses. Results from the analyses and modal tests support the conclusion that the Periscope Pedestal will not exceed the stability budget, which is described in reference 1 .

The results of the modal tests for the Periscope End Wall in Laser Bay 1 have provided examples of modal properties that can be derived from future modal tests of the entire Periscope Assembly (excluding the LRU's). This next series of larger modal tests can be performed after the support structure for the Periscope Assembly has been completed.

There are five optical elements in the Periscope Assembly: PEPC; Polarizer; LM3; LM2; and the Periscope Light Source. All of these optical elements have stability requirements except for the PEPC. During the Title II Design phase, two prototypes of the LM3/Polarizer LRU were used in two different series of modal tests (Figure 1-2 and appendix A) [ref 2,3]. A similar series of modal tests were conducted on a prototype of the PEPC LRU (Figure 1-3 and Appendix D). The results of the modal tests were used to verify the modal properties assumed for use in the corresponding finite-element analyses.

Appendix B of this report shows a method for estimating the modal damping for selected global modes of vibration. Appendix $\mathrm{C}$ briefly describes the modal assurance criteria (MAC). The MAC number provides a quantitative comparison that can be made between the numerical and test results. The MAC number estimates the degree of correlation between mode shape vectors calculated from: the numerical finite element model; and those from the experimental modal analysis. This method provides information that aids comparison of mode shapes beyond just the means of visualization.

In summary, there is good agreement between the analytical predictions of the modal properties from the FEA models and the results of the experimental modal tests for the cases of: the Periscope End Wall in Laser Bay 1; the prototype LM3/Polarizer LRU; and the prototype PEPC LRU. 


\subsection{Purpose of Modal Tests for NIF Periscope}

Structural analyses were performed for the NIF Periscope Support Structure during the Title II design phase [ref 4,5]. After the reinforced concrete pedestals were built in the Laser Bays $1 \& 2$, there was an opportunity to conduct a set of experimental modal tests on one of the Periscope End Walls in NIF Laser Bay 1. The FEA model results were compared with the experimental modal test results as a verification of assumptions for modal properties used during the design phase. For location reference of the Periscope End Walls, the FEA model for the entire NIF Periscope Assembly (including LM3/Polarizer LRU's, PEPC LRU's, and support structure) in Laser Bay 1 is shown in Figure 1-1.

The modal test and analysis of two prototypes of the LM3/Polarizer LRU (and its kinematic mounts and mock mirrors) were also used to verify assumptions about modal properties used in corresponding FEA models (see Figure 1-2). The most recent modal test was conducted in preparation for the Title II Design Review in September 1998 [ref 2 \& Appendix A of this report]. A similar modal test was conducted on a prototype of the PEPC LRU (and its kinematic mounts and mock mirrors) as shown in Figure 1-3 and Appendix D.

\subsection{NIF Criteria - The NIF Stability Budget}

The NIF laser system features 192 high-powered laser beams that will produce $1.8 \mathrm{MJ}$ of laser energy in the near-ultraviolet spectral region (about 0.35 micron wavelength). NIF stability allocations are primarily developed from the requirement that the deviation in the position of all 192 beams on target shall not exceed 50 microns. The major contributors to the beam position on target are the accuracy of the alignment process and the stability of the laser system before and during a shot [ref 1].

All components that are involved in beam alignment, or are capable of moving a beam on the target, must meet the requirements of the NIF stability budget. Allocations in this budget must account for three major aspects of stability considerations. First, multiple input sources can cause structural drift, such as ambient vibration, acoustical excitation, wind fluctuations, flow-induced vibrations, and thermal transients. In addition, thousands of structural elements can transmit or amplify the input perturbations if their design is not optimized. Finally, the optics that the structures support are mirrors or lenses contained in 192 independent beam paths, and their motion will influence beam propagation [ref 1].

NIF optical components are supported in the laser bays primarily by hybrid support structures of reinforced concrete (RC) pedestals and steel frames or vessels; and in the switchyards by large, steel space frames attached to the corners of the RC switchyard /target area building. Inside the target area are the target chamber and floors that also support optical components and diagnostic equipment [ref 1].

There are five optical elements in the Periscope Assembly: PEPC; Polarizer; LM3; LM2; and the Periscope Light Source. All of these optical elements have stability requirements except for the PEPC. During the Title II Design phase, two prototypes of the LM3/Polarizer LRU were used in two different series of modal tests (Figure 1-2) [ref 2,3]. A similar series of modal tests were conducted on a prototype of the PEPC LRU (Figure 1-3). The results of the modal tests helped to verify the modal properties assumed for use in the corresponding finite-element analyses.

Due to the large mass of the Periscope Pedestal, it is difficult to excite the entire series of Periscope Pedestal Walls all at once. It was decided that the experimental modal tests would be performed on just one Periscope End Wall in Laser Bay 1. Experimental modal properties for the Periscope End Wall have been used to validate and update the FE analyses. Results from the analyses and modal tests support the conclusion that the Periscope Pedestal will not exceed the stability budget, which is described in reference 1. 
The results of the modal tests for the Periscope End Wall in Laser Bay 1 have provided examples of modal properties that can be derived from future modal tests of the entire Periscope Assembly (excluding the LRU's). This next series of modal tests can be performed once the support structure for the Periscope Assembly has been completed.

Similar modal tests are to be planned and conducted for the NIF Switchyards and for the NIF Target Area, to aid in the verification process for frequency and modal damping assumptions used in corresponding FEA models of those structures.

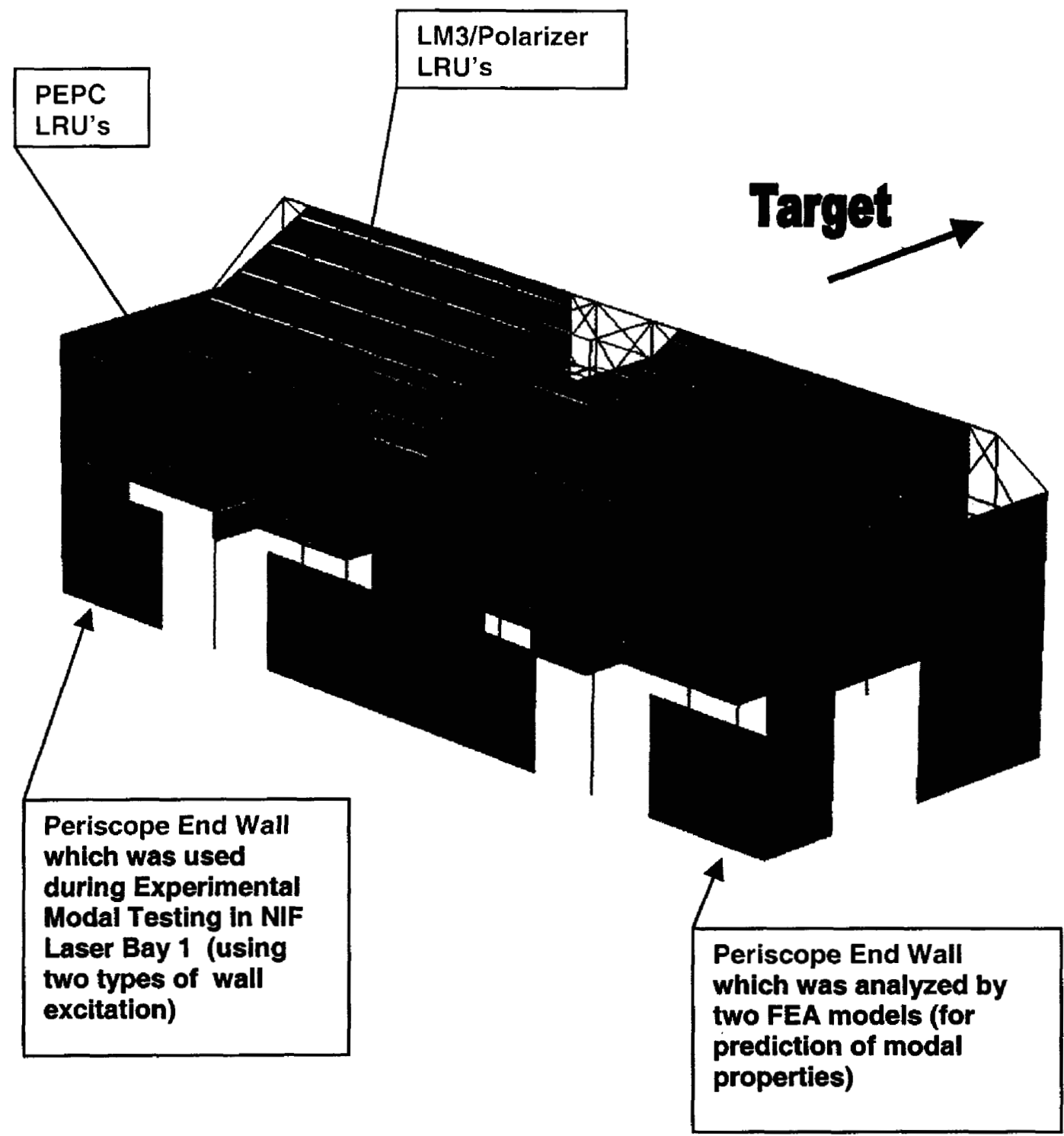

Figure 1-1. View of the FEA model for the entire NIF Periscope Assembly (including LM3/Polarizer LRU's, PEPC LRU's, and support structure) in NIF Laser Bay 1. 

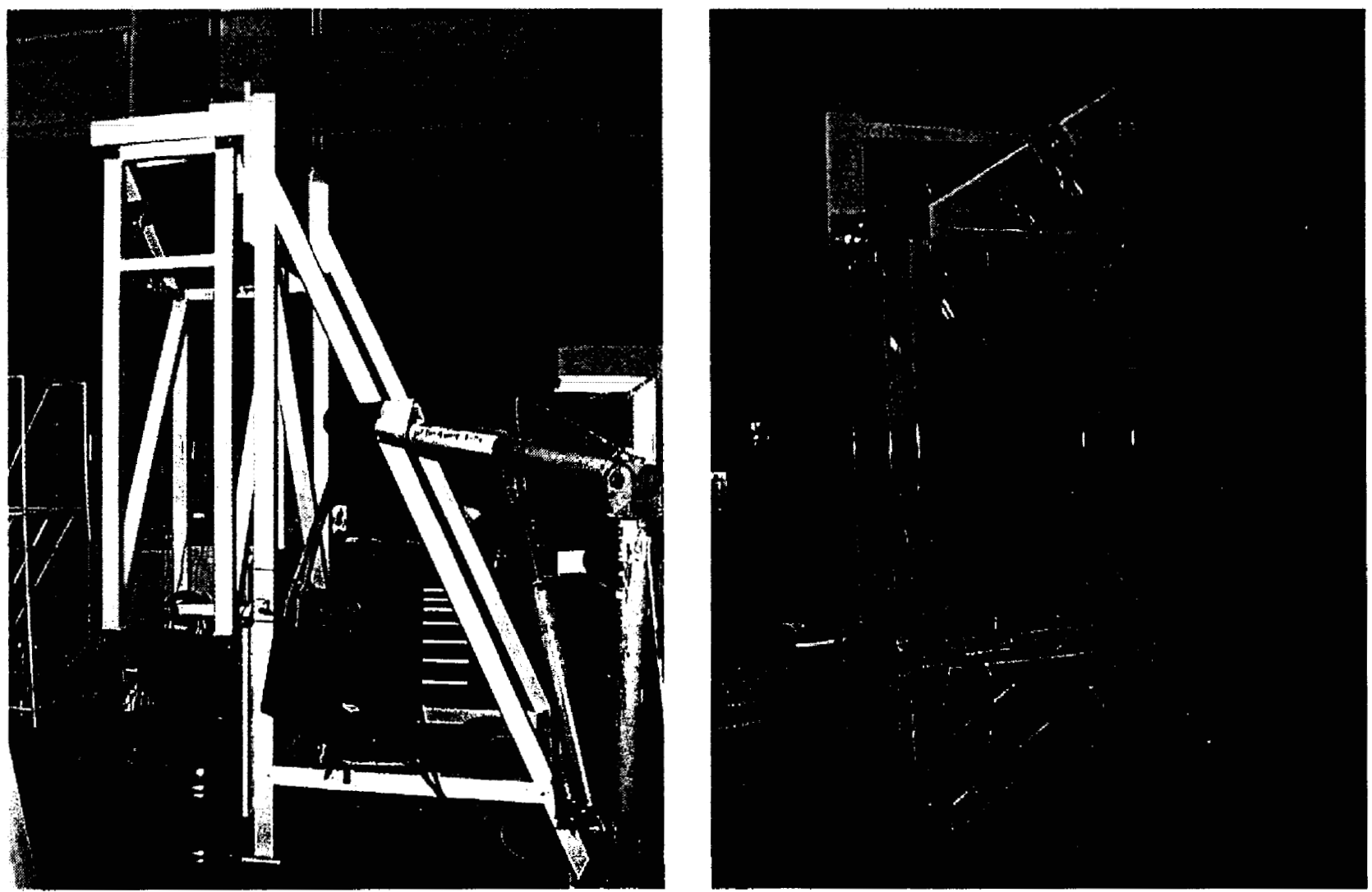

Figure 1-2. Modal Test setup (in September 1998) for a prototype LM3/Polarizer LRU (with its kinematic mounts and mock mirrors) on a test stand in B-432 [ref 2,3]. 

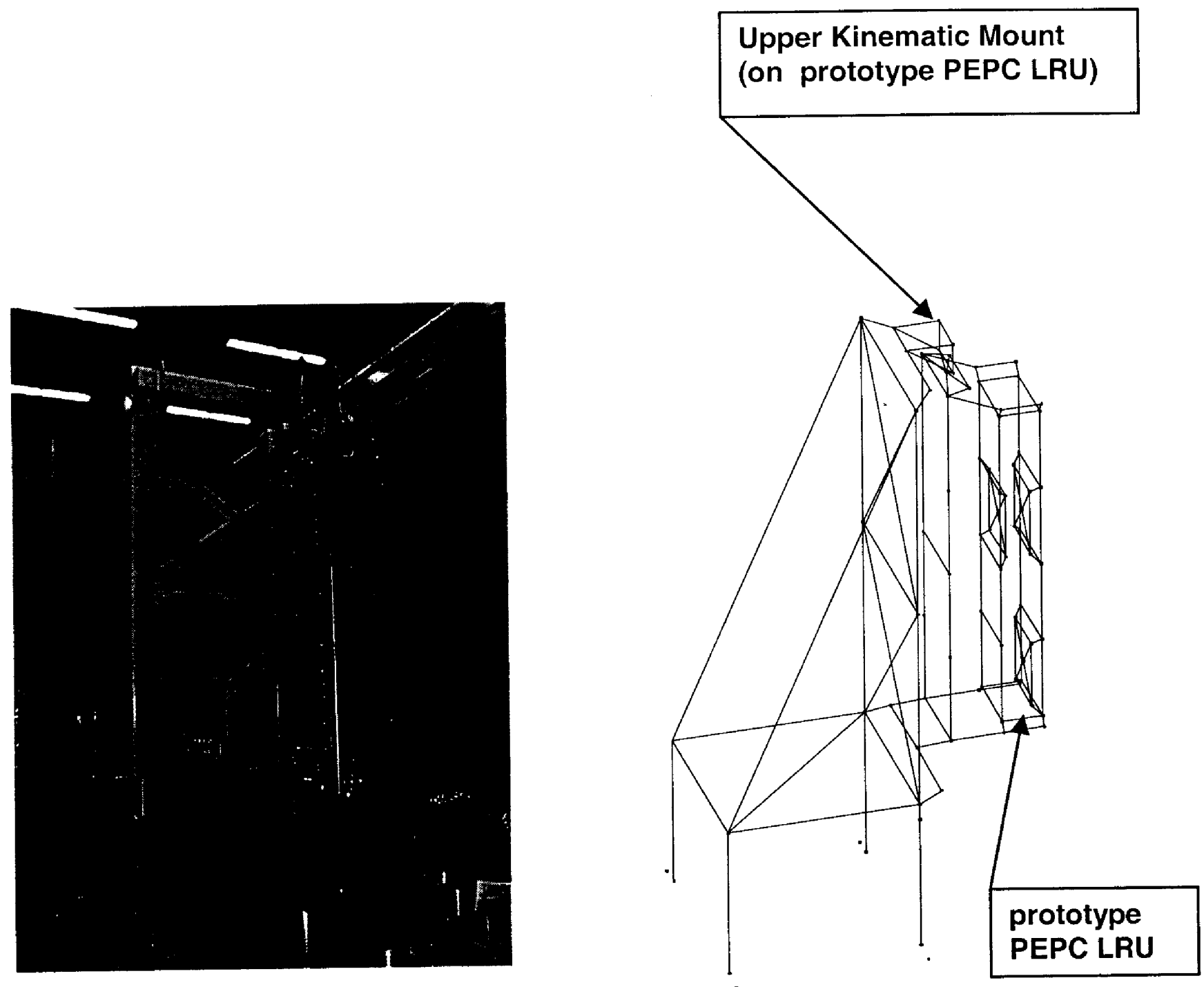

Figure 1-3. A series of experimental modal tests was conducted (in June 1998) on a prototype for the NIF PEPC LRU (with its kinematic mounts and mock mirrors), on a test stand in B-432 (photo at left). 



\subsection{Analytical Predictions Using Periscope Wall Finite Element Model}

The mesh generator SLIC [ref 6] was used to construct two finite element models of the Periscope superstructure end wall for verification and comparison to modal test results. The first model represents the concrete walls utilizing shell elements, while the second model represents the concrete walls using solid elements (Figure 2-1). The shell element model is based on center-line geometry of the end wall, while the solid element model uses the full physical dimensions of the end wall. The concrete was modeled using linear elastic material properties with a Young's Modulus of 3.2 million psi, a Poisson's Ratio of 0.17 , and a weight density of $0.08694 \mathrm{lbs} / \mathrm{in}^{3}$. The weight of the shell model is $216935 \mathrm{lbs}$, while the weight of the solid model is $223309 \mathrm{lbs}$. The weight of the shell model is slightly less (2.8\%) than the weight of the solid model because the center-line geometry of the shell model approximates the geometry in the corners, resulting in slightly smaller volumes. Fixed boundary conditions (no displacements, no rotations) were applied at the base of both models. The first five mode shapes were extracted using the finite element analysis program GEMINI [ref 7]. The mode shapes were calculated using the subspace iteration method. The mode shape frequencies are shown in Table 2-1. The first five mode shapes for the shell and solid models are shown in Figures 2-2 through 2-6. The slight difference in global mode frequencies between the FEA models (Table 2-1) can be attributed to:

- difference in geometric stiffening effects of the elements, particularly in areas of geometry discontinuities such as the corners;

- variation in the effective horizontal span along the long, tall wall (clear distance between near face of wing walls);

- variation in the effective horizontal span of wing walls (clear distance from near face of wall at corner to edge of wing wall)

- volume differences which result in mass differences;

- different numerical formulation of the elements between the shell model and the solid model;

- total number of elements used across a span of a wall, for adequate capture of bending and torsional modes.

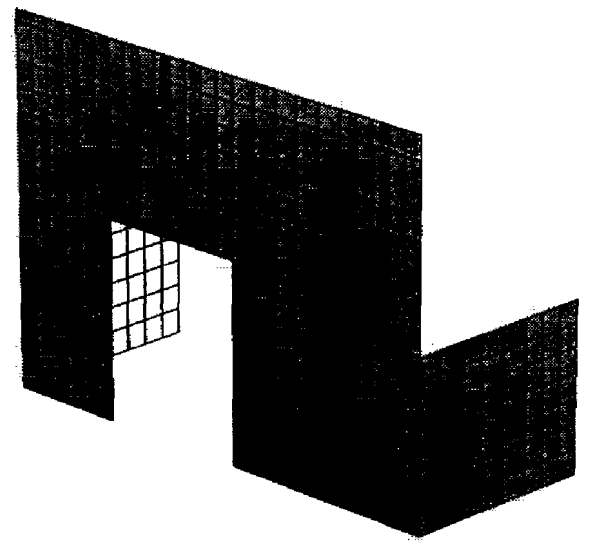

Shell Model

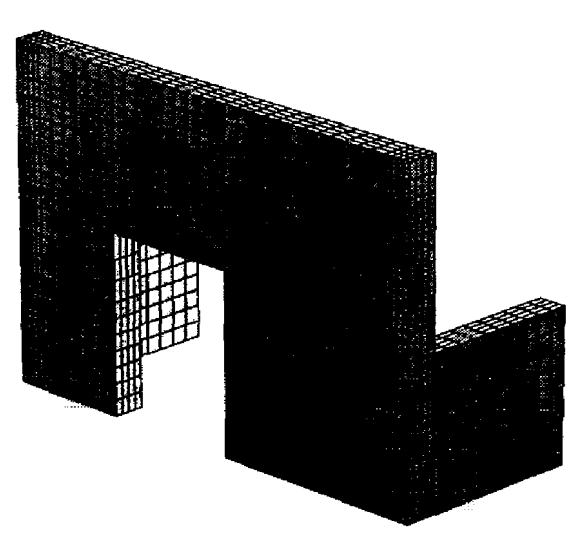

Solid Model

Figure 2-1. Finite Element Models

Table 2-1. Mode Shape Frequencies

\begin{tabular}{|c|c|c|c|}
\hline \multirow{2}{*}{ Mode } & \multicolumn{2}{|c|}{ Frequency $(\mathrm{Hz})$} & \multirow{2}{*}{ \% difference } \\
\cline { 2 - 3 } & Shell Model & Solid Model & $10.2 \%$ \\
\hline 1 & 9.35 & 10.3 & $3.3 \%$ \\
\hline 2 & 21.5 & 22.2 & $4.7 \%$ \\
\hline 3 & 36.5 & 34.8 & $0.9 \%$ \\
\hline 4 & 43.9 & 44.3 & $3.4 \%$ \\
\hline 5 & 47.6 & 49.2 & \\
\hline
\end{tabular}




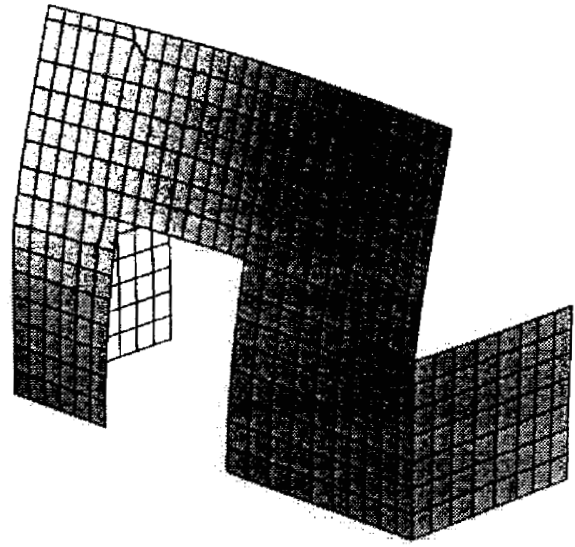

Shell Model: $9.35 \mathrm{~Hz}$

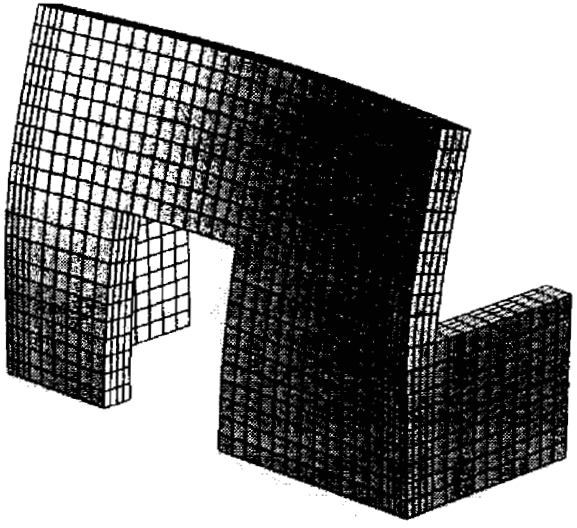

Solid Model: $10.3 \mathrm{~Hz}$

Figure 2-2. Mode shape for mode 1.

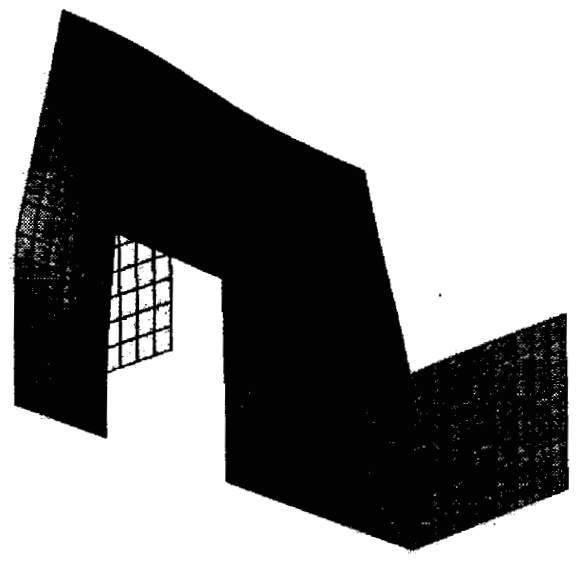

Shell Model: $21.5 \mathrm{~Hz}$

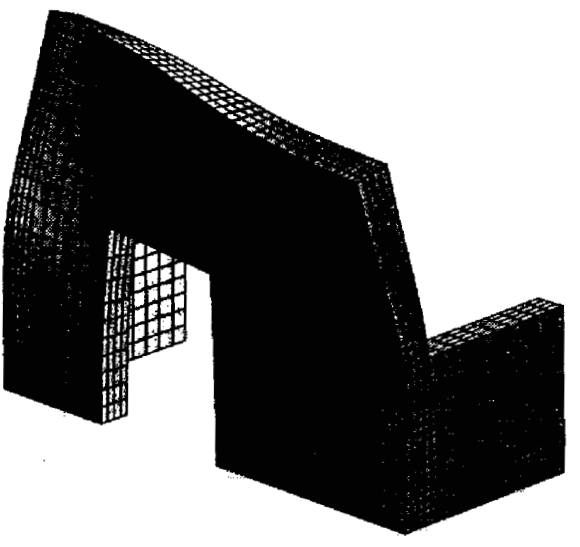

Solid Model: $22.2 \mathrm{~Hz}$

Figure 2-3. Mode shape for mode 2. 


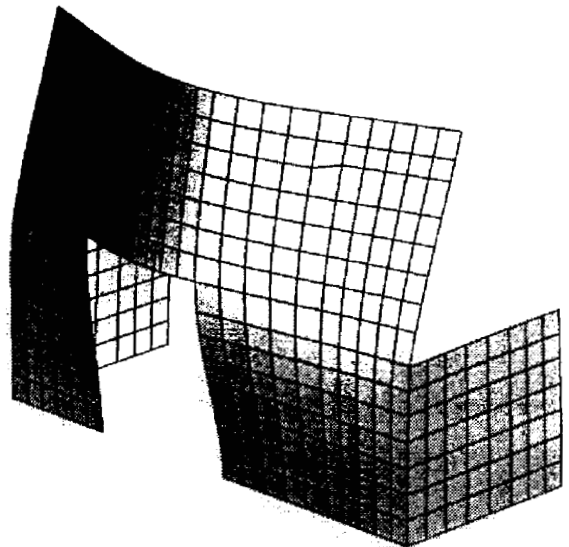

Shell Model: $36.5 \mathrm{~Hz}$

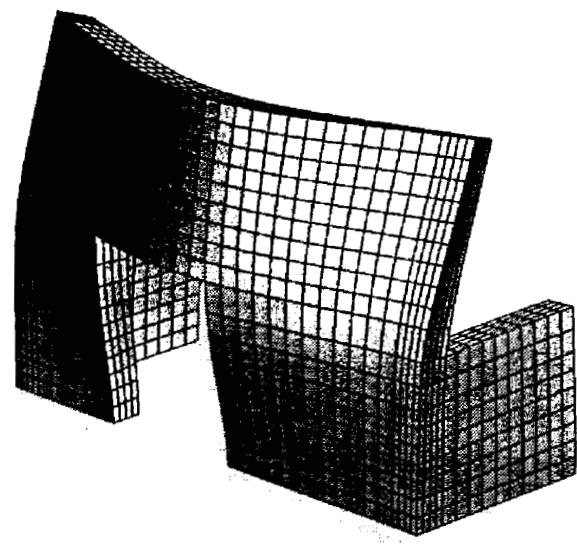

Solid Model: $34.8 \mathrm{~Hz}$

Figure 2-4. Mode shape for mode 3.

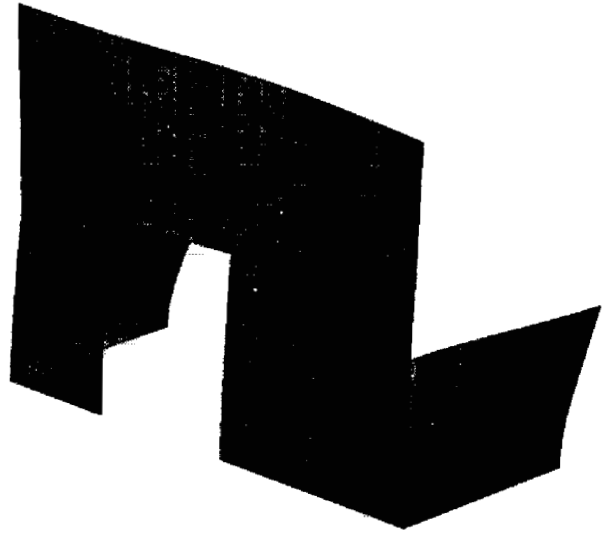

Shell Model: $43.9 \mathrm{~Hz}$

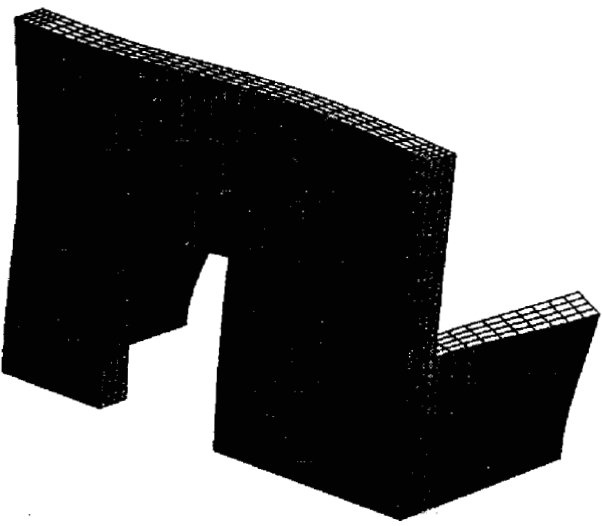

Solid Model: $44.3 \mathrm{~Hz}$

Figure 2-5. Mode shape for mode 4. 


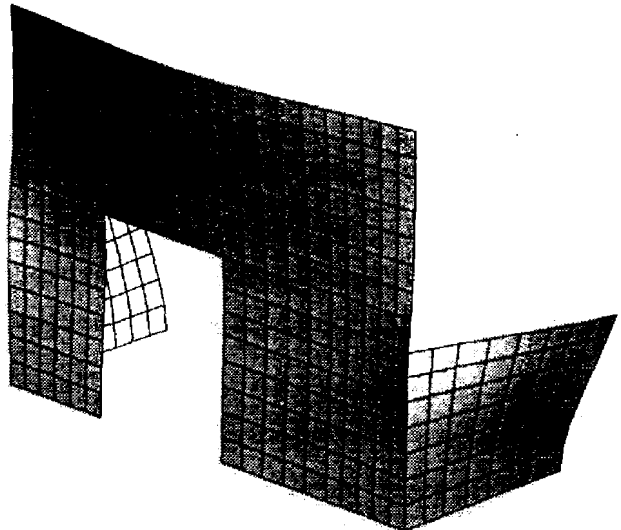

Shell Model: $47.6 \mathrm{~Hz}$

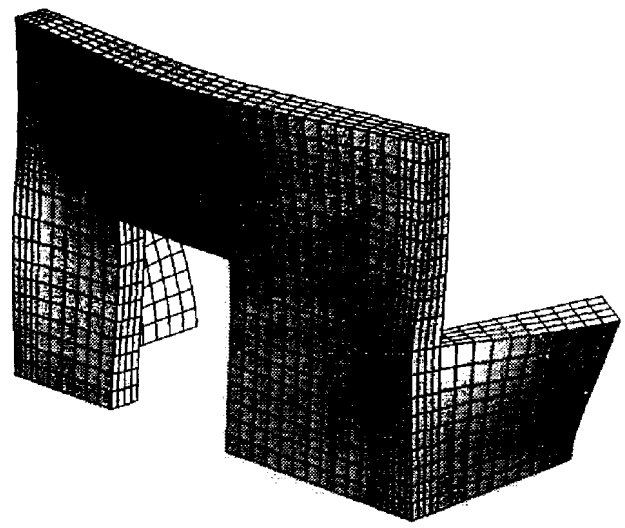

Solid Model: $49.2 \mathrm{~Hz}$

Figure 2-6. Mode shape for mode 5. 


\subsection{Modal Test Equipment and Calibration}

The Periscope End Wall was excited by two methods: "burst random" input from a shaker suspended from a bridge crane; and also by an instrumented impulse hammer. The shaker system used was a Briel and Kjær model 4802/4817. This shaker system had a maximum capacity of $400 \mathrm{lbf}$. peak sine output, over a frequency range of 0 to $4000 \mathrm{~Hz}$. The instrumented impulse hammer used was a Dytran model 5803A with a hammer-head weight of $12 \mathrm{lb}$. A load cell was mounted in the hammer head in order to measure the input force at its impact with the wall. A changeable tip on the hammer head was used for varying the impulse duration in order to tailor the range of frequency response desired. Both types of wall excitation were input to the upper left corner of the Periscope End Wall.

Input sensors were used to measure the force being transferred to the structure. For the shaker, a Dytran model $1061 \mathrm{~V} 2$ load cell was used. This load cell had a maximum compression and tension range of 0 to $1000 \mathrm{lbf}$. and a nominal sensitivity of $5 \mathrm{mV} / \mathrm{lbf}$. The load cell was stud mounted to one of the embedded steel mounting plates in the reinforced concrete wall. The load cell in the head of the instrumented impulse hammer had a maximum input force of $5000 \mathrm{lbf}$. and a nominal sensitivity of $1 \mathrm{mV} / \mathrm{lbf}$. Load cells were selected due to suitability for use in the frequency range of interest.

The response accelerometers were Endevco model $63 \mathrm{~A}-500$ tri-axial units. The $63 \mathrm{~A}-500$ was a 0.88 inch cube, with a frequency response of 1 to $2000 \mathrm{~Hz}$, a nominal output of $500 \mathrm{mV} / \mathrm{g}$, and a weight of 0.71 ounces. The accelerometers were mounted to the concrete wall in the following sequence: first the concrete surface was cleaned and allowed to dry; then a piece of duct tape was attached to the wall; and finally the accelerometer was attached to the tape using a hot-melt glue gun. Twenty-three response accelerometers were used to capture the modal behavior of the Periscope End Wall. Figure 4-1 shows an example of locations of the response accelerometers (which are the solid dots on the figure). Lines in Figure 4-1 which connect the measurement points are for aid in visualizing the undeformed shape of the end pedestal as well as the global mode shapes of the end pedestal. Accelerometers were located on the front face of the Periscope End Wall during the modal tests.

The method of attaching the shaker to the periscope wall to input the desired force was with a stinger. A stinger was traditionally a long thin rod that would not transmit lateral force into the structure under test. In this case, there were other problems to consider. The first and foremost reason was to transfer as much force into the wall as possible, due to the mass and size of the wall. We wanted to make sure that there was enough input force to excite the wall. The other concern was to keep the natural frequency of the stinger rod above the frequency range of interest. The stinger used in this case was a piece of $1 / 2-13$ threaded steel rod 7 inches long. The calculated natural frequency for this rod is 1356 $\mathrm{Hz}$, far above the frequency range of interest.

The data acquisition system used is a Data Physics 620 (DP620) spectrum analyzer. The DP620 is based on the HP VXI modules and is controlled by a PC running Windows NT. This particular unit has a total of 32 input channels, with a maximum input frequency of $10 \mathrm{kHz}$. The unit also contains a signal source, which is used to drive the shaker. The analyzer calculates the frequency response functions and then they are stored in the control PC.

The load cell and calibrated hammer are returned to Dytran every 2 years for calibration. The accelerometers are calibrated on an Endevco model 28959 E/EV Portable Accelerometer Calibration System. Finally the DP620 HP hardware is returned yearly to Agilent Technologies (formerly Hewlett Packard) for calibration. All calibrated equipment is traceable to the National Institute of Standards and Testing (NIST).

Similar equipment was used for the modal testing of the the prototype LM3/Polarizer LRU and the prototype PEPC LRU. The main differences were that the following were all a smaller size: the instrumented impulse hammer; the diameter of the stinger; and the shaker. The other difference is that the mass of the LRU's and their test stands was small enough so that a longer and more flexible stinger was allowed to be used, in order to avoid transmitting lateral forces into the structure under test. 

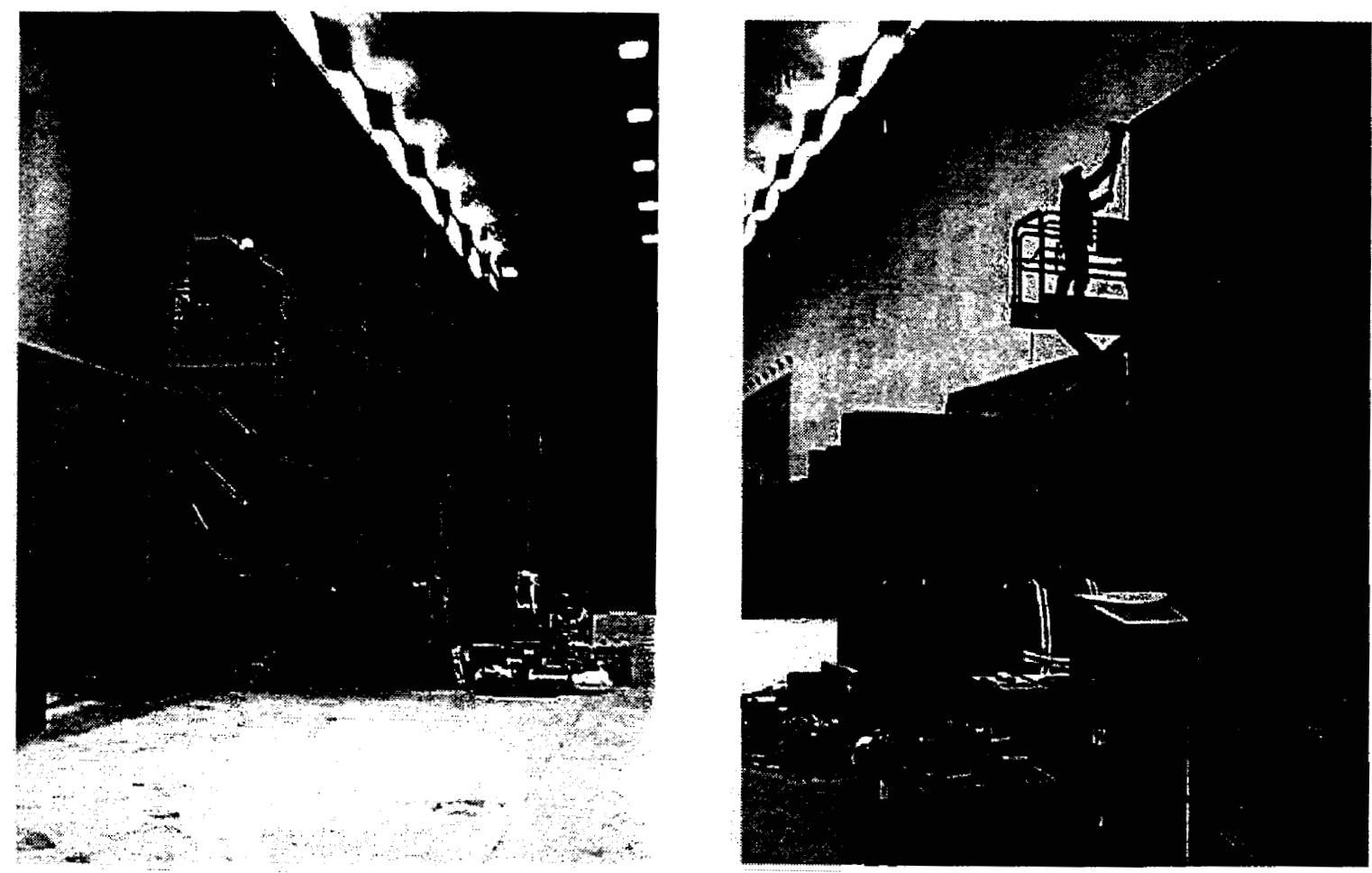

Figure 3-1. Using an Instrumented Impulse Hammer is one method of providing non-destructive input excitation to the embedded steel plate in the concrete (located at an upper corner of end pedestal), during the Experimental Modal Testing of the NIF Periscope Pedestal.
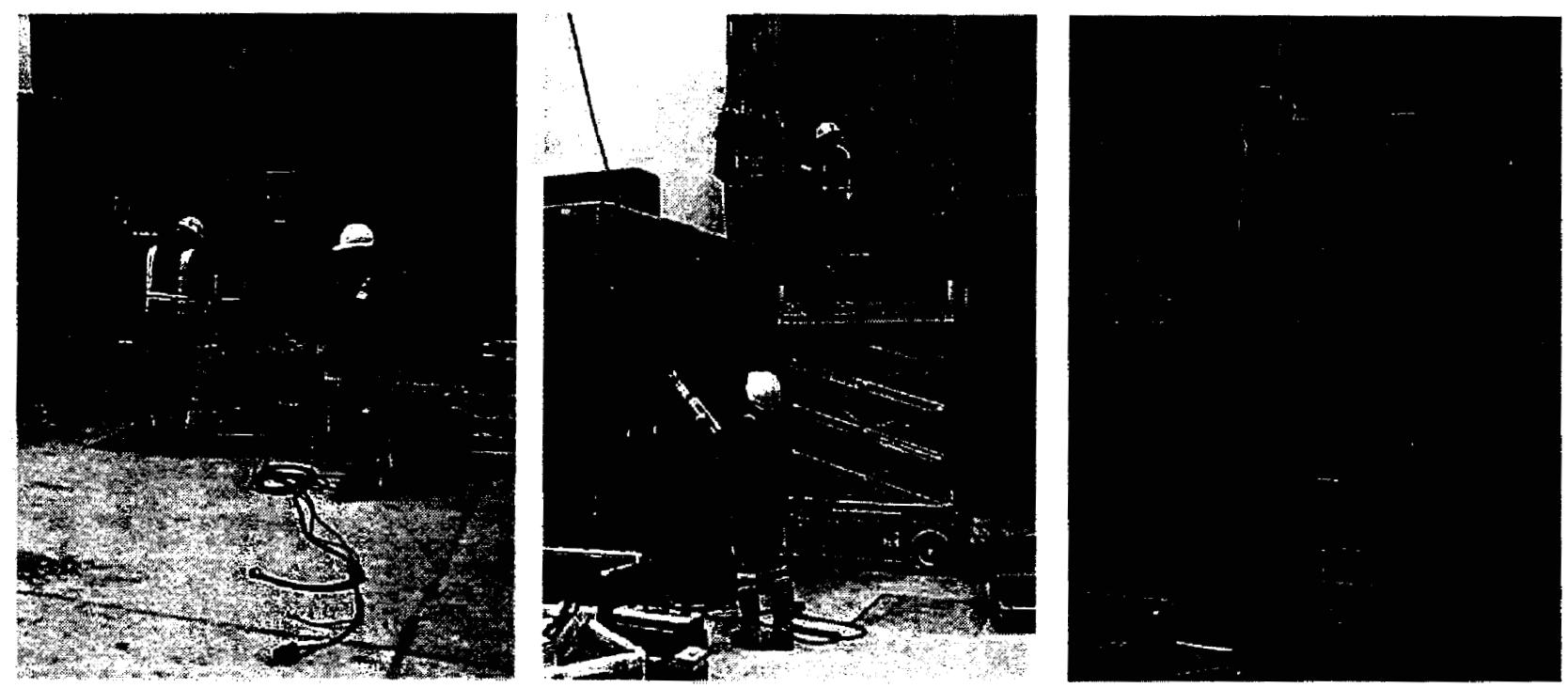

Figure 3-2. Experimental Modal Testing was set up and conducted at night in NIF Laser Bay 1, after all of the construction crews were done for the day. 

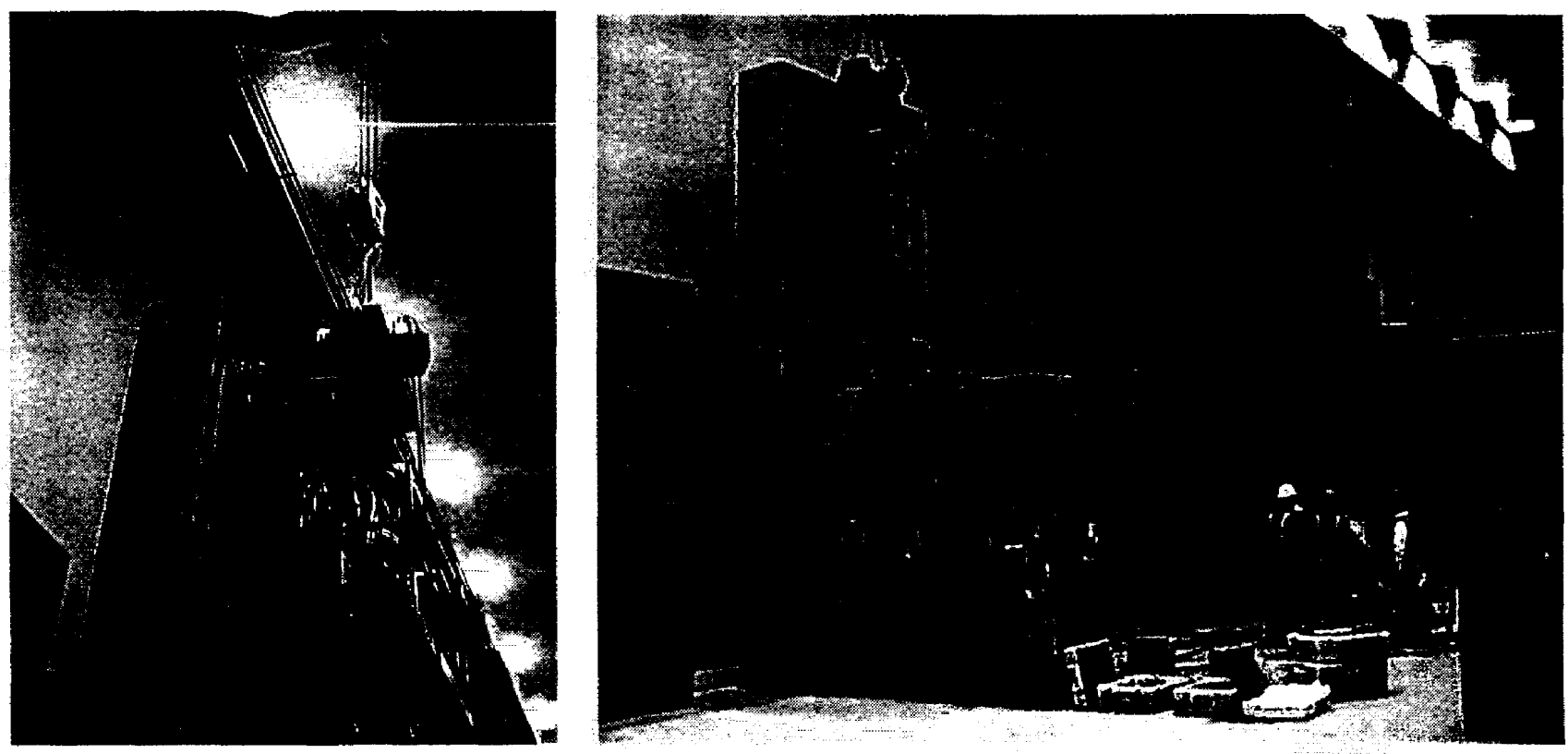

Figure 3-3. 'Burst Random' Vibration from a Large Shaker (suspended from the Bridge Crane) is another method of providing non-destructive input excitation at an upper corner of the NIF Periscope Pedestal, during Modal Testing in Laser Bay 1. 



\subsection{Experimental Modal Testing and Analysis for Periscope Wall}

As a verification of assumptions that were made during the design phase of the NIF Periscope End Wall, experimental modal testing was performed in Laser Bay 1. Predicted values for frequency and mode shapes from the FEA model were compared with the results from the modal testing and analysis summarized in Table 4-1.

The modal test data for the Periscope End Wall was analyzed using the Star Modal Software (SMS) by Spectral Dynamics [ref 8], to yield the following modal parameters: frequencies, damping, and mode shapes for the test structure. Resonance peaks were determined from the "modal peaks function" by combining the frequency response function (FRF) contributions from responses at each measurement location for each direction. With the modal peaks function, bandwidths for each mode were selected for inclusion in a multi-step curve-fitting process for obtaining eigenvalues and eigenvectors. This provided the results of interest, including an animated mode shape for help in interpreting the response of the structure for each mode. Figures 4-1 through 4-5 show the mode shapes for the first 5 global modes, which are compared with the undeformed shape for the Periscope End Wall.

Table 4-1. Summary of Experimental Modal Test Results

\begin{tabular}{|c|c|c|c|c|c|c|}
\cline { 3 - 7 } \multicolumn{2}{c}{} & \multicolumn{2}{|c|}{ Significant Global Modes } & \multicolumn{2}{l|}{} \\
\cline { 3 - 7 } \multicolumn{2}{c|}{} & 1 & 2 & 3 & 4 & 5 \\
\hline $\begin{array}{c}\text { Modal Test } \\
\text { (Shaker Input) }\end{array}$ & Frequency (Hz) & 9.8 & 22.6 & 37.0 & 48.2 & 49.1 \\
\hline $\begin{array}{c}\text { Modal Test (Instrumented } \\
\text { Hammer Impulse) }\end{array}$ & Frequency (Hz) & 9.9 & 22.4 & 37.0 & 47.9 & 49.2 \\
\hline
\end{tabular}

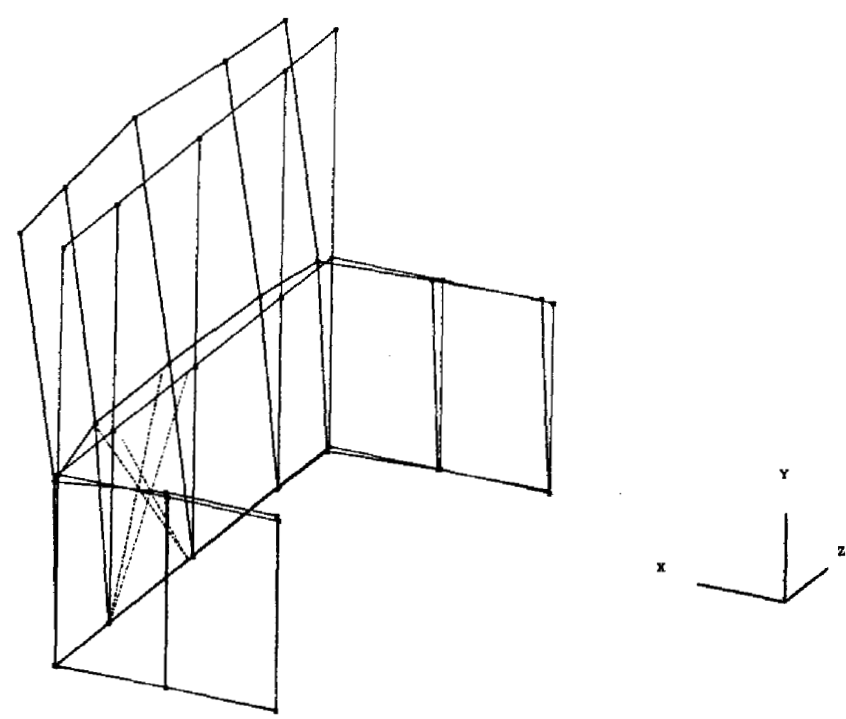

Figure 4-1.

Experimental Global Mode $1=9.8 \mathrm{~Hz}$ (for Shaker Input)

Experimental Global Mode $1=9.9 \mathrm{~Hz}$ (for Hammer Input) 


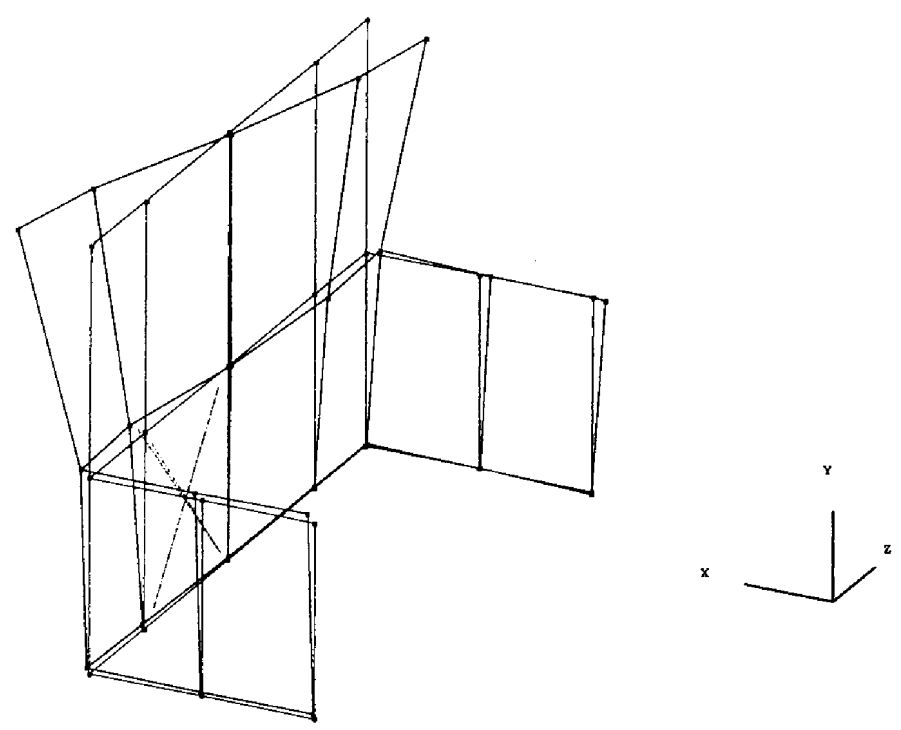

Figure 4-2.

Experimental Global Mode $2=22.6 \mathrm{~Hz}$ (for Shaker Input) Experimental Global Mode $2=22.4 \mathrm{~Hz}$ (for Hammer Input)
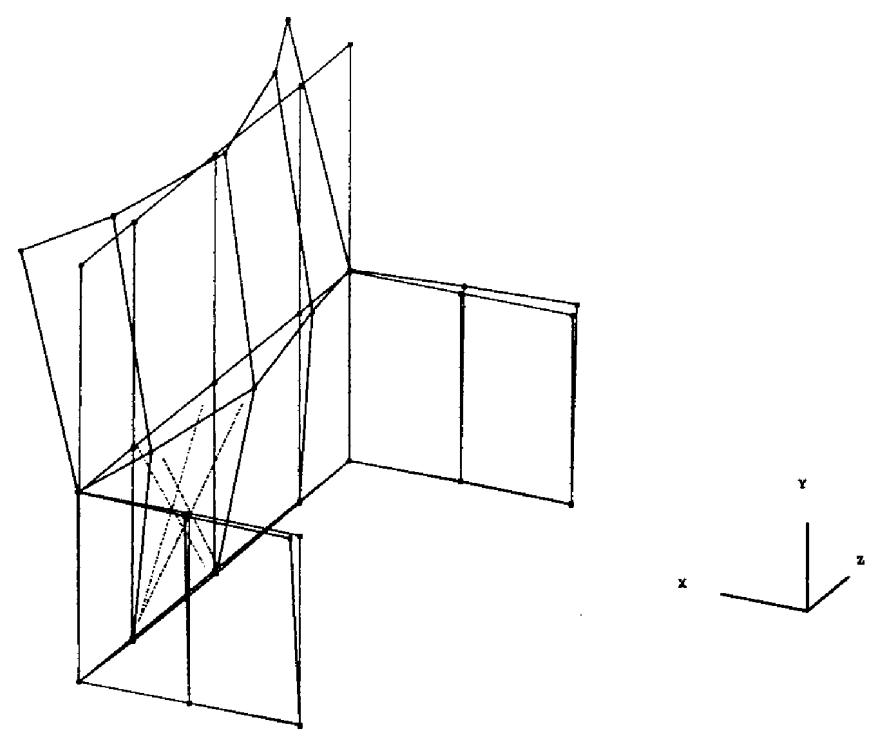

Figure 4-3.

Experimental Global Mode $3=37.0 \mathrm{~Hz}$ (for Shaker Input) Experimental Global Mode $3=37.0 \mathrm{~Hz}$ (for Hammer Input) 


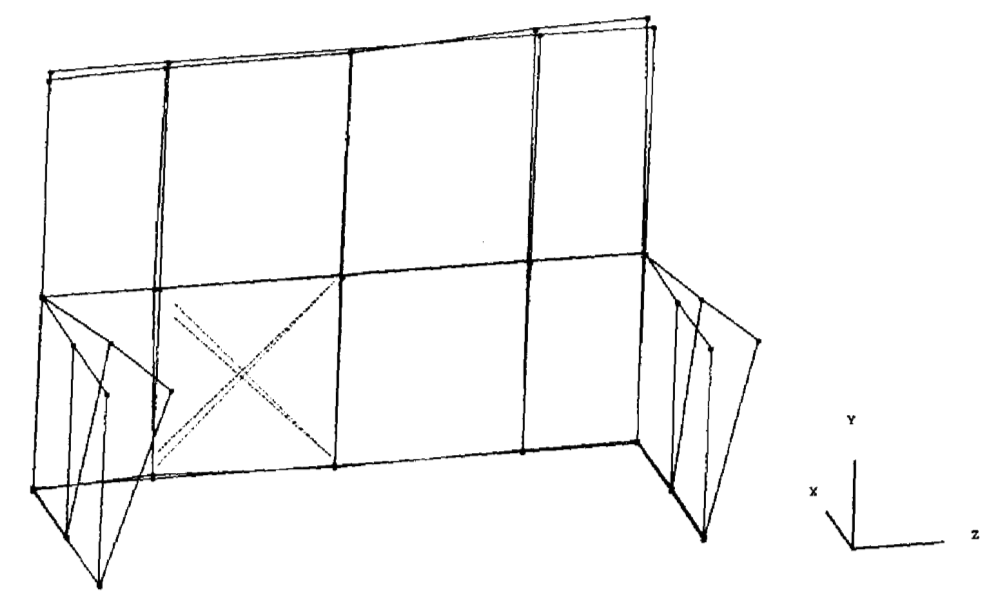

Figure 4-4.

Experimental Global Mode $4=48.2 \mathrm{~Hz}$ (for Shaker Input)

Experimental Global Mode $4=47.9 \mathrm{~Hz}$ (for Hammer Input)

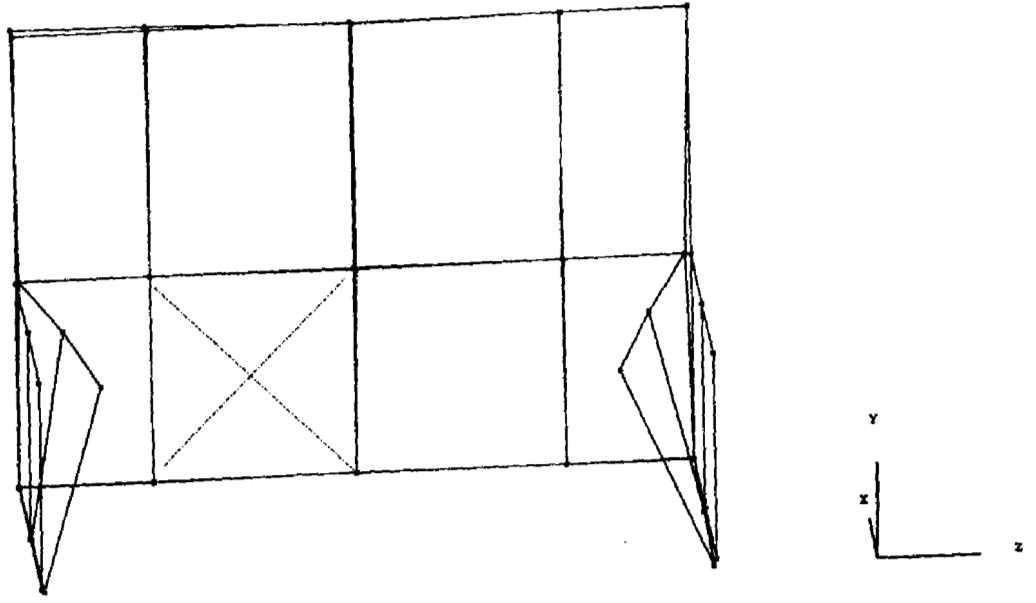

Figure 4-5.

Experimental Global Mode $5=49.1 \mathrm{~Hz}$ (for Shaker Input) Experimental Global Mode $5=49.2 \mathrm{~Hz}$ (for Hammer Input) 



\subsection{Comparison of Analytical and Experimental Modal Test Results for Periscope Wall}

The differences between results of the shell model and the solid model for the FEA are discussed in Section 2.0 and are listed for comparison in Table 2-1. This section focuses on describing the differences between the FEA models and the recent modal tests performed on the Periscope End Wall. Table 5-1 presents a summary comparison between the FEA models and the experimental modal test results for the first five global mode frequencies of the Periscope End Wall. The FEA models include the shell model and the solid model. The experimental modal tests include excitation by shaker (suspended from a bridge crane) and by instrumented hammer impulse.

For each global mode of the Periscope End Wall, there is close agreement between at least one of the FEA models and both of the experimental modal test results. The first global mode for both FEA models is within $4 \%$ to $5.1 \%$ of the value for each modal test frequency for mode 1 . Mode 2 had a range of $0.9 \%$ to $1.8 \%$ difference between the predicted values and the modal tests. Mode 3 had a $1.4 \%$ difference between the modal tests and the shell model.

Global mode 4 is the "in-phase" horizontal Z-direction motion of the lower-height wing walls. As constructed in Laser Bay 1, these wing walls are heavily reinforced with steel re-bar. The primary difference of about $4 \mathrm{~Hz}$ (approx $7.5 \%$ to $8.9 \%$ ) between the FEA models and the experimental modal tests is due to the fact that the FEA models do not include any of the stiffening effects of the steel re-bar in the Periscope End Wall. This is a significant difference for the wing walls, which have a larger ratio of steel reinforcement to concrete area (for each principal direction) than does the taller wall. Mode 5 had a negligible difference between the solid model and the modal tests.

Further experimental modal tests could also be conducted by using more response measurement points for capturing the vibration response of the Periscope End Wall to the two methods of wall excitation. Closer control over the placement (or re-location for updating) of node points on each FEA model compared to actual sensor positions in the field could possibly provide even better agreement between the some of the predicted modal frequencies and the experimental values derived from modal tests. Different locations for wall excitation can also be attempted during additional modal tests.

Table 5-1. Comparison of Significant Natural Frequencies by Mode

\begin{tabular}{|c|c|c|c|c|c|c|}
\cline { 3 - 7 } \multicolumn{2}{c}{} & \multicolumn{2}{c|}{ Significant Global Modes } & \multicolumn{2}{c|}{5} \\
\cline { 3 - 7 } \multicolumn{2}{c|}{} & 1 & 2 & 3 & 4 & 47.6 \\
\hline $\begin{array}{c}\text { FEA Model } \\
\text { (Shell elements) }\end{array}$ & Frequency (Hz) & 9.4 & 21.5 & 36.5 & 43.9 & 49.2 \\
\hline $\begin{array}{c}\text { FEA Model } \\
\text { (Solid elements) }\end{array}$ & Frequency (Hz) & 10.3 & 22.2 & 34.8 & 44.3 & 49.1 \\
\hline $\begin{array}{c}\text { Modal Test } \\
\text { (Shaker Input) }\end{array}$ & Frequency (Hz) & 9.8 & 22.6 & 37.0 & 48.2 & 49.2 \\
\hline $\begin{array}{c}\text { Modal Test } \\
\text { (Instrumented } \\
\text { Hammer Impulse) }\end{array}$ & Frequency (Hz) & 9.9 & 22.4 & 37.0 & 47.9 & \\
\hline
\end{tabular}




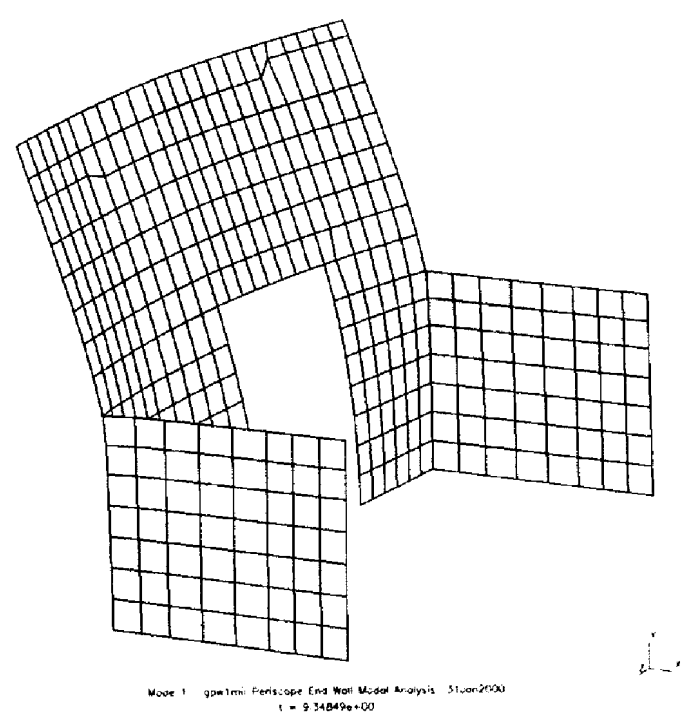

Figure 5-1.

Mode $1=9.4 \mathrm{~Hz}$ (for Shell Model)

Mode $1=10.3 \mathrm{~Hz}$ (for Solid Model)

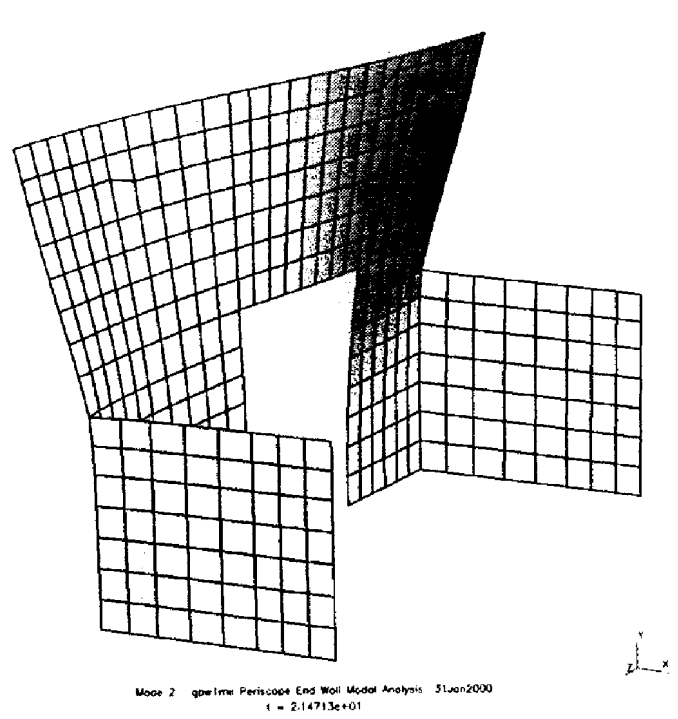

Figure 5-2.

Mode $2=21.5 \mathrm{~Hz}$ (for Shell Model) Mode $2=22.2 \mathrm{~Hz}$ (for Solid Model)

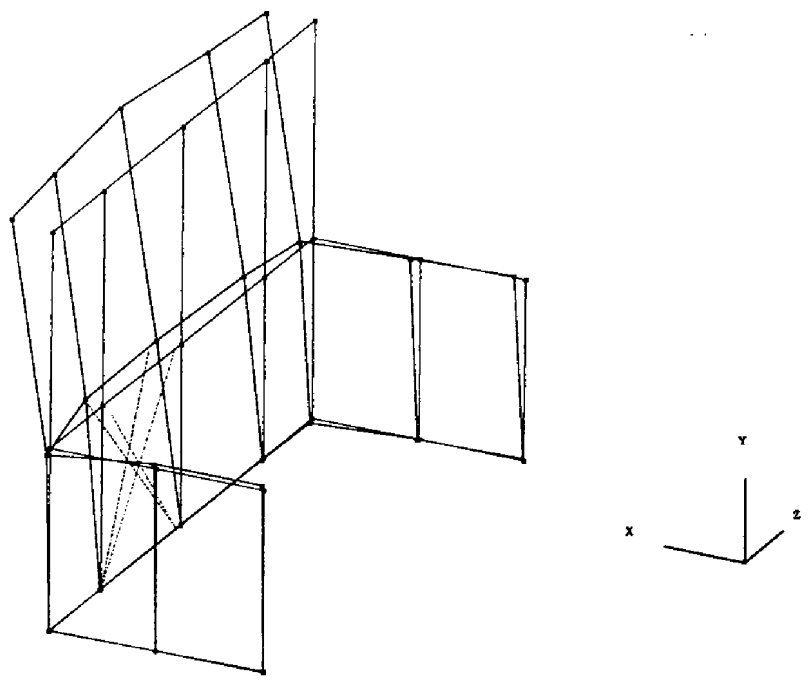

Exper. Global Mode $1=9.8 \mathrm{~Hz}$ (for Shaker Input) Exper. Global Mode $1=9.9 \mathrm{~Hz}$ (for Hammer Input)

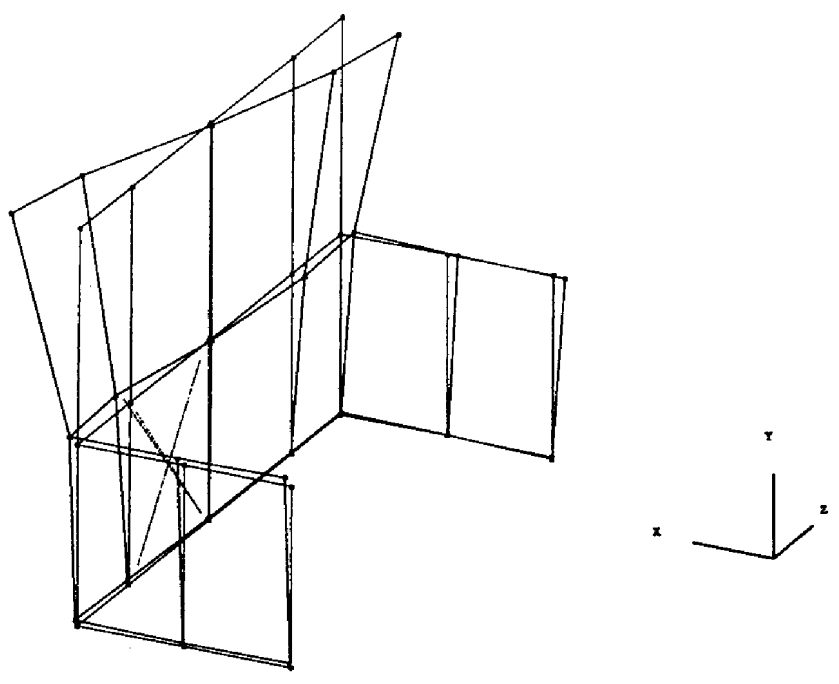




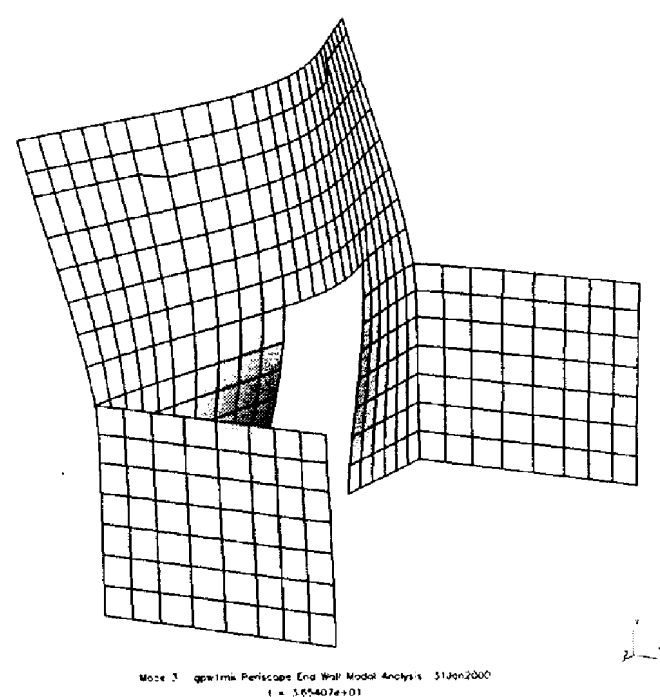

Figure 5-3.

Mode $3=36.5 \mathrm{~Hz}$ (for Shell Model)

Mode $3=34.8 \mathrm{~Hz}$ (for Solid Model)

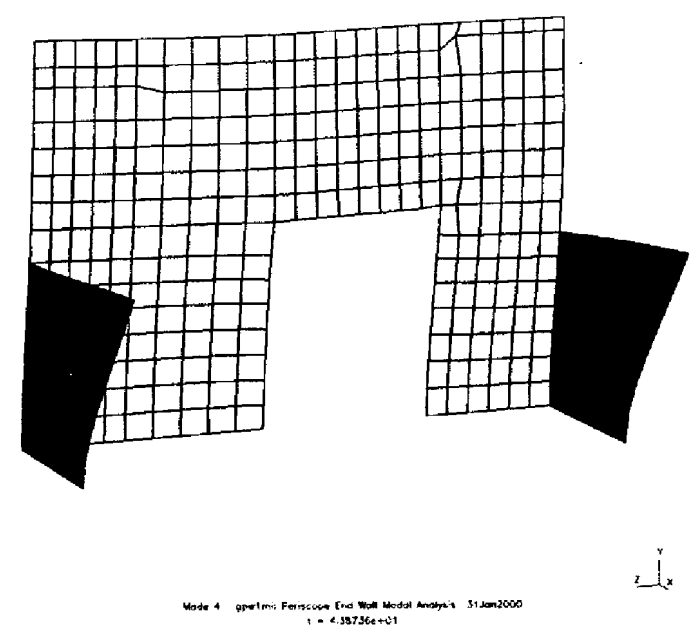

Figure 5-4.

Mode $4=43.9 \mathrm{~Hz}$ (for Shell Model)

Mode $4=44.3 \mathrm{~Hz}$ (for Solid Model)

Section 5

NIF - 0054932-OA, NIF Periscope Wall

Modal Study

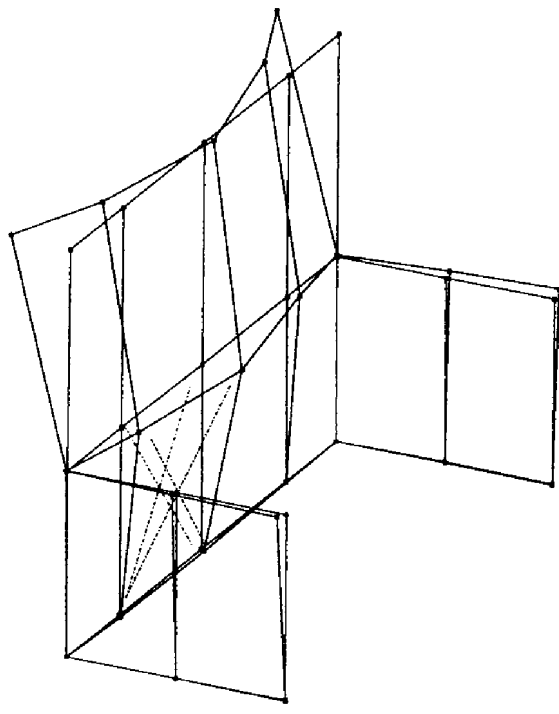

Exper. Global Mode $3=37.0 \mathrm{~Hz}$ (for Shaker Input) Exper. Global Mode $3=37.0 \mathrm{~Hz}$ (for Hammer Input)

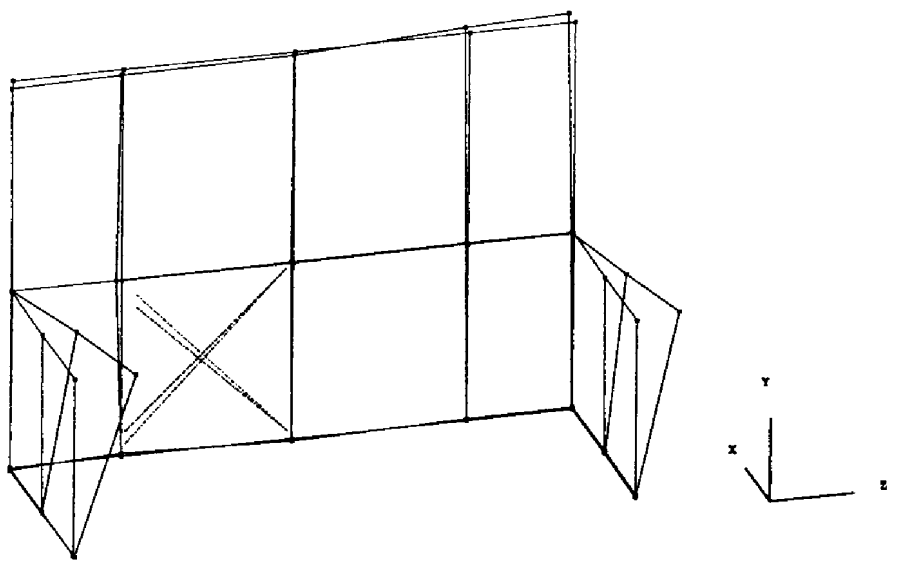

Exper. Global Mode $4=48.2 \mathrm{~Hz}$ (for Shaker Input) Exper. Global Mode $4=47.9 \mathrm{~Hz}$ (for Hammer Input) 


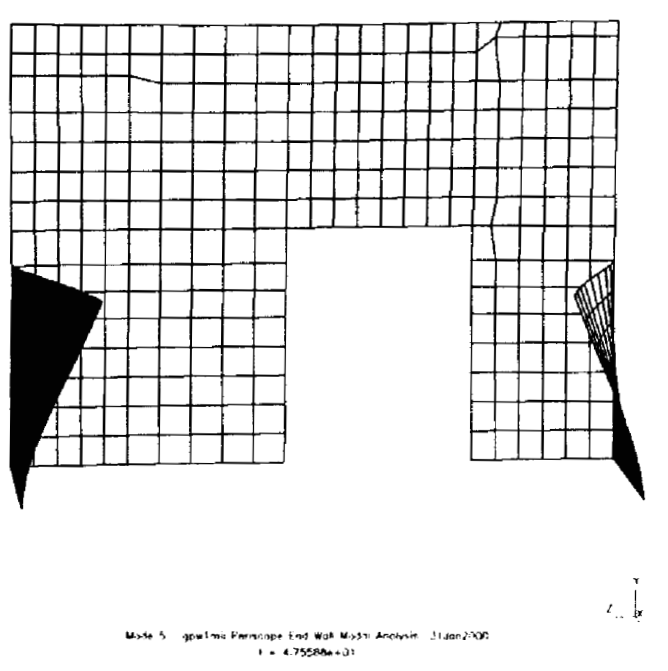

Figure 5-5.

Mode $5=47.6 \mathrm{~Hz}$ (for Shell Model) Mode $5=49.2 \mathrm{~Hz}$ (for Solid Model)

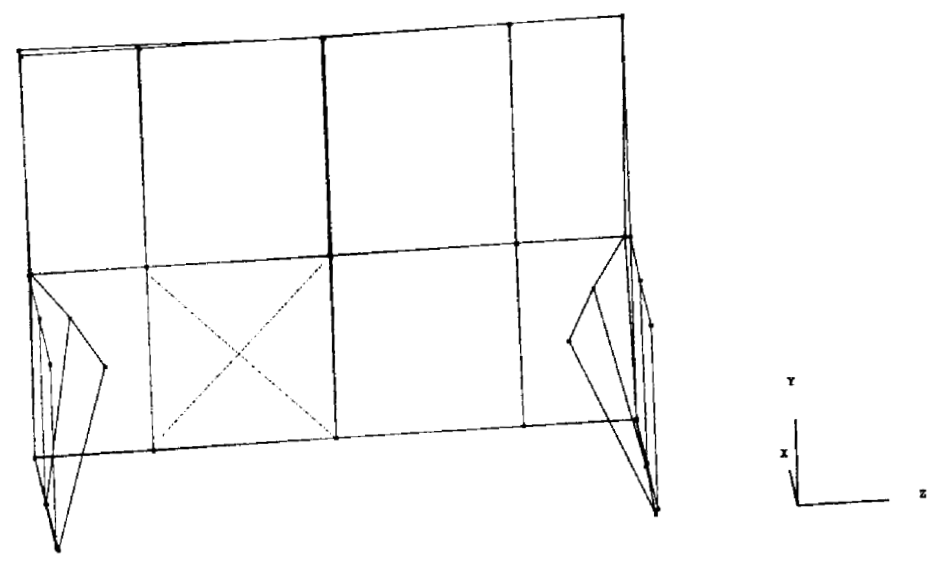

Exper. Global Mode $5=49.1 \mathrm{~Hz}$ (for Shaker Input) Exper. Global Mode $5=\mathbf{4 9 . 2} \mathrm{Hz}$ (for Hammer Input) 


\subsection{Modal Test Damping Results for Periscope Wall}

Section 6 presents a summary of the damping values resulting from the modal tests conducted on the Periscope End Wall in Laser Bay 1. Table 6-1 shows damping values for modal tests using two different methods of excitation: burst-random excitation frequency input from a shaker suspended from the bridge crane; and instrumented hammer impulse.

Table 6-1. Modal Damping Values from Modal Test of Periscope Reinforced Concrete End Pedestal in NIF Laser Bay 1

\begin{tabular}{|c|c|c|c|c|c|c|}
\hline $\begin{array}{l}\text { Excitation } \\
\text { method for } \\
\text { Modal Test }\end{array}$ & Parameters & $\begin{array}{l}\text { Global } \\
\text { Mode } 1\end{array}$ & $\begin{array}{c}\text { Global } \\
\text { Mode } 2\end{array}$ & $\begin{array}{l}\text { Global } \\
\text { Mode } 3\end{array}$ & $\begin{array}{c}\text { Global } \\
\text { Mode } 4\end{array}$ & $\begin{array}{l}\text { Global } \\
\text { Mode } 5\end{array}$ \\
\hline \multirow[t]{2}{*}{$\begin{array}{l}\text { Burst } \\
\text { Random } \\
\text { Shaker } \\
\text { Excitation }\end{array}$} & $\begin{array}{l}\text { Frequency } \\
\quad(\mathrm{Hz})\end{array}$ & $9.80 \mathrm{~Hz}$ & $22.6 \mathrm{~Hz}$ & $37.0 \mathrm{~Hz}$ & $48.2 \mathrm{~Hz}$ & $49.1 \mathrm{~Hz}$ \\
\hline & Damping & $3.2 \%$ & $6.0 \%$ & $1.0 \%$ & $4.8 \%$ & $2.3 \%$ \\
\hline \multirow[t]{2}{*}{$\begin{array}{l}\text { Instrumented } \\
\text { Hammer } \\
\text { Impact }\end{array}$} & $\begin{array}{l}\text { Frequency } \\
\quad(\mathrm{Hz})\end{array}$ & $9.90 \mathrm{~Hz}$ & $22.4 \mathrm{~Hz}$ & $37.0 \mathrm{~Hz}$ & $47.9 \mathrm{~Hz}$ & $49.2 \mathrm{~Hz}$ \\
\hline & Damping & $3.9 \%^{*}$ & $6.0 \%$ & $1.0 \%$ & $4.1 \%$ & $2.5 \%$ \\
\hline
\end{tabular}

* Note: see Appendix B for the method of determining damping for global modes 1 \& 2, resulting from impulse by the instrumented hammer. All other damping values are from the curve-fitting process within the Star Modal Software (SMS) by Spectral Dynamics [ref 8].

Table 6-2 shows a list of typical modal damping values for low-strain excitation for both steel and for reinforced concrete. The range of modal damping values presented for reinforced concrete is from $0.4 \%$ to $3.2 \%$. Experimentally tested modes falling within this range for the Periscope End Wall are:

- Global Mode 1 of the Periscope End Wall. This corresponds to a mode shape which is primary bending of the upper portion of the wall as a cantilever in the weak direction (global X-dir) of that upper part of the wall.

- Global Mode 3 of the Periscope End Wall. This corresponds to a mode shape which is an "outof-plane" bending response of the wall at the upper portion (above the wing walls) in the global $\mathrm{X}$-direction.

- Global Mode 5 of the Periscope End Wall. This corresponds to a mode shape which is an "outof-phase" motion of the wing walls. 
Table 6-2. Modal Damping Values for Low-Strain Excitation

\begin{tabular}{|c|c|l|}
\hline Material & Value & Reference \\
\hline steel & $0.3 \%-0.9 \%$ & UCID-20116, Pastrnak \& Weaver, June 22, 1984, Table 1 [ref 9] \\
\hline steel & $6.5 \%$ & NUREG/CR-3006, Coats, November 1982 [ref 10] \\
\hline reinforced concrete & $0.7 \%-1.5 \%$ & EESD, Farrar \& Baker, June 27, 1994, Table III [ref 11] \\
\hline reinforced concrete & $1.0 \%-2.0 \%$ & EESD, Farrar \& Baker, June 27, 1994, Page 453 [ref 11] \\
\hline reinforced concrete & $1 \%$ & NUREG/CR-5776, Farrar \& Baker, May 1993, Page 66 [ref 12] \\
\hline reinforced concrete & $0.9 \%-2.4 \%$ & LA-12767-MS, Farrar \& et. al., June 1994, Table IV [ref 13] \\
\hline reinforced concrete & $0.6 \%-2.2 \%$ & LA-12767-MS, Farrar \& et. al., June 1994, Table VII [ref 13] \\
\hline reinforced concrete & $0.4 \%-1.6 \%$ & LA-12767-MS, Farrar \& et. al., June 1994, Table XI [ref 13] \\
\hline
\end{tabular}

For the low-strain excitation cases (which usually involved ambient vibration input), the finiteelement analyses for the Periscope support structure used the following modal damping values during the Title II design phase: $0.5 \%$ damping for steel; and $2.0 \%$ damping for reinforced concrete [ref 14].

Comparing these values with the modal damping values in Tables 6-1 and 6-2, the finite-element analyses for the Periscope support structure were reasonably conservative.

The experimental modal damping values are obtained as part of the curve-fitting procedure that is used for determining the resonant frequencies, as briefly described in Section 4 of this report. The following process is used for reducing the modal test data from each type of wall excitation as separate cases (i.e., "burst random" shaker input or "transient" input by instrumented hammer impulse):

- Initially, the resonance peaks are determined from the "modal peaks function" by combining the frequency response function (FRF) contributions from responses at each measurement location (for each direction, for a given number of averages of modal test data). With the "modal peaks function" within the Star Modal Software (SMS) by Spectral Dynamics [ref 8], bandwidths for each identified mode are selected for inclusion in a two-step curve-fitting process for obtaining eigenvalues and eigenvectors. 
- In this particular case for the Periscope End Wall in Laser Bay 1, the option for "Global Curve Fitting" was selected within the SMS software. During the first step of the curve-fitting, the global frequencies and damping are computed from the modal test data.

- In the second step of the curve-fitting process, the global residues (mode shapes) are determined for all identified modes. This two-step curve-fitting process results in better estimates of mode shapes. This is due to the fact that the frequency and damping are already known for each selected mode from the curve-fitting in the global frequency and damping step. 



\subsection{Verification of "Beta" Factor for SSI effects}

It was planned that the modal test could demonstrate the frequency shift due to the flexible foundation and soil stiffness. Since the FEA model assumed a fixed-base condition, this frequency. shift was conservatively represented in the stability budget with the "beta" factor [ref 1,15$]$. With a better understanding of the "beta" factor, there is a possibility that the stability allocations for different optical components (especially those in the switchyards and target building) can be increased. There are several reasons why the frequency shift was not observed in the Periscope End Wall modal test:

1. Only about $1 / 10$ to $1 / 5$ of the total mass of the Periscope was excited (the frequency shift is inertia dependent)

2. The first three fundamental modes of the exterior wall occur above the $X Y$ wing walls, and these modes will have minimal influence from the foundation

3. Only a small part of the total footprint of the Periscope support structure was captured in the modal test. 



\subsection{Future Modal Test Plans for "Full" Periscope Assembly (excluding LRU's)}

Once the construction and installation of the Full Periscope Assembly (excluding LRU's) is completed in Laser Bay 1, an additional set of modal tests can be conducted. The experimental modal tests would be performed in order to verify the assumptions made for modal properties of the NIF Periscope Assembly, which were used during the Title II Design phase. These modal properties include frequencies and mode shapes, as well as estimates of modal damping.

Discussions are continuing with regard to the appropriate and available methods for experimental modal testing of the Full Periscope Assembly. Figures 8-1 and 8-2 show mode shapes of the FEA model for the Periscope Pedestal (reinforced concrete support structure) as well as the LM3/Polarizer LRU's, the PEPC LRU's, and their supporting structural steel framework. There will need to be enough tri-axial accelerometer locations included in the modal test layout to adequately capture the fundamental modes of vibration of the entire Periscope Assembly. One of the potential techniques for modal testing involves the use of white noise as an input excitation of the structure during the modal tests. The future set of experimental modal tests of the Full Periscope Assembly (excluding LRU's) is also intended to help to verify the "Beta" Factor for SSI effects (see Section 7) [ref $1,15,16]$.

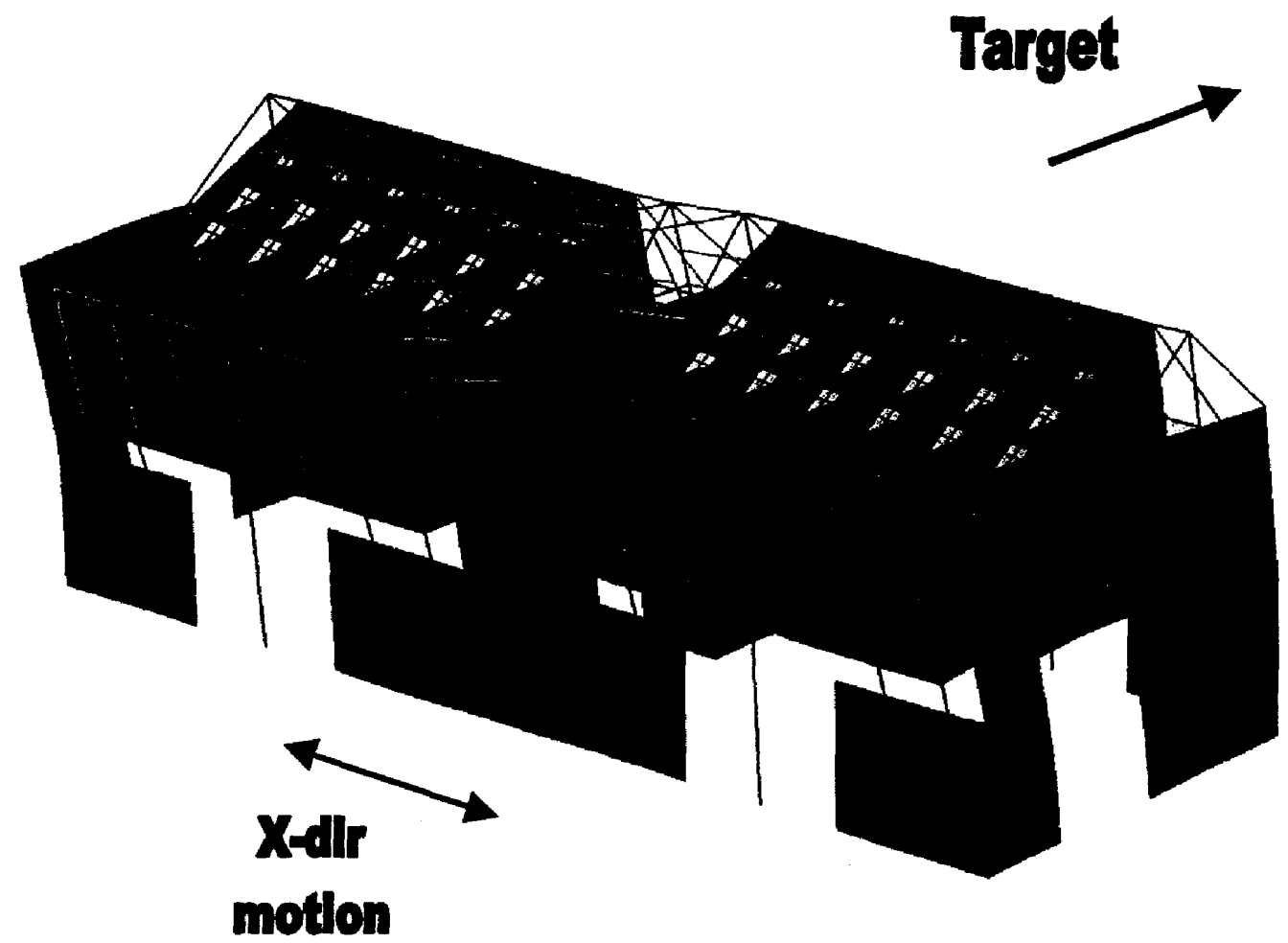

Figure 8-1. Mode 1 (15.1 Hz in X-direction) of the FEA model for the entire NIF Periscope Assembly in Laser Bay 1. 


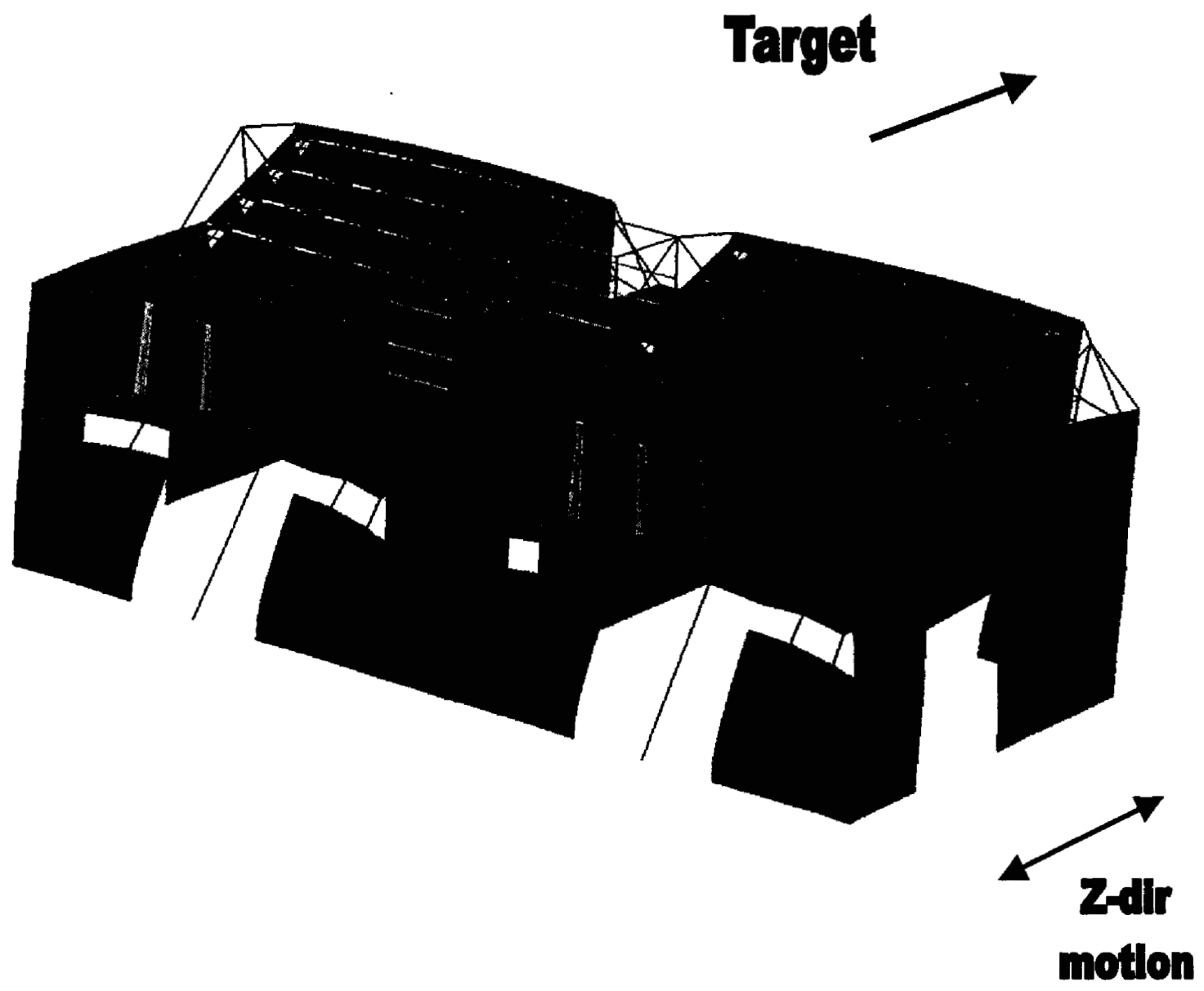

Figure 8-2. Mode $2(17.2 \mathrm{~Hz}$ in $\mathrm{Z}$-direction) of the FEA model for the entire NIF Periscope Assembly in Laser Bay 1. 


\subsection{References}

1. Sommer, Stanley C., NIF Systems Engineering, and Erlan S. Bliss, Systems Control Engineer, Chapter 11. Beam Positioning, "NIF Laser System Performance Ratings", UCRL-ID-131115, p. 112 \& section 11.4, LLNL, CA, July 1998.

2. Eli, Mark W., Structural and Applied Mechanics Group (SAMG)/NTED/ME, "Modal Analysis for Periscope LM3/Polarizer LRU", subject of E-mail \& Attachment sent to Mike Richardson \& Layton Hale of NIF, LLNL, September 18, 1998.

3. Woehrle, Tom W., SAMG/NTED/ME, "Experimental Modal Surveys on the LM3 Prototype Periscope and 'A' Frame", Memo SM97-022TGW to Mike Richardson \& Layton Hale of NIF, LLNL, July 7, 1997.

4. Ilg, Thomas, Engineering Science and Application Division (ESAD)/LANL, "Periscope Structural Steel Support Analysis", NIF-5000476, MESN98-015-OA, 3/19/98.

5. Gerhard, Michael A., SAMG/NTED/ME, "Periscope Support Structure Finite Element Analyses", NIF5000476, MESN98-015-OA, 3/19/98.

6. Gerhard, Michael A., SAMG/NTED/ME, "SLIC / IV, The Interactive, Graphic Mesh Generator", UCRL-52823, Version 4.82, October 15, 1997.

7. Murray, Robert C., NTED/ME, "GEMINI, A Computer Program for Two and Three Dimensional Linear Static, and Seismic Structural Analysis”, UCID-20338, updated September 10, 1997.

8. Star Modal Software (SMS) version 5.24, by Spectral Dynamics, San Jose, CA.

9. Pastrnak, John W., and H. Joseph Weaver, "Dynamic Testing of NOVA Laser Structural Systems: The North Side Spaceframe Tower", UCID-20116, June 22, 1984, Table 1.

10. Coats, Jr., David W., "Damping in Building Structures during Earthquakes: Test Data and Modeling", NUREG/CR-3006, UCRL-53043, November 1982.

11. Farrar, Charles R., and William E. Baker, "Damping in Low-Aspect-Ratio, Reinforced Concrete Shear Walls", Earthquake Engineering and Structural Dynamics (EESD), Vol. 24, June 27, 1994, Table III.

12. Farrar, Charles R., and William E. Baker, "Damping in Low-Aspect-Ratio, Reinforced Concrete Shear Walls", NUREG/CR-5776, LA-12201-MS, May 1993, Page 66.

13. Farrar, Charles R., et al, "Dynamic Characterization and Damage Detection in the I-40 Bridge over the Rio Grande", LA-12767-MS, June 1994, Table IV.

14. Sommer, Stanley C., "Ambient Ground Vibrations and Structural Damping Values", NIF-LLNL-96141, February 26, 1996.

15. McCallen, David, "The effect of foundation flexibility on the vibrational stability of the National Ignition Facility optical system support structures", UCRL-ID-124700, May, 1997.

16. Speck, D.R., Senior Commissioning Scientist, et al, "Laser Commissioning Plan", NIF-0053422, September 1, 2000, DRAFT. 
17. Maia, Nuno M. M. and Julio M. M. Silva, "Theoretical and Experimental Modal Analysis", pp. 45, 46, Research Studies Press Ltd., 1997. 


\section{Appendix A}

\section{Modal Test of Periscope LM3/Polarizer LRU}

(conducted 9-98 in Test Stand at B-432) 



\section{A.0 Modal Test of Periscope LM3/Polarizer LRU}

In September 1998, a modal test of a prototype for the Periscope LM3/Polarizer LRU was conducted for a Title II Design Review for the LM3/Polarizer LRU and associated systems [ref 2]. In that prototype, there were new kinematic mounts and mock mirrors. The LM3/Polarizer LRU was mounted on a test frame in B-432 High-Bay (Figure A-1).

At that time, the modal test was requested in order to provide a comparison with the assumed modal properties for the kinematic mounts. Table A-1 shows the frequencies and damping for each global mode, along with a brief description of the corresponding mode shapes. Figures A-2 through A-7 show the locations of the accelerometers used during the modal test. Figures A-8 through A-19 show selected views of the mode shapes for the first five global modes.

A similar modal test on a prototype for the LM3/Polarizer LRU, which included an earlier design version of the kinematic mounts, was performed in mid-1997 [ref 3].
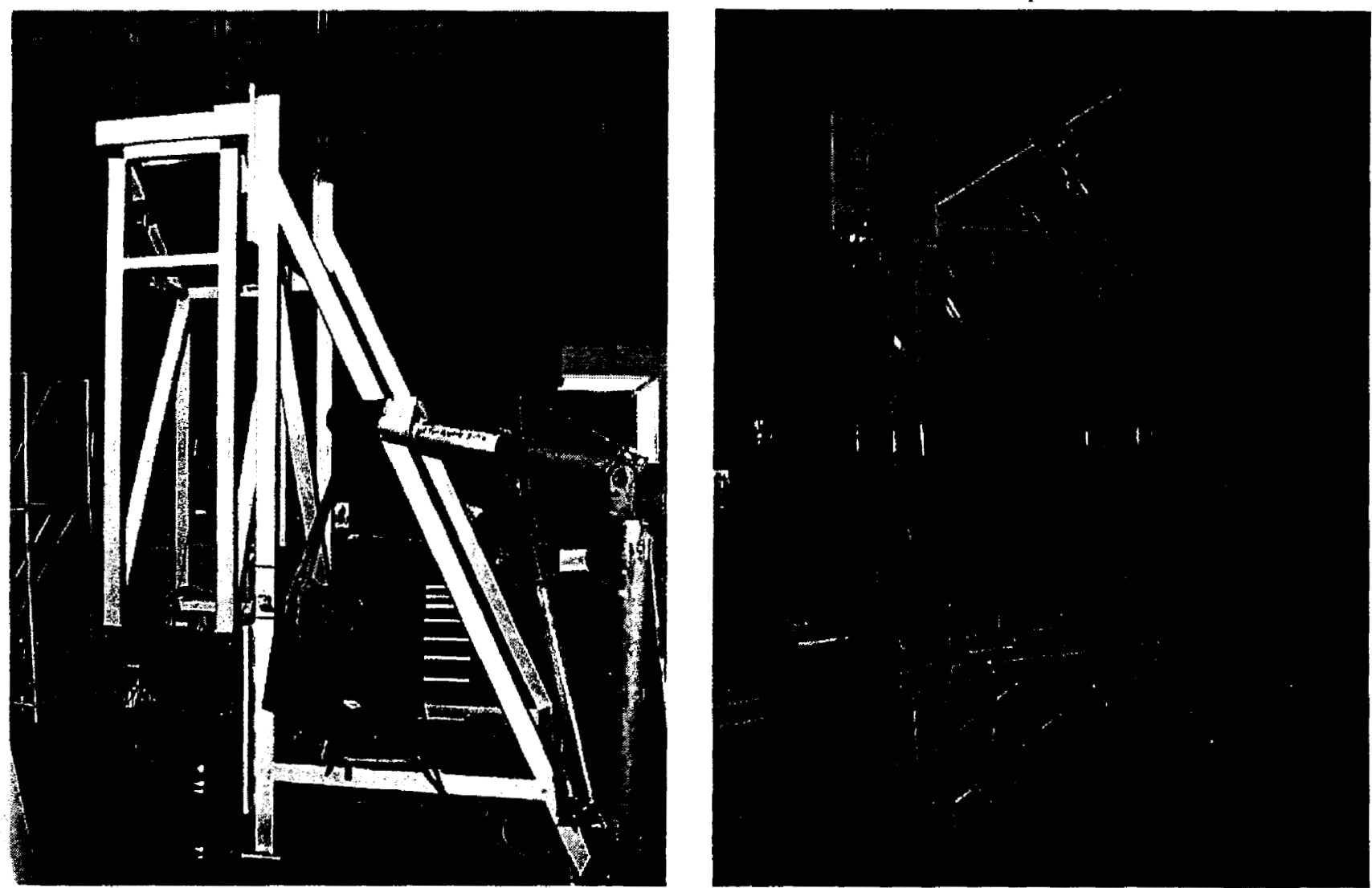

Figure A-1. Modal Test setup (in September 1998) of a prototype for the NIF Periscope LM3/Polarizer LRU (with its kinematic mounts and mock mirrors) on a test stand in B-432. 
Table A-1. Summary of Frequencies \& Mode Shapes for prototype of NIF Periscope LM3/Polarizer LRU

\begin{tabular}{|c|c|c|l|}
\hline $\begin{array}{c}\text { Mode } \\
\text { No. }\end{array}$ & $\begin{array}{c}\text { Freq. } \\
(\mathrm{Hz})\end{array}$ & $\begin{array}{c}\text { Modal } \\
\text { Damping } \\
(\%)\end{array}$ & $\mathbf{1}$ \\
\hline 1 & 15.9 & 0.6 & $\begin{array}{l}\text { Primary Bending Mode of A-frame in Horizontal Z-direction; Mirrors have "in-plane" } \\
\text { motion along inclined axis -- the "in-plane" motion lags behind the global Z- } \\
\text { displacement of the Periscope LM3/Polarizer LRU Frame; }\end{array}$ \\
\hline 2 & 25.6 & 0.5 & $\begin{array}{l}\text { Periscope LM3/Polarizer LRU Frame pivots in Horizontal X-direction about the top of } \\
\text { the A-frame; The Lower Mirror shifts side-to-side in Horizontal X-direction (relative } \\
\text { to the LM3/Polarizer LRU Frame) \& lags slightly behind the swinging of the } \\
\text { LM3/Polarizer LRU Frame; }\end{array}$ \\
\hline 3 & 26.4 & 0.7 & $\begin{array}{l}\text { Modes \# 3 \& \# 4 are similar in that both have a twisting motion of the A-frame about } \\
\text { the Vertical Y-axis in combination with tilting toward the LM3/Polarizer LRU Frame; } \\
\text { however, the twisting is in opposite directions for the two modes as the A-frame tilts } \\
\text { toward the LM3/Polarizer LRU Frame; Mode \# 3 has a Clock-wise twist as it leans } \\
\text { toward the Periscope Frame; This gives the LM3/Polarizer LRU Frame a downward } \\
\text { motion in a "corkscrew" fashion; }\end{array}$ \\
\hline 5 & 28.4 & 0.9 & $\begin{array}{l}\text { Mode \# 4 has a Counter Clock-wise twist of the A-frame as it leans toward the } \\
\text { LM3/Polarizer LRU Frame; This gives the LM3/Polarizer LRU Frame a downward } \\
\text { motion in a "corkscrew" fashion; }\end{array}$ \\
\hline 39.4 & 0.8 & $\begin{array}{l}\text { Appears to be a torsion mode of the Periscope LM3/Polarizer LRU Frame about the } \\
\text { Vertical Y-axis; The Upper Mirror has significant relative "in-plane" motion as it lags } \\
\text { behind the LM3/Polarizer LRU Frame torsional motion; }\end{array}$ \\
\hline
\end{tabular}




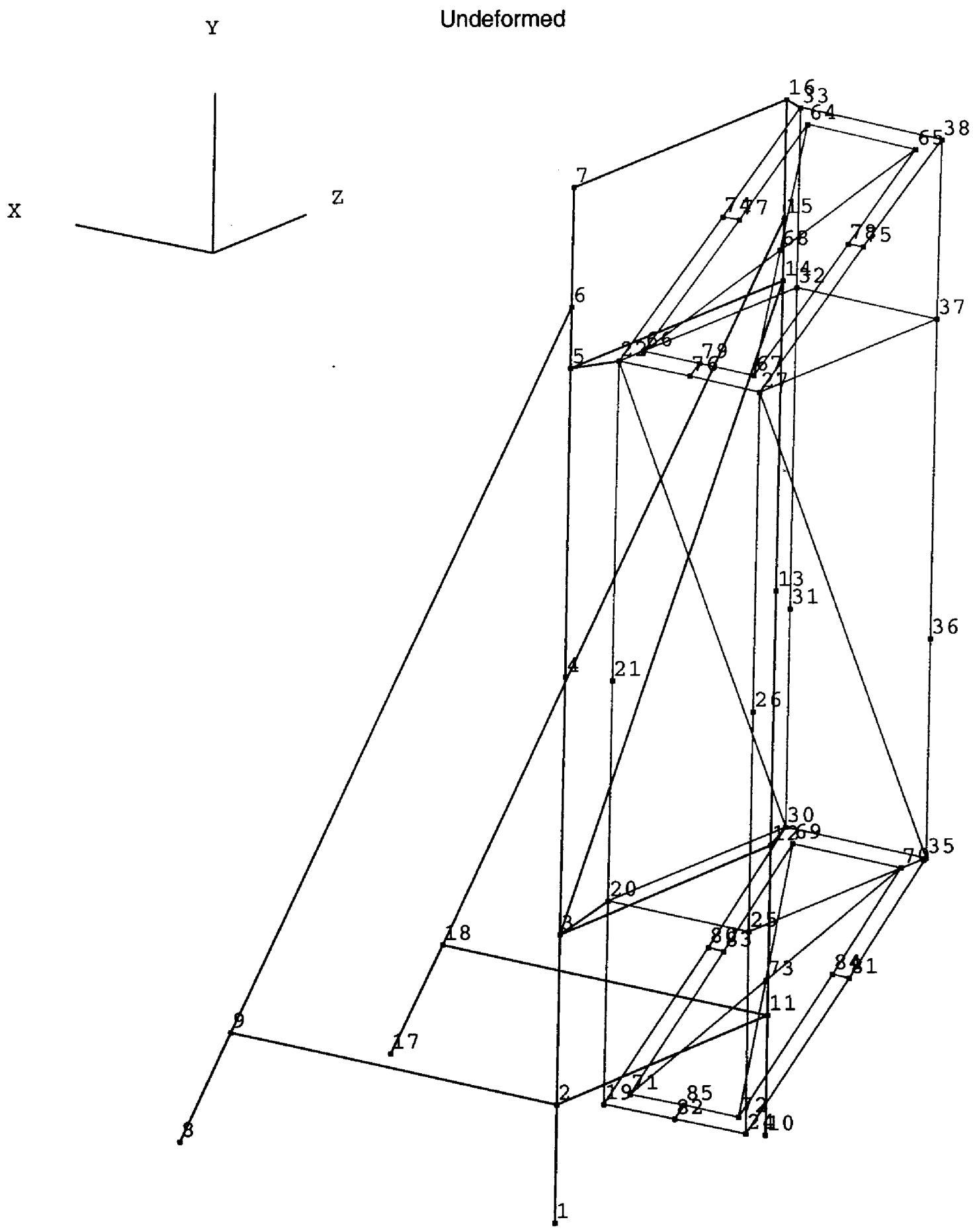

Figure A-2. Modal Test setup of of a prototype for the NIF Periscope LM3/Polarizer LRU and its kinematic mounts, showing locations of sensors used during modal test. This modal test used a test stand in B-432. 


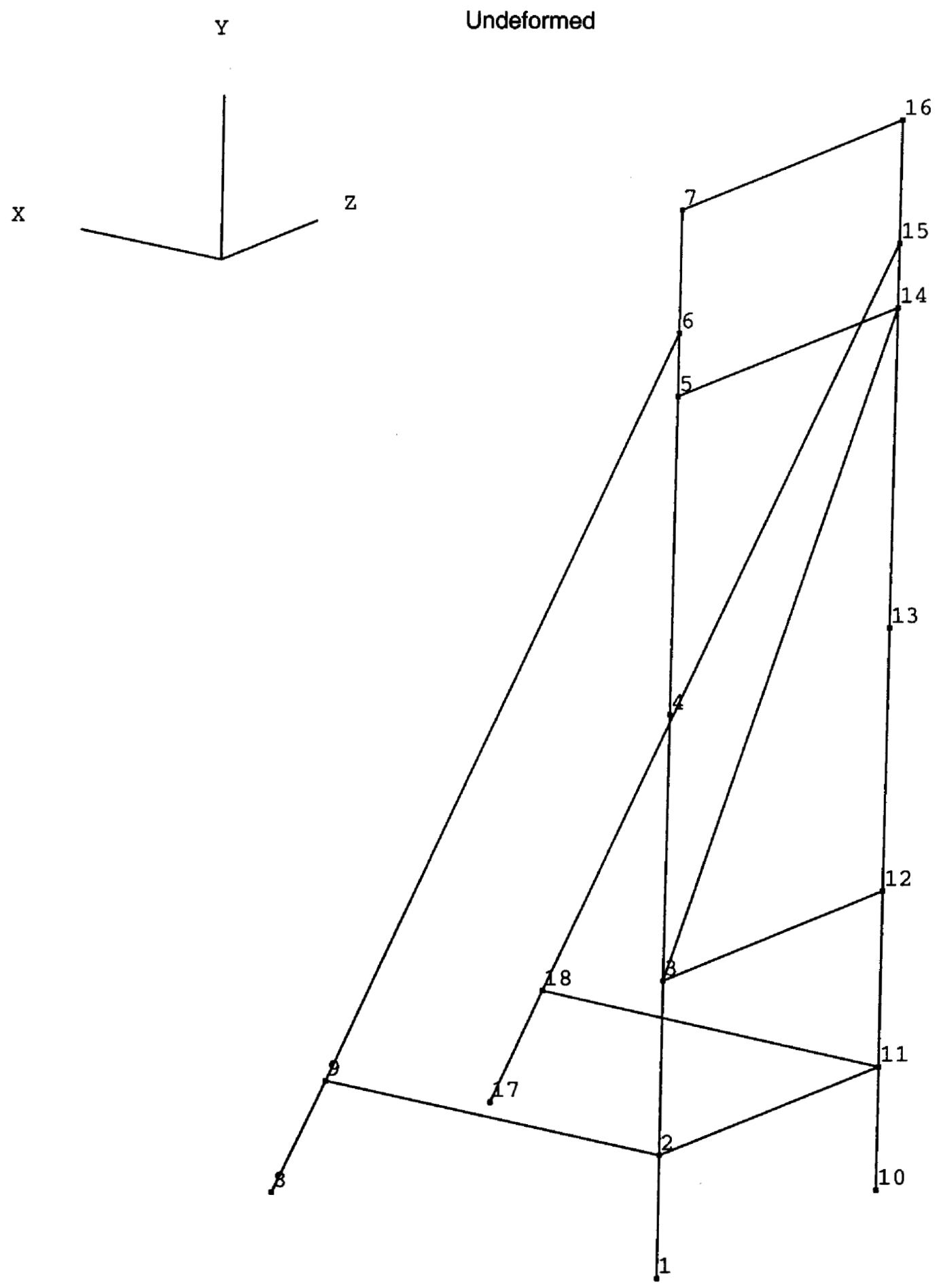

Figure A-3. Measurement locations for sensors on just the Test stand in B-432. 

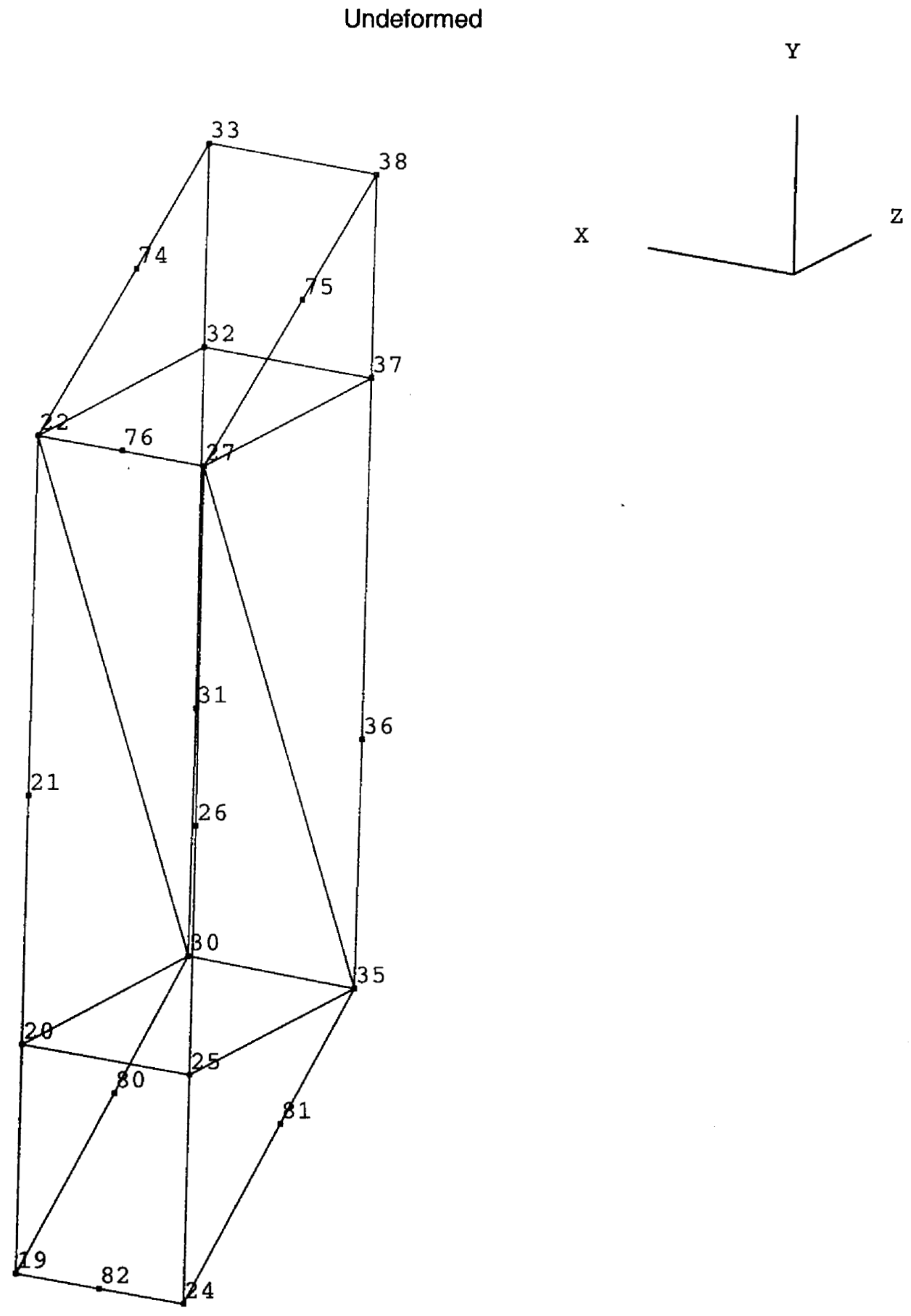

Figure A-4. Measurement locations for sensors on prototype frame for NIF Periscope LM3/Polarizer LRU and its kinematic mounts. 

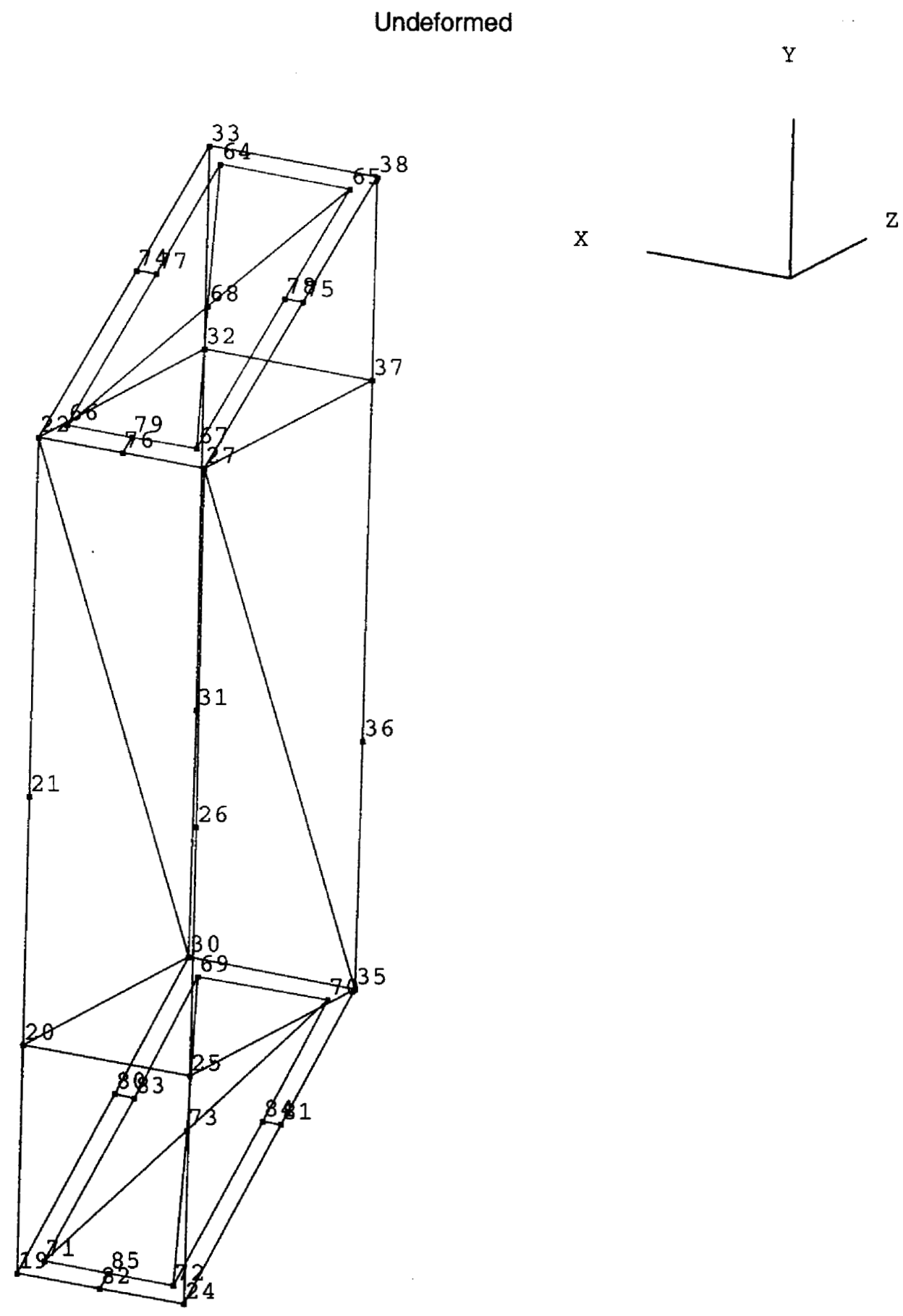

Figure A-5. Measurement locations for sensors on mock mirrors, prototype frame for NIF Periscope LM3/Polarizer LRU, and the kinematic mounts to the frame. 


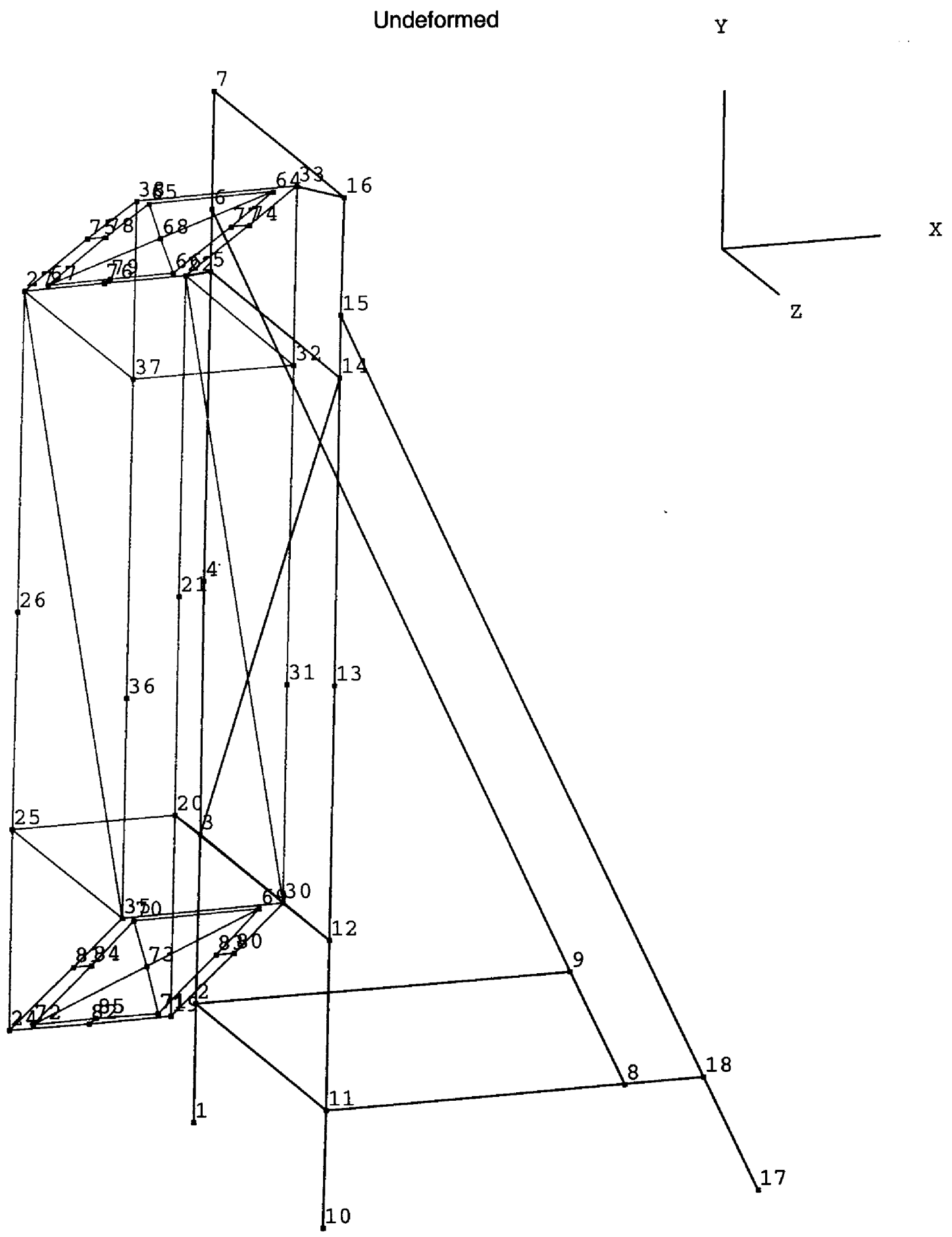

Figure A-6. Alternate view of Modal Test setup of a prototype for the NIF Periscope LM3/Polarizer LRU and its kinematic mounts, showing locations of sensors used during modal test. This modal test used a test stand in B-432. 


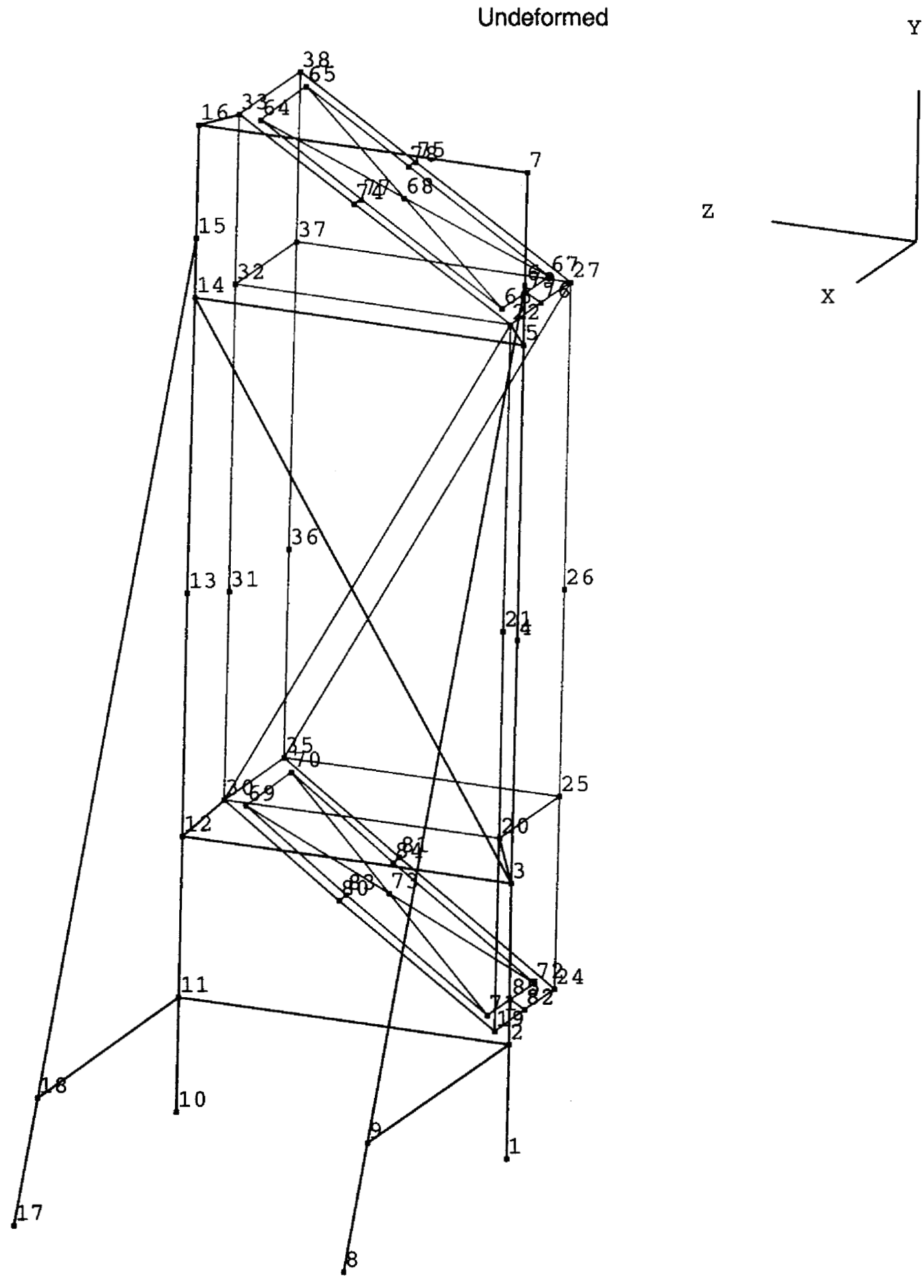

Figure A-7. A view of Modal Test setup of a prototype for the NIF Periscope LM3/Polarizer LRU and its kinematic mounts, showing locations of sensors used during modal test. This modal test used a test stand in B-432. 


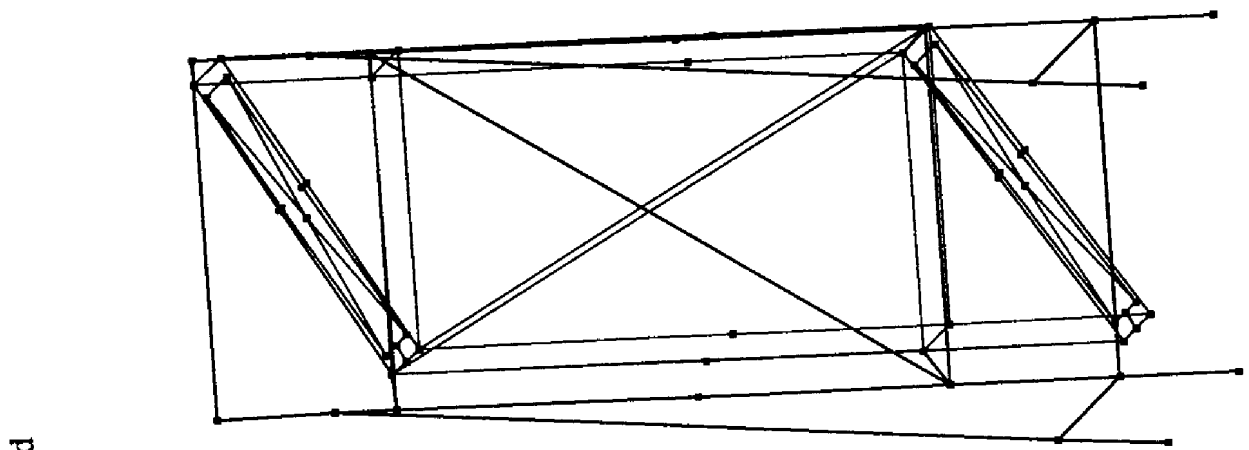

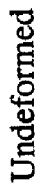

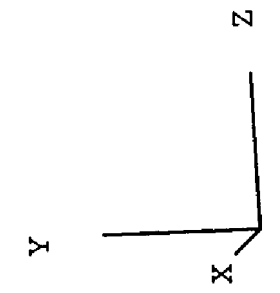

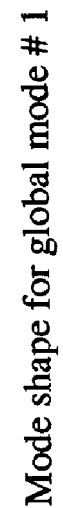

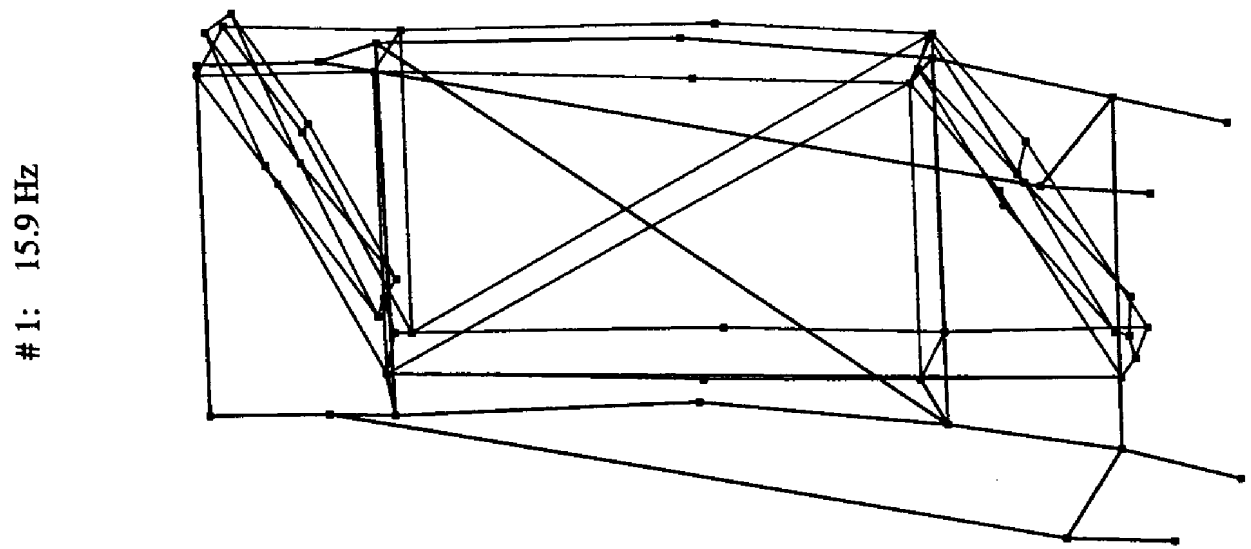

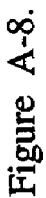




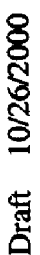
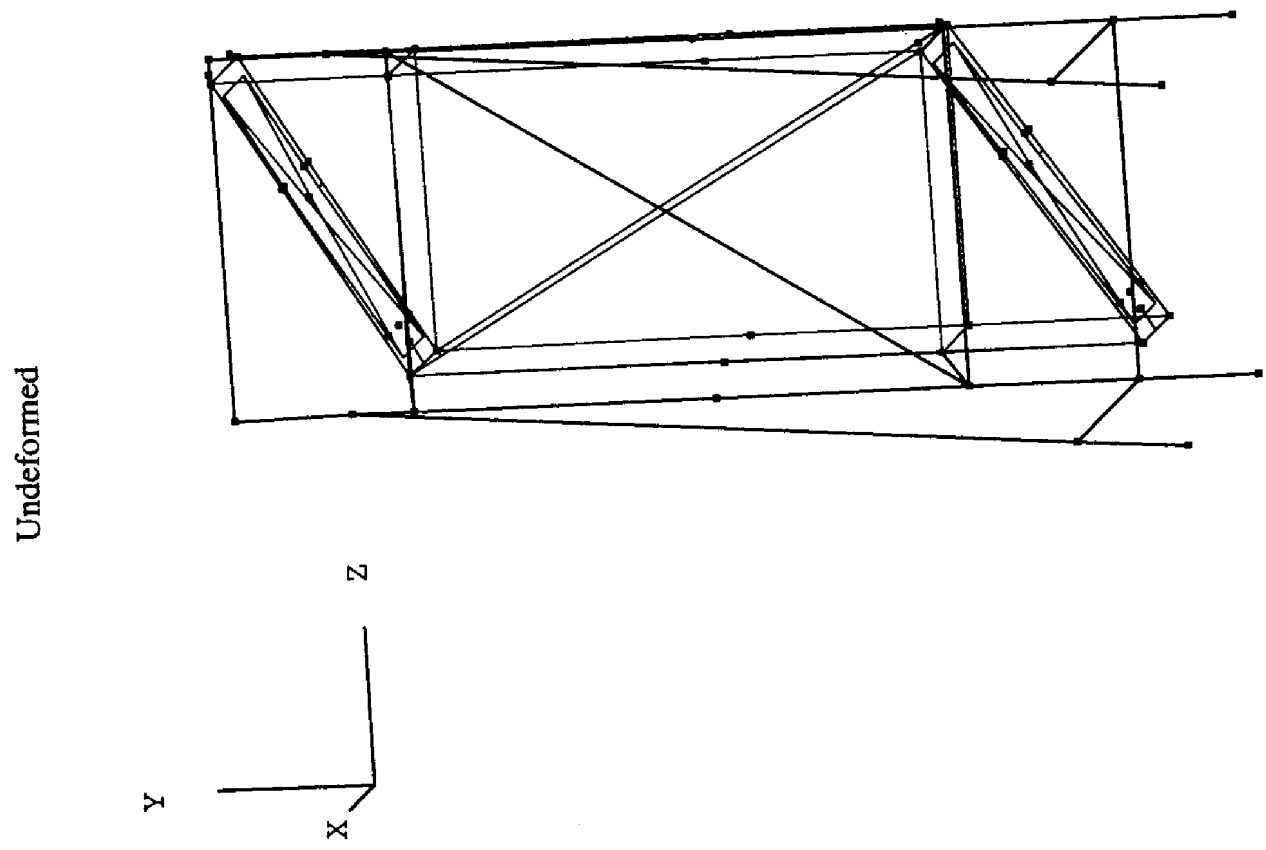

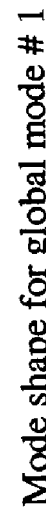

ì

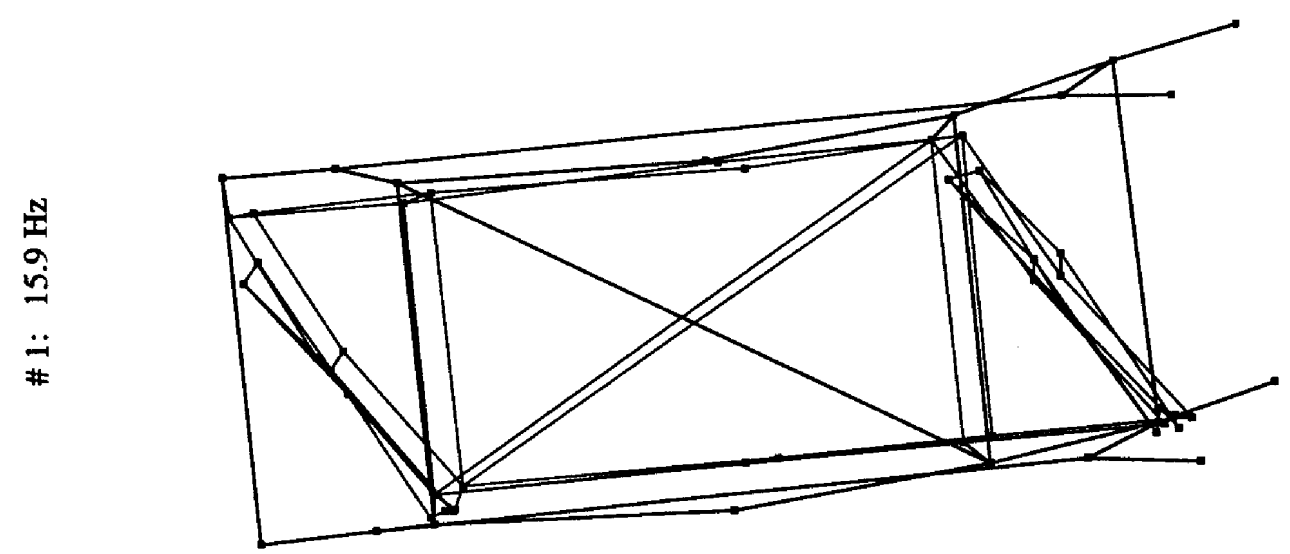




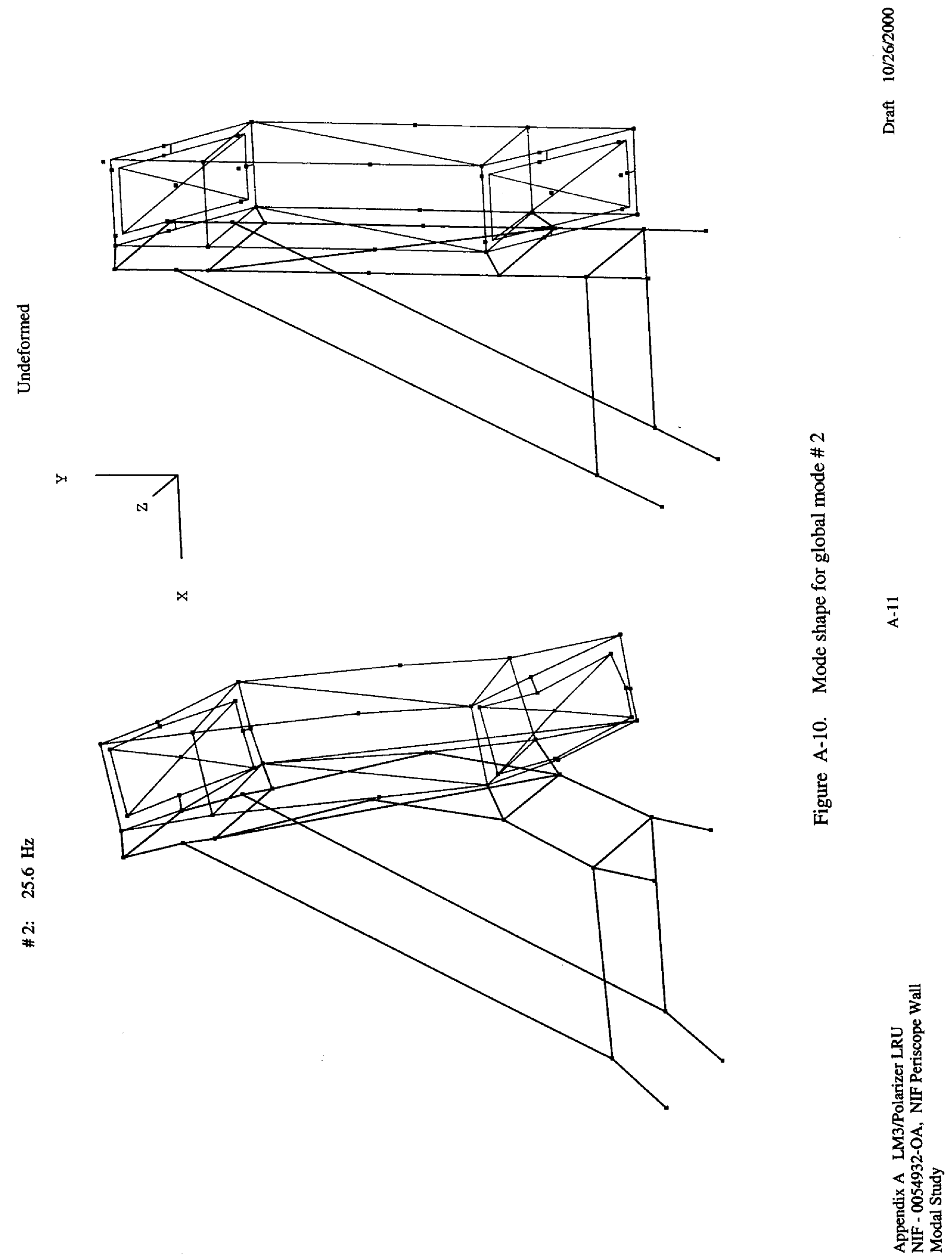




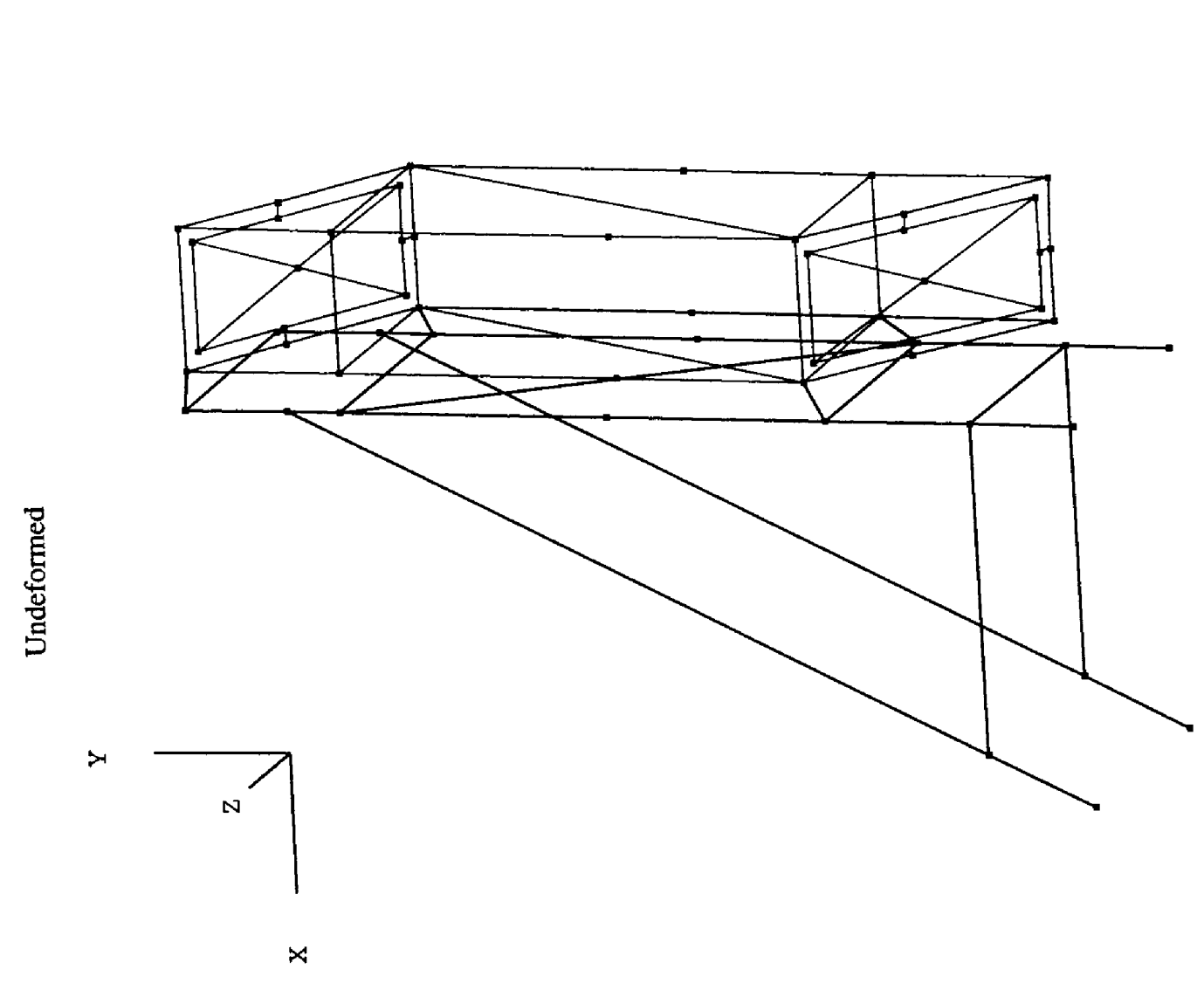

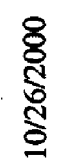

茝

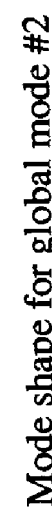

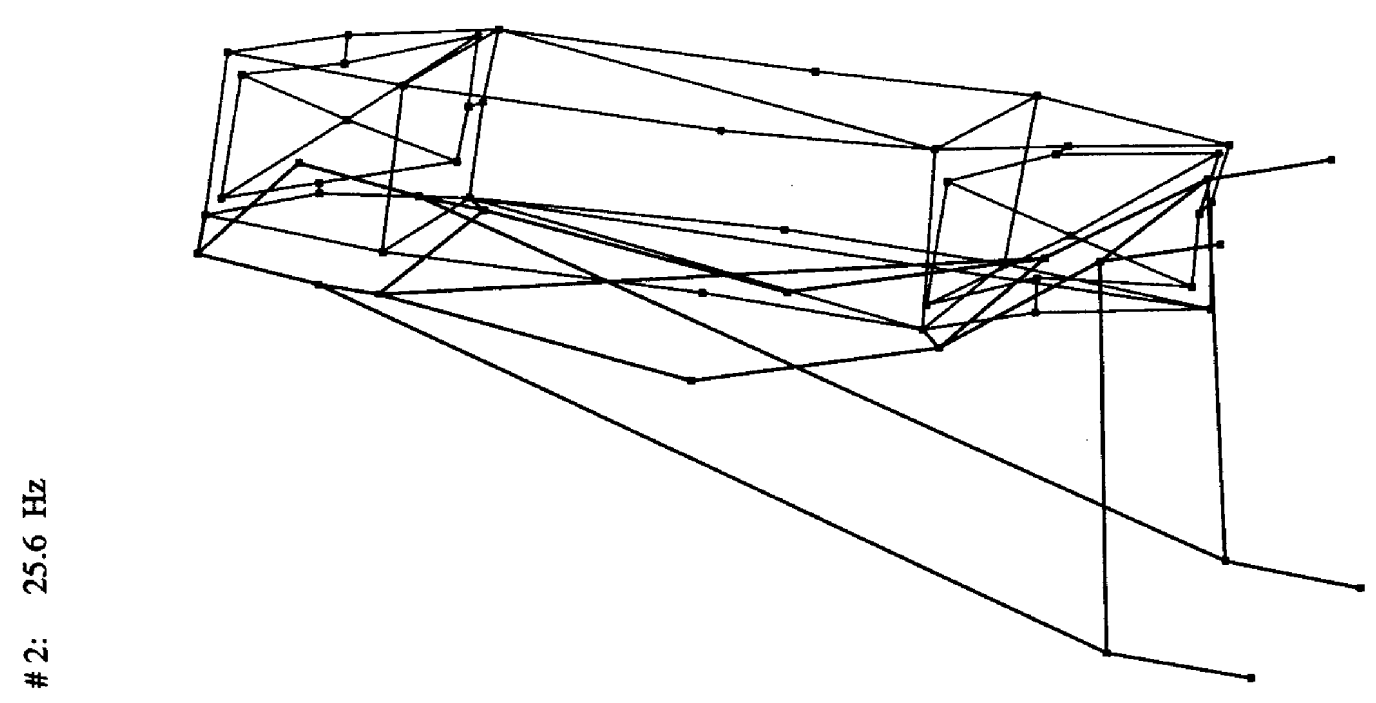



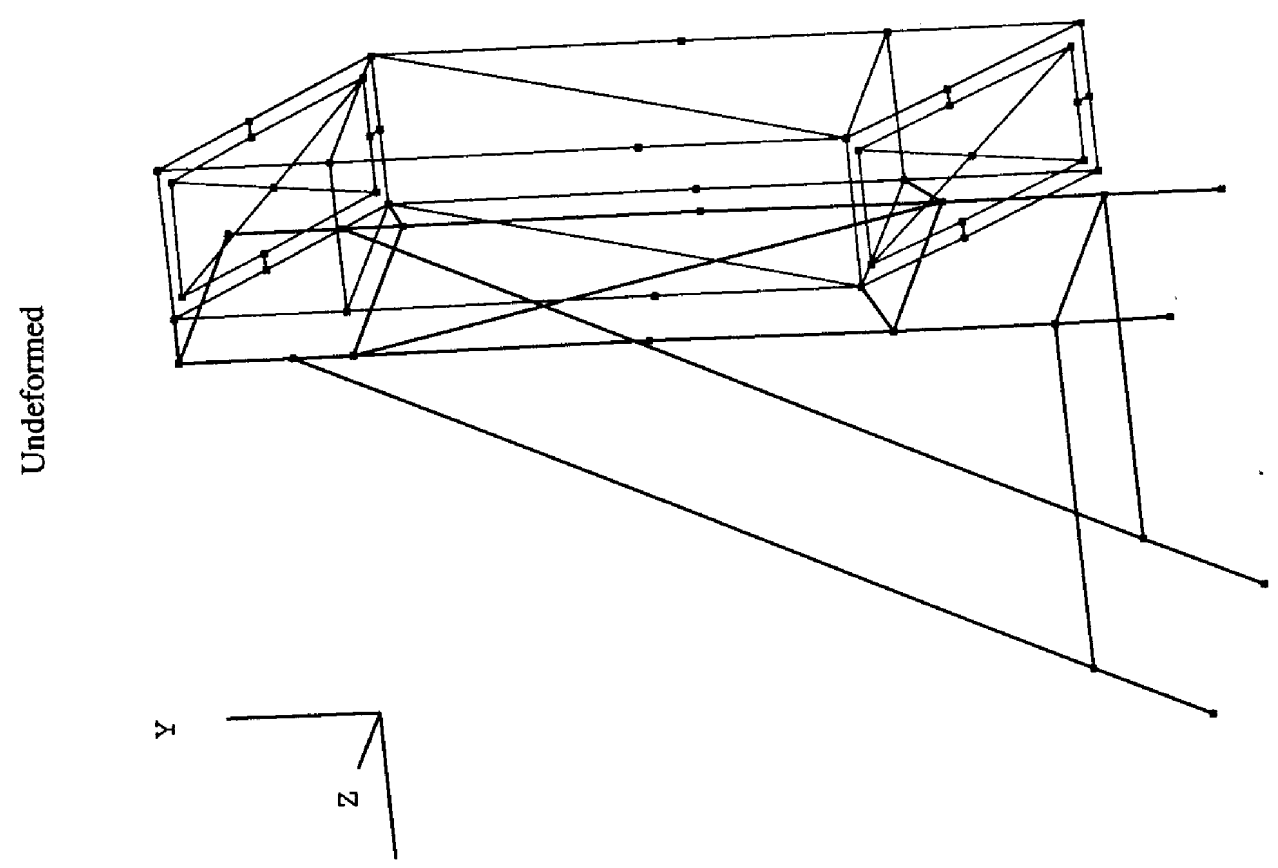

$x$

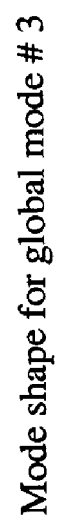

$\frac{m}{4}$

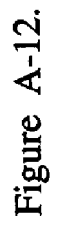

N
Uे
N
$\ddot{n}$
\#

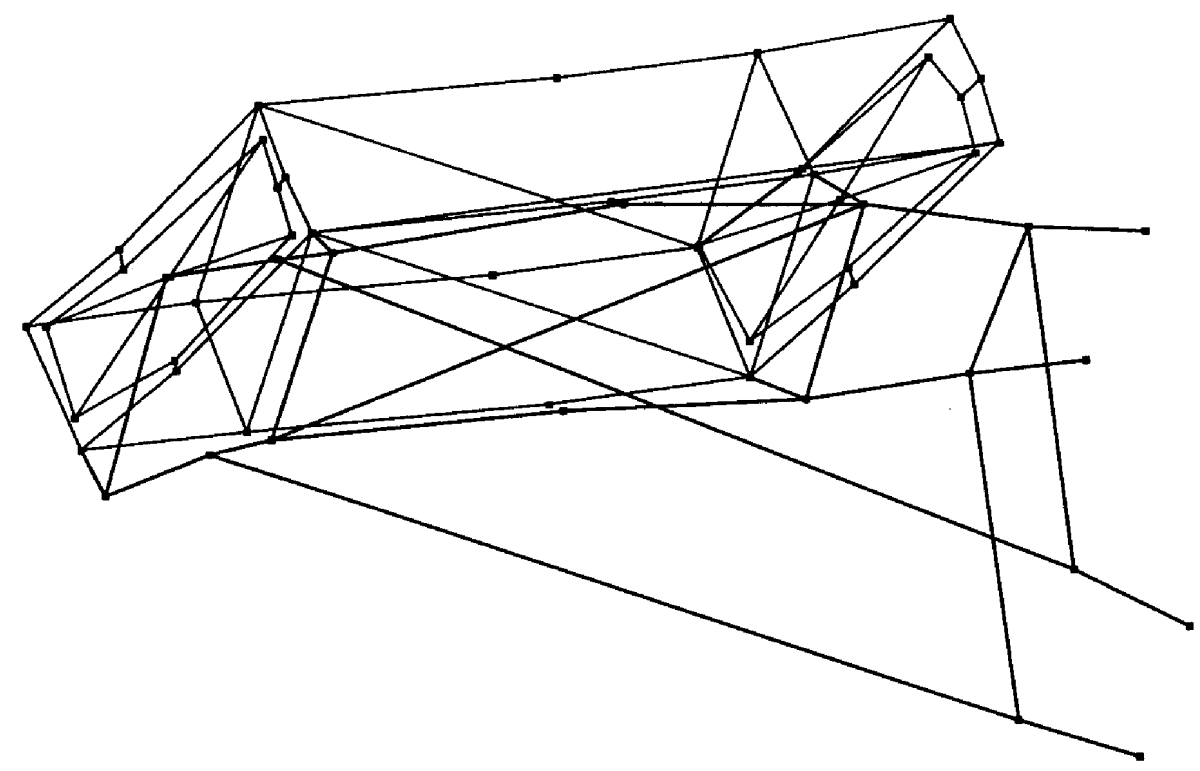

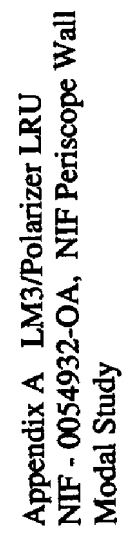



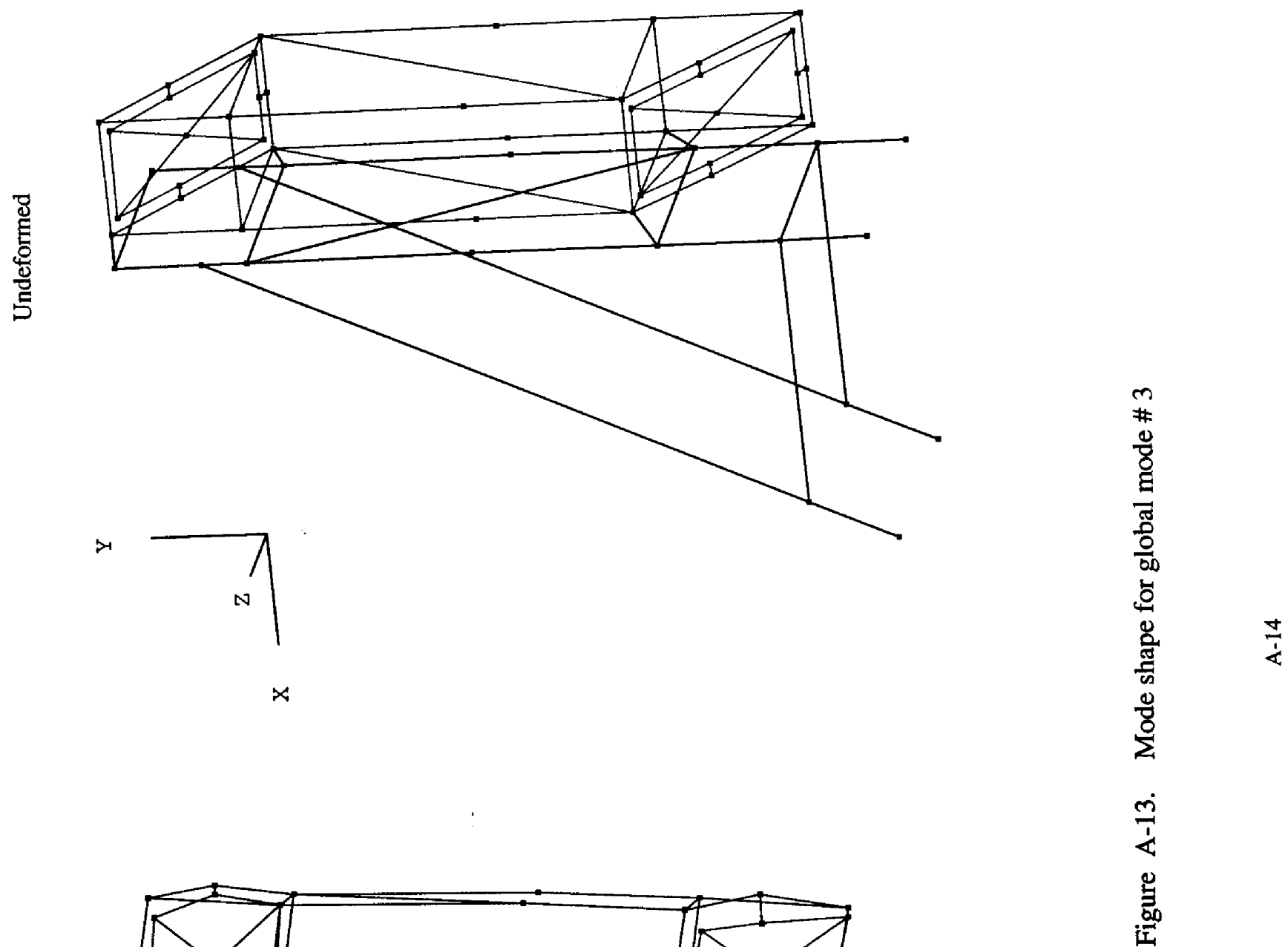

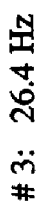
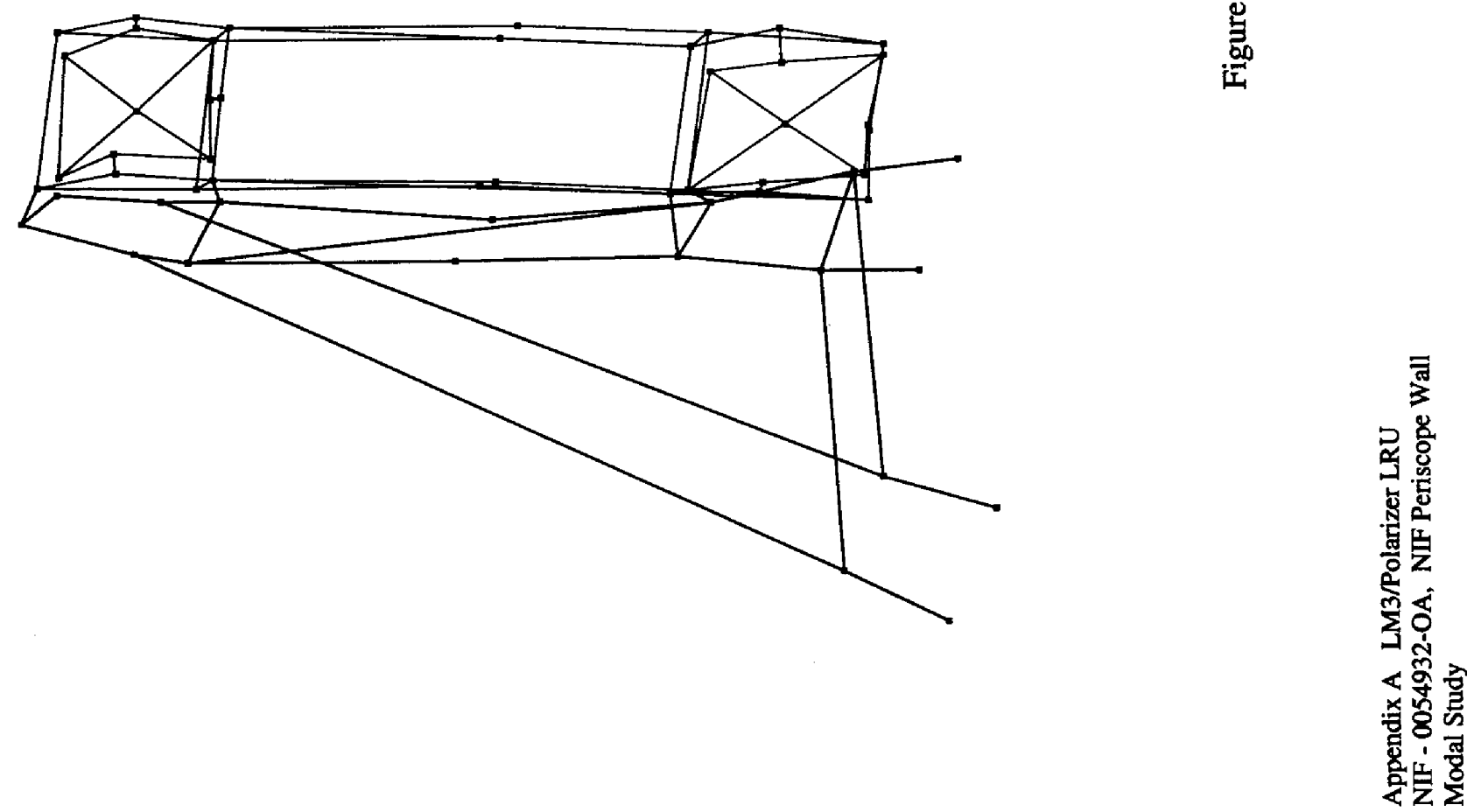

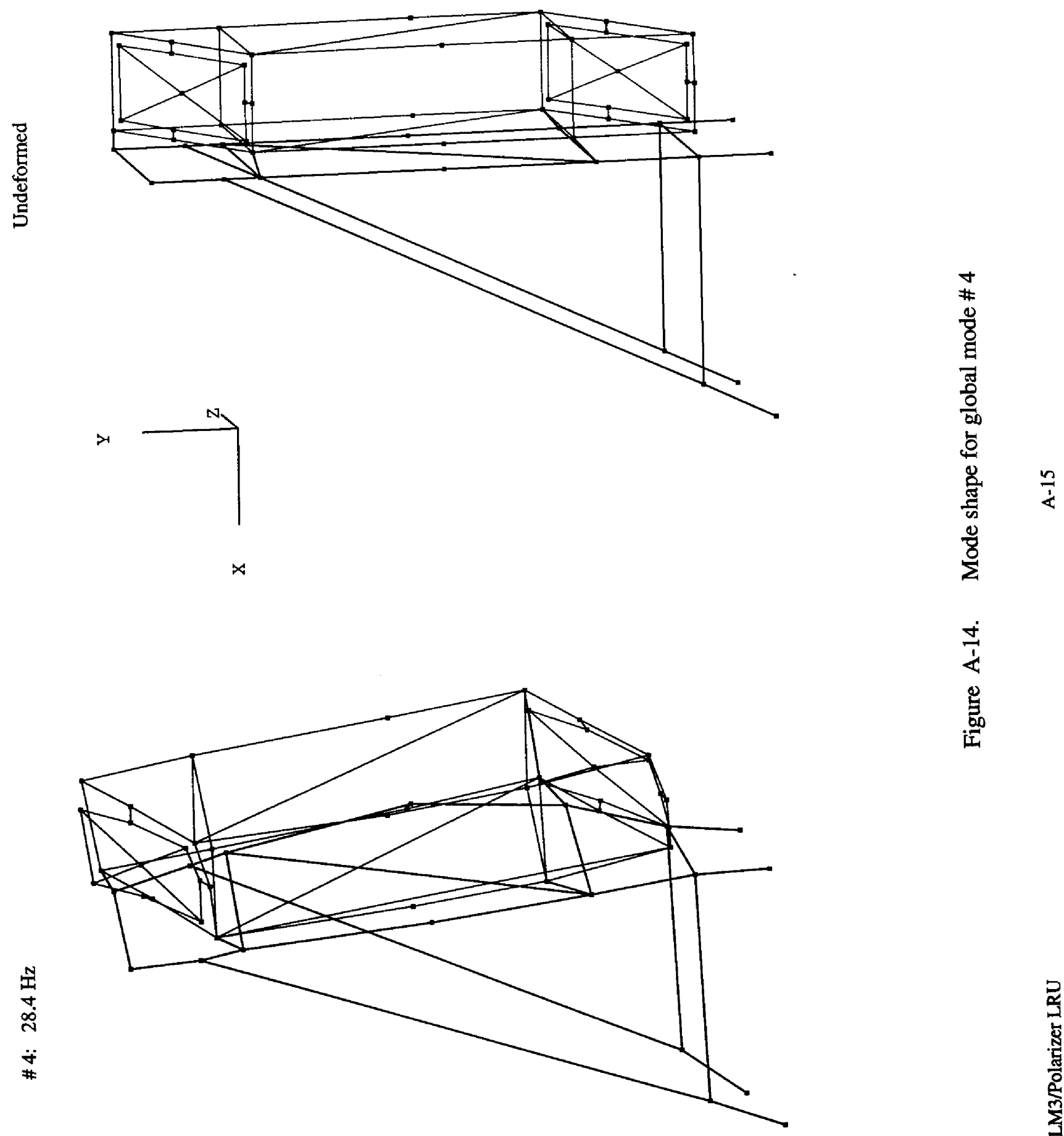

$\frac{8}{4}$

葛 
额
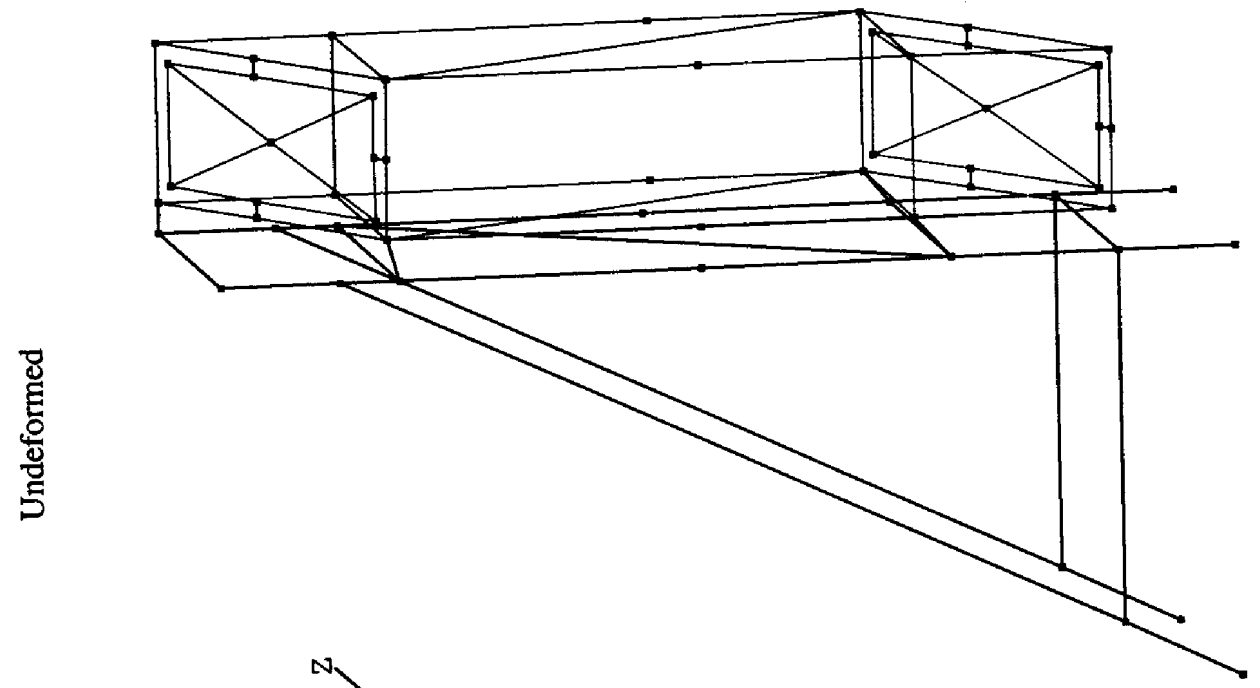

$\frac{1}{4}$
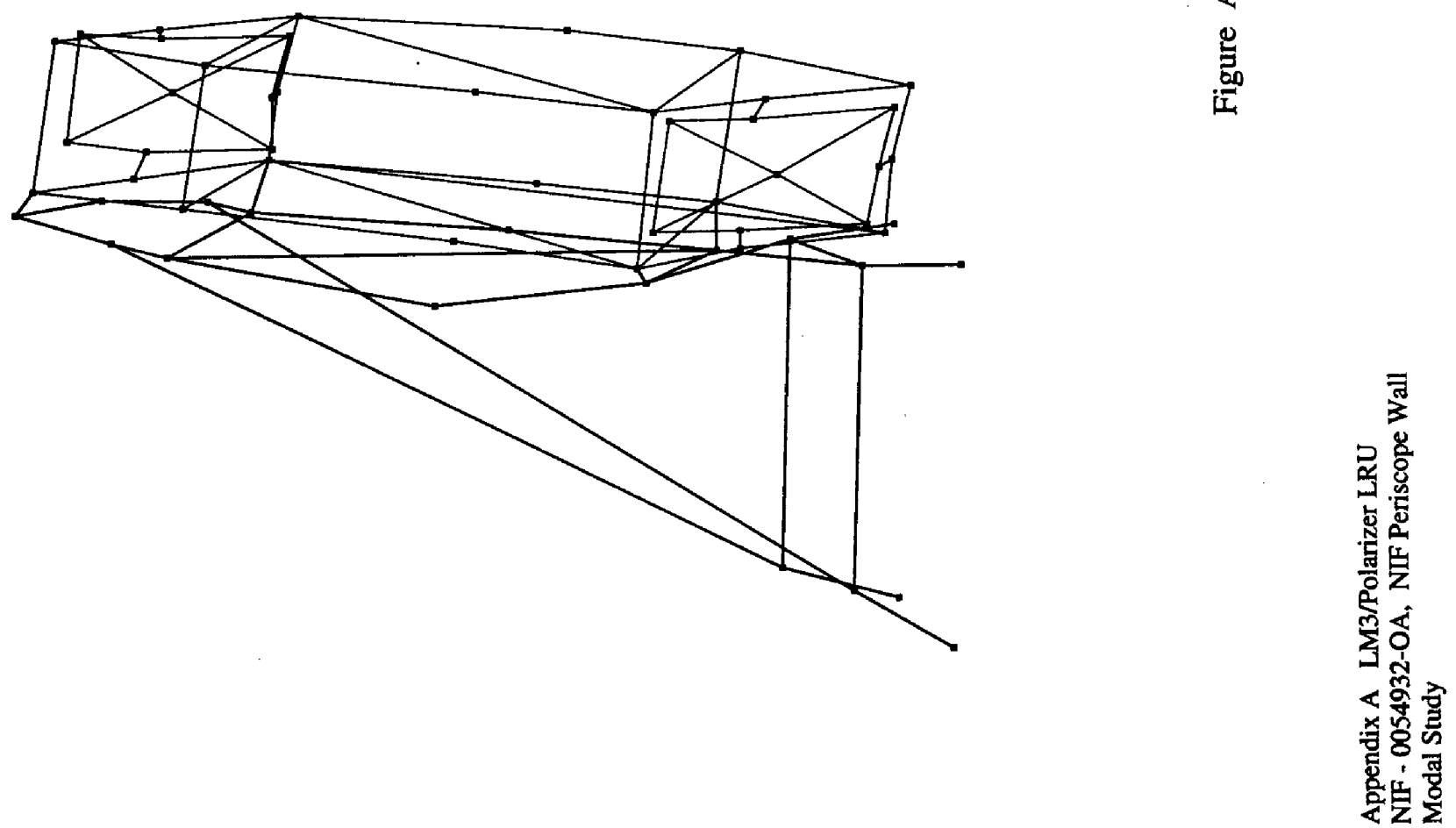


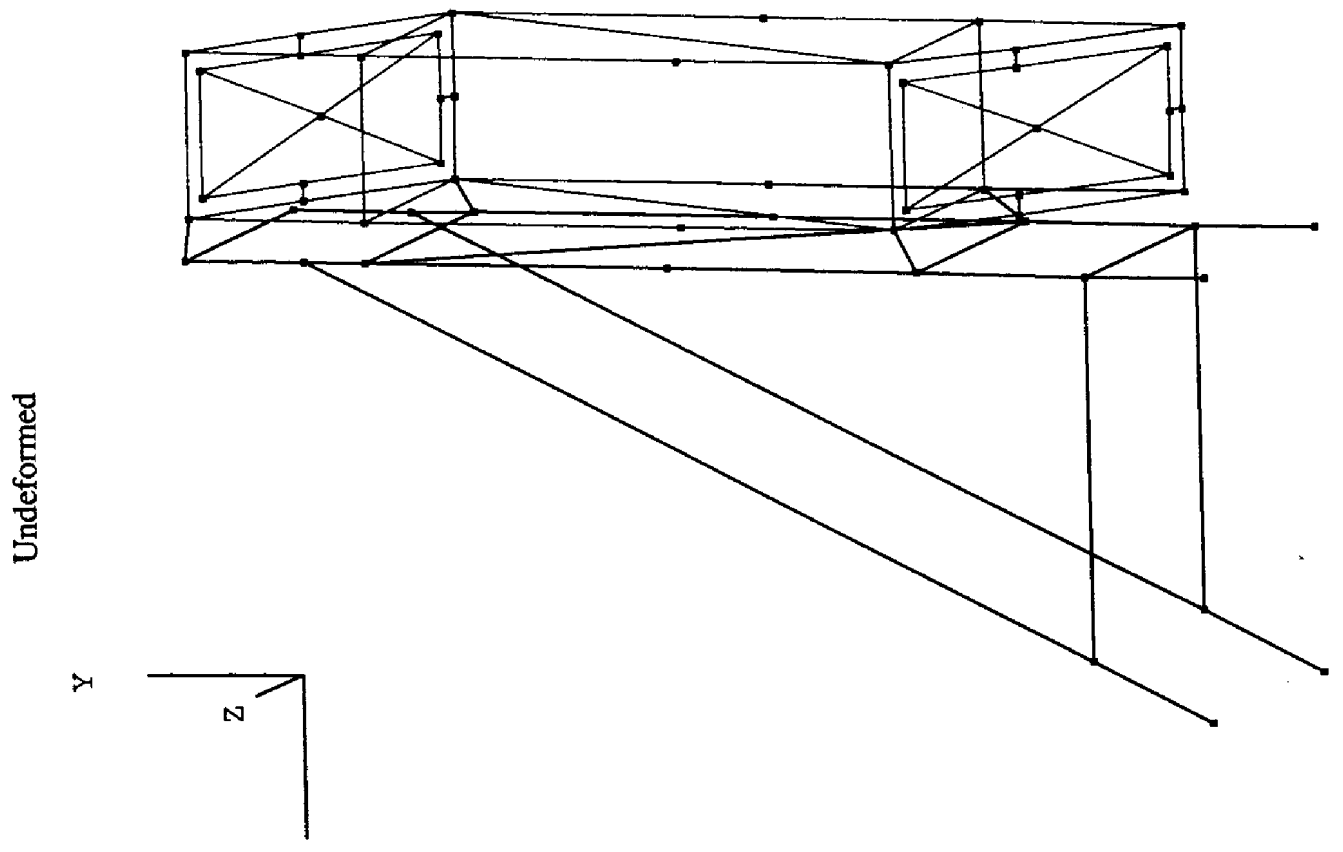

$x$

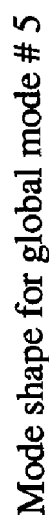

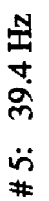

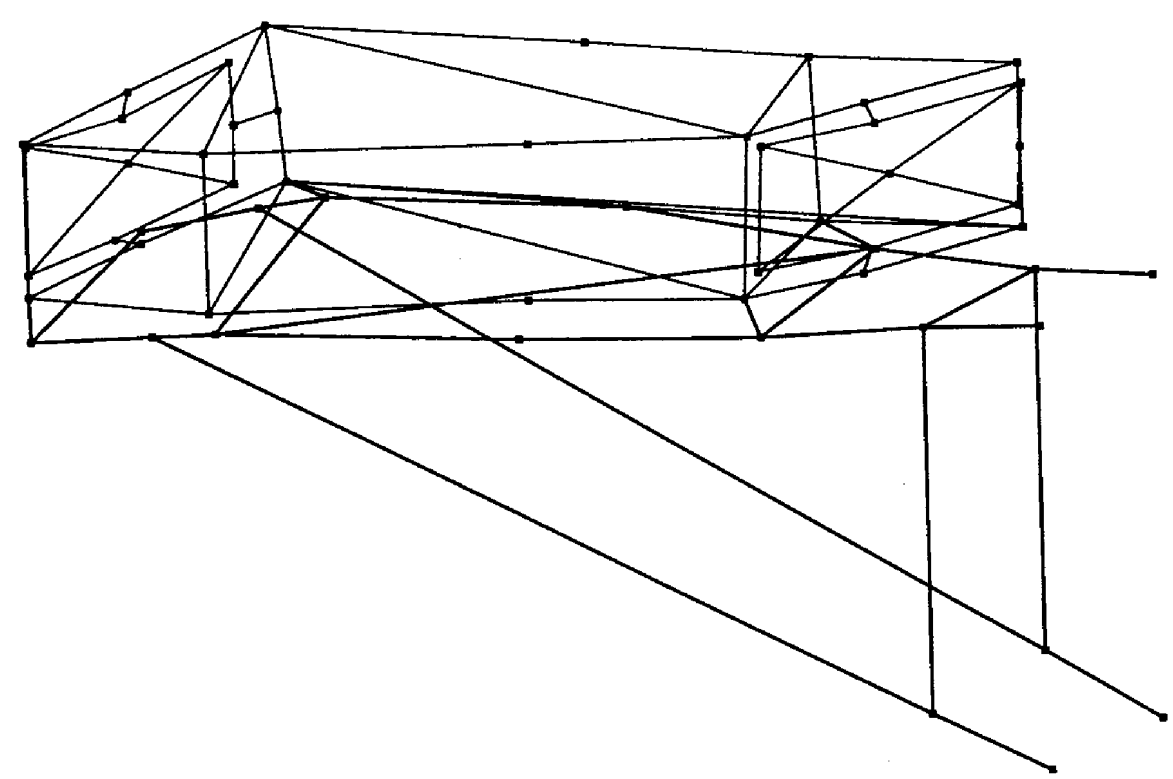

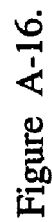



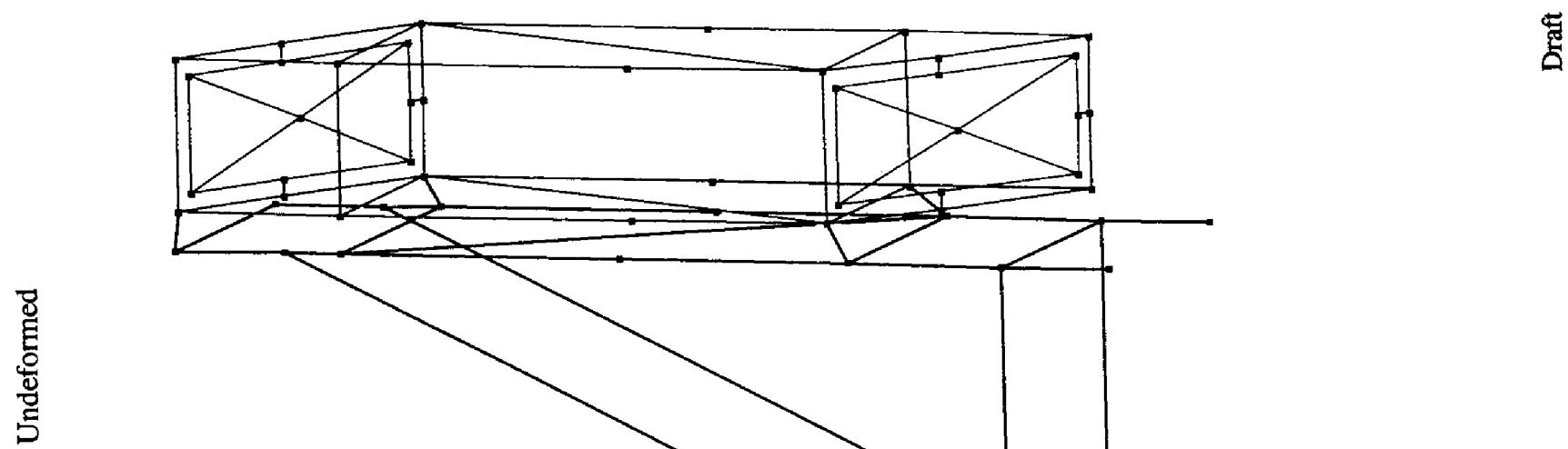

营

马्ठ
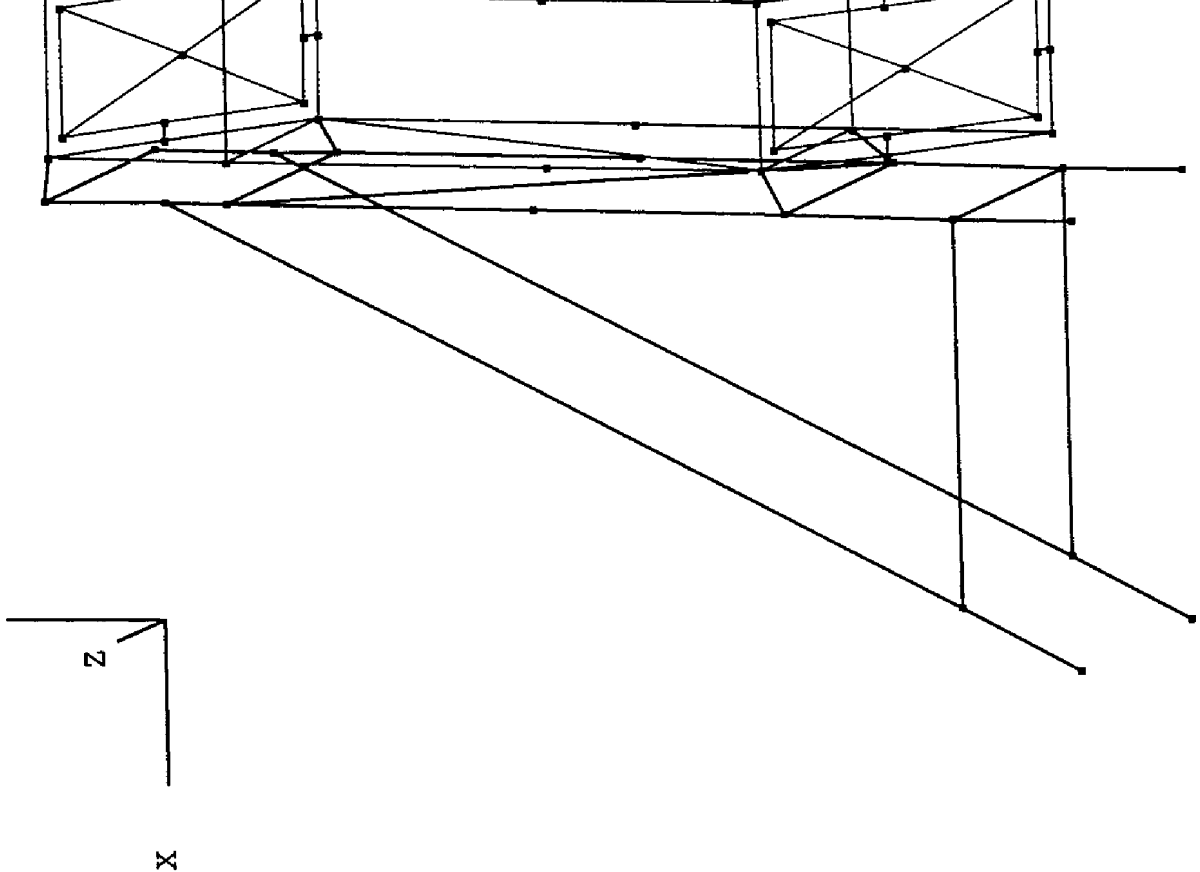

望

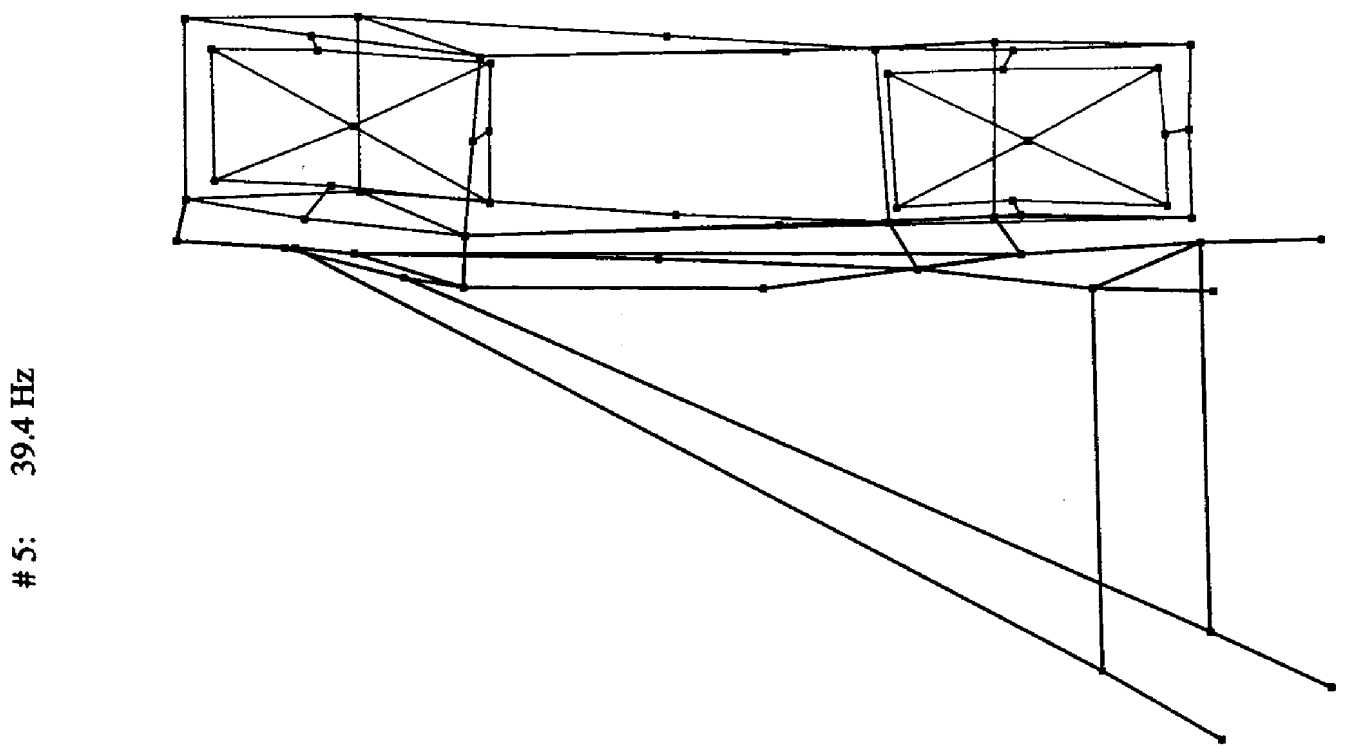

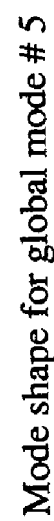

E

岂

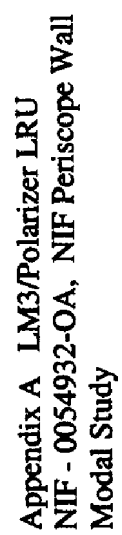



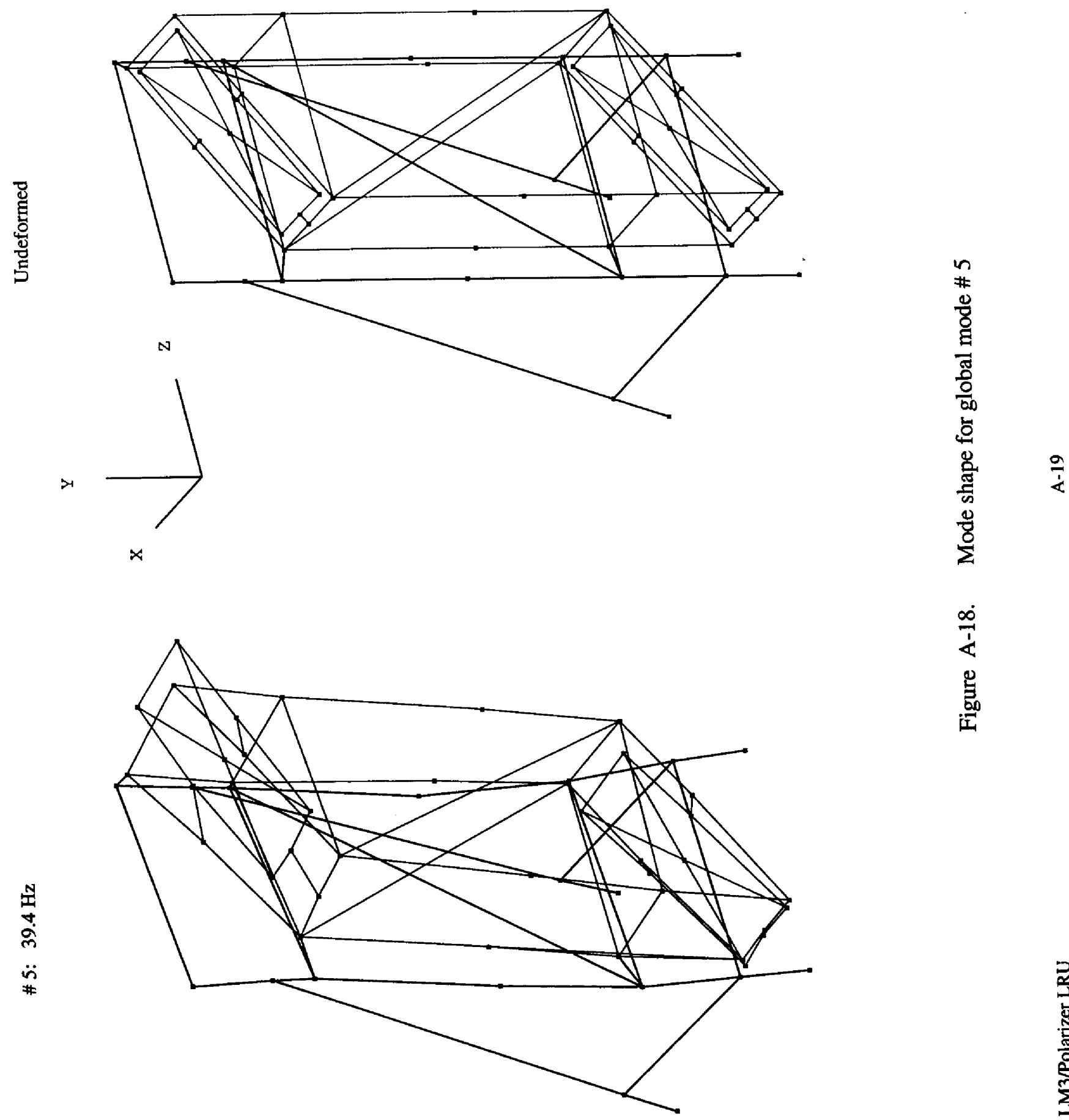

$\frac{\infty}{4}$

常 
\# 5: $39.4 \mathrm{~Hz}$

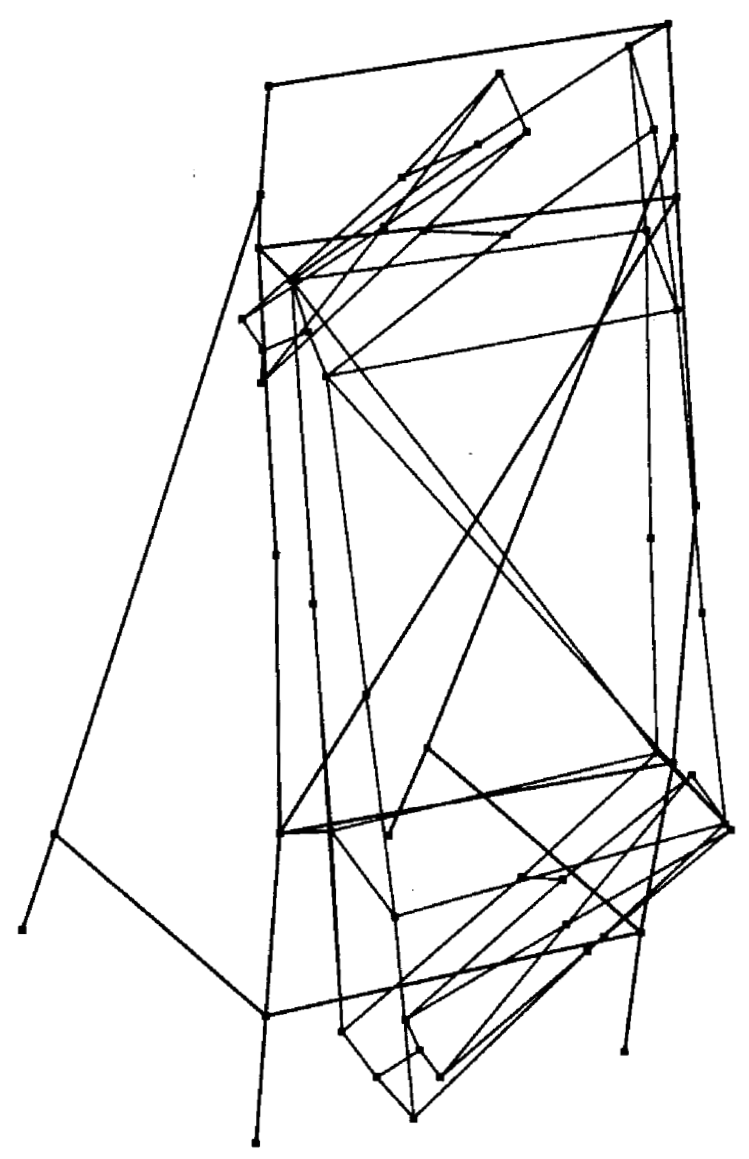

Undeformed

Y

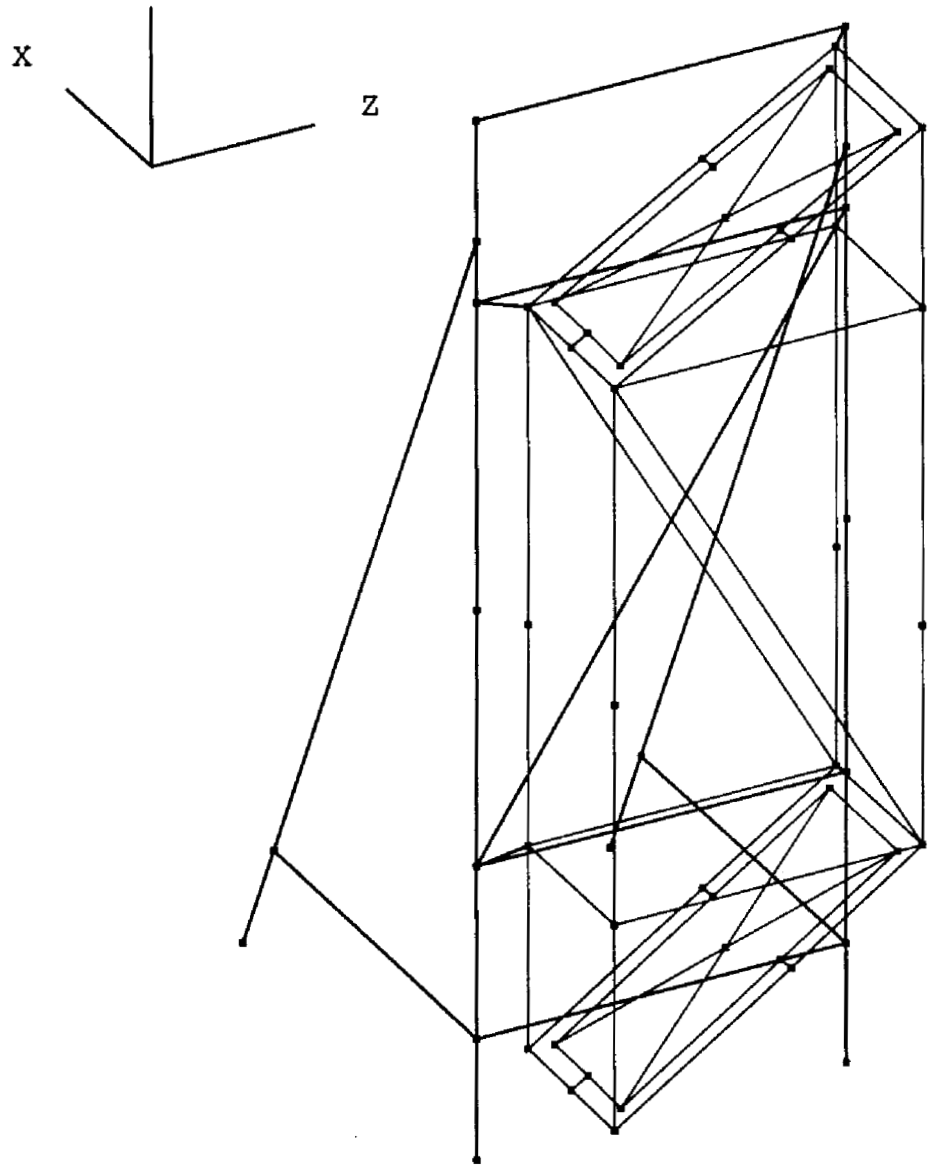

Figure A-19. Mode shape for global mode \# 5 


\section{Appendix B}

Modal Damping Estimates for

Global Modes 1 \& 2

of Instrumented Hammer Impulse 



\section{B.0 Modal Damping Estimates for Global Modes 1 \& 2 of Instrumented Hammer Impulse Tests}

This section covers a summary of the method used to estimate damping for global modes $1 \& 2$ for the modal test using the Instrumented Hammer Impulse technique. The method for estimating the damping is based on the "half-power points" bandwidth [see pp. 45, 46, ref 17].

The first global mode for the Periscope End Wall (using the Instrumented Hammer Impulse technique) is $9.9 \mathrm{~Hz}$ (Figure B-1 and Table 4-1). The dominant motion for the first global mode is cantilever bending (weak direction of wall in X-direction) of the upper portion for the long, tall section of the Periscope End Wall (see Figure 4-1). The first two peaks on the "modal peaks function" in Figure B-1 are essentially the same global mode (i.e., first global mode for the upper portion of that long, tall section of wall). These frequencies are $9.9 \mathrm{~Hz}$ and $11.1 \mathrm{~Hz}$. The only difference between the first two hammer impulse modes is the slight change in mode shape for the lower wing walls, which is relatively insignificant.

In estimating the damping, the "half-power points" bandwidth requires the following:

- Logarithmic scale for amplitude axis

- half-power point amplitudes for $\omega_{1}$ and $\omega_{2}$ are exactly $3 \mathrm{~dB}$ lower than the peak amplitude

The first peak on Figure B-1 has less than a $3 \mathrm{~dB}$ drop in amplitude from the peak at $9.9 \mathrm{~Hz}$ to the next valley (where $\omega_{2}$ would usually be selected). Since the first two modes for the Instrumented Hammer Impulse technique are essentially the same global mode, the second peak at $11.1 \mathrm{~Hz}$ is used for estimating the damping for the first global mode of the Periscope End Wall. The result is about $3.9 \%$ damping for the first global mode.

Referring to the third peak on Figure B-1, the second global mode is $22.4 \mathrm{~Hz}$ from the Instrumented Hammer Impulse modal test. Using the "half-power points" bandwidth, the resulting damping is about $6.0 \%$.

Using the approach shown for the "half-power points" bandwidth, the damping loss factor is defined as

$$
\eta=\text { damping loss factor }=\left(\omega_{2}-\omega_{1}\right) / \omega_{\mathrm{n}}=2 \xi \quad \text { for low damping [ref 17]. }
$$

Referring to Figure B-5 through B-7, the frequency response function (FRF) is used for determining the damping loss factor for the $x$-direction of the upper right corner (location 23 in modal test) of the end wall. For the first global mode of the end wall:

$$
\begin{aligned}
& \omega_{\mathrm{n}}=11.06 \mathrm{~Hz}, \omega_{2}=11.56 \mathrm{~Hz}, \text { and } \omega_{1}=10.7 \mathrm{~Hz} . \\
& \eta=(11.56 \mathrm{~Hz}-10.7 \mathrm{~Hz}) /(11.06 \mathrm{~Hz})=.0778=\text { damping loss factor } \\
& \xi=\eta / 2=.0778 / 2=.0389 \rightarrow \xi=3.89 \% \text { damping for the first global mode. }
\end{aligned}
$$

Using a similar approach for the second global mode, Figures B-8 through B-10 show:

$$
\begin{aligned}
& \omega_{\mathrm{n}}=22.75 \mathrm{~Hz}, \omega_{2}=23.81 \mathrm{~Hz}, \text { and } \omega_{1}=21.06 \mathrm{~Hz} . \\
& \eta=(23.81 \mathrm{~Hz}-21.06 \mathrm{~Hz}) /(22.75 \mathrm{~Hz})=.1209 \\
& \xi=\eta / 2=.1209 / 2=.0604 \rightarrow \xi=6.04 \% \text { damping for the second global mode. }
\end{aligned}
$$




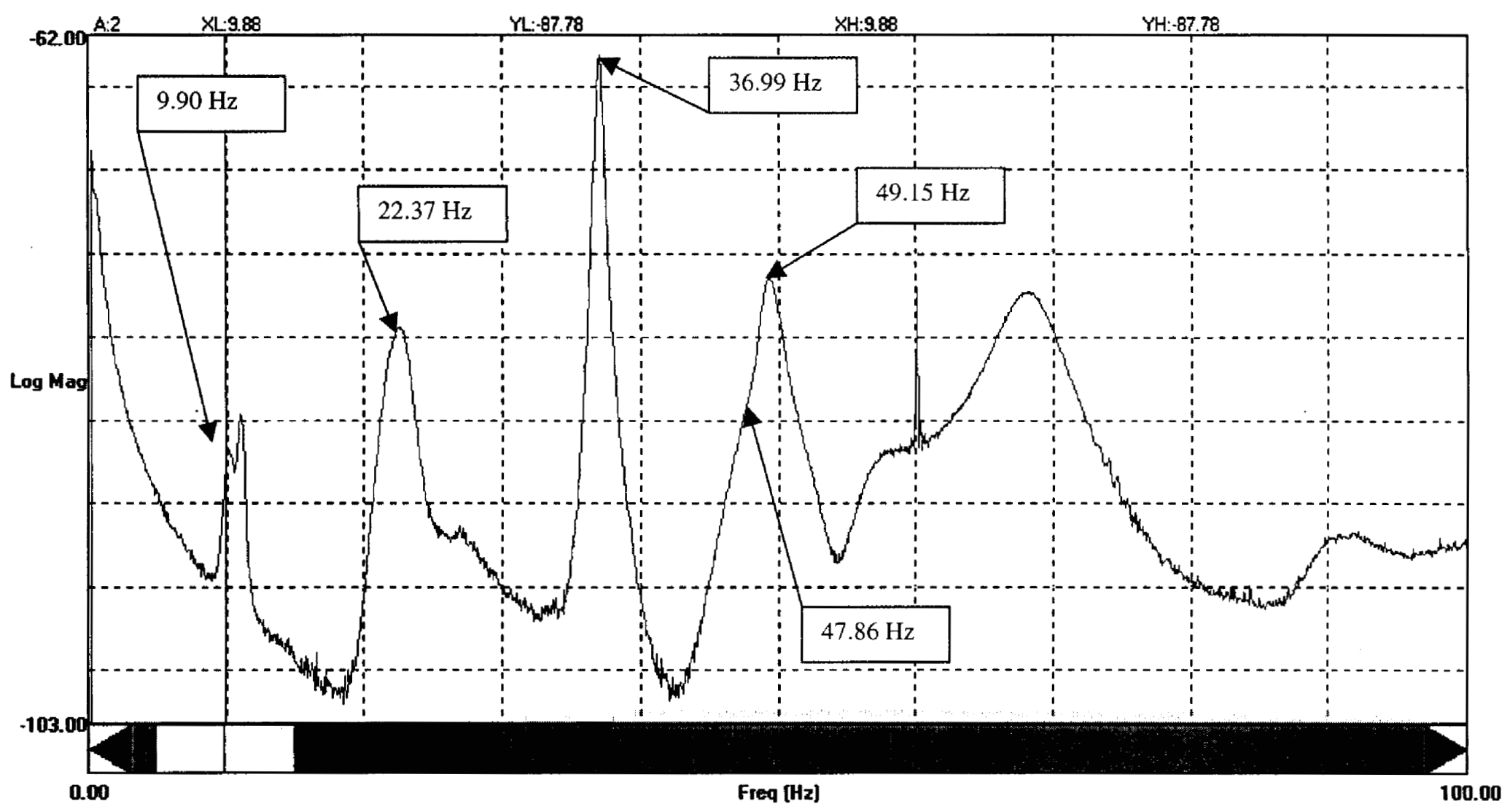

Figure B-1. Modal Peaks Function for Instrumented Impulse Hammer on Periscope End Wall 


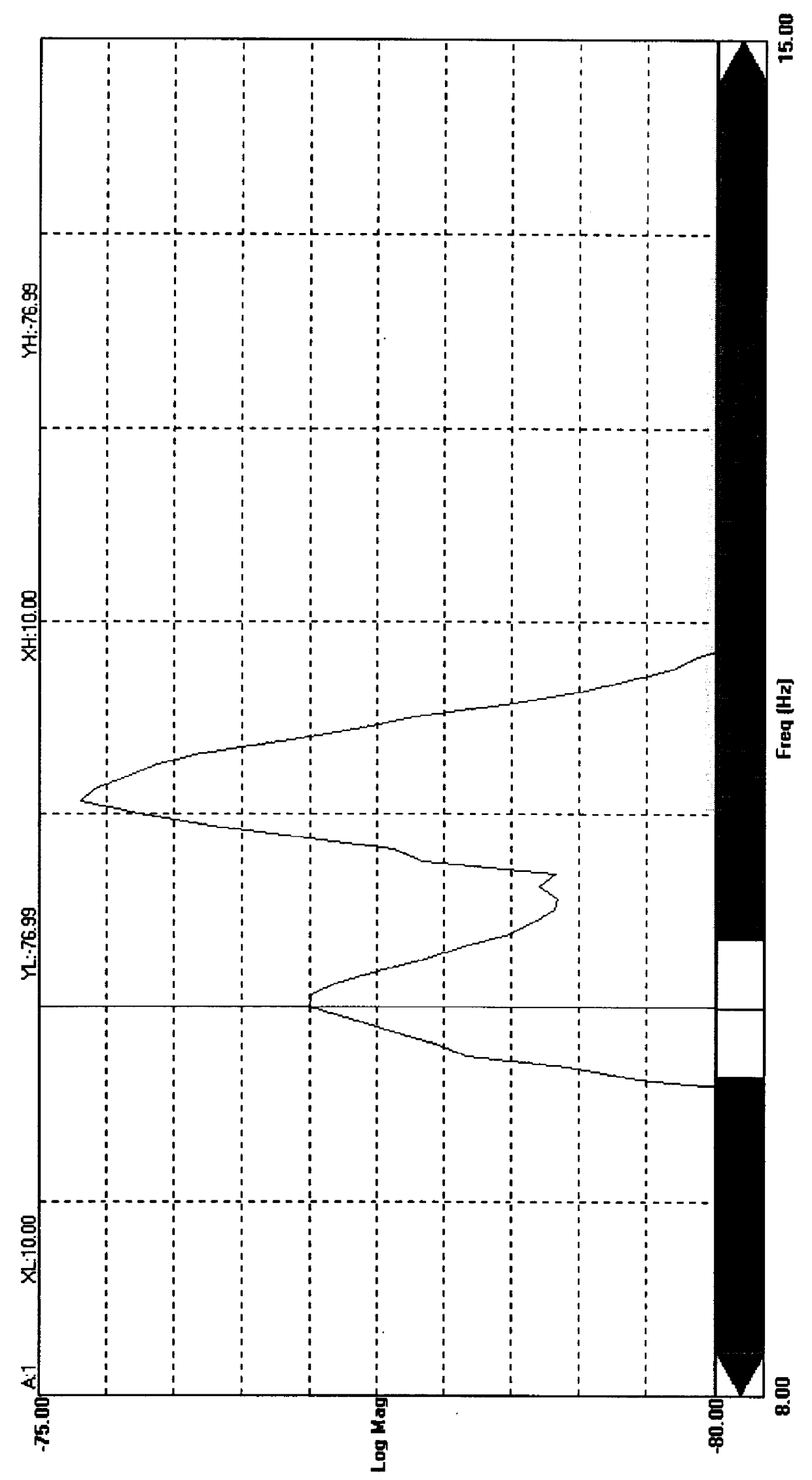

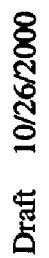

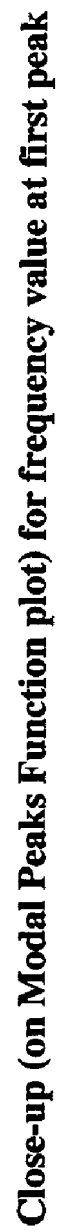

串

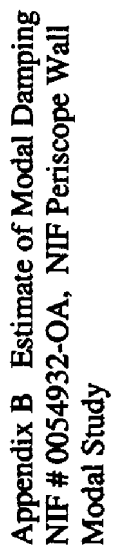




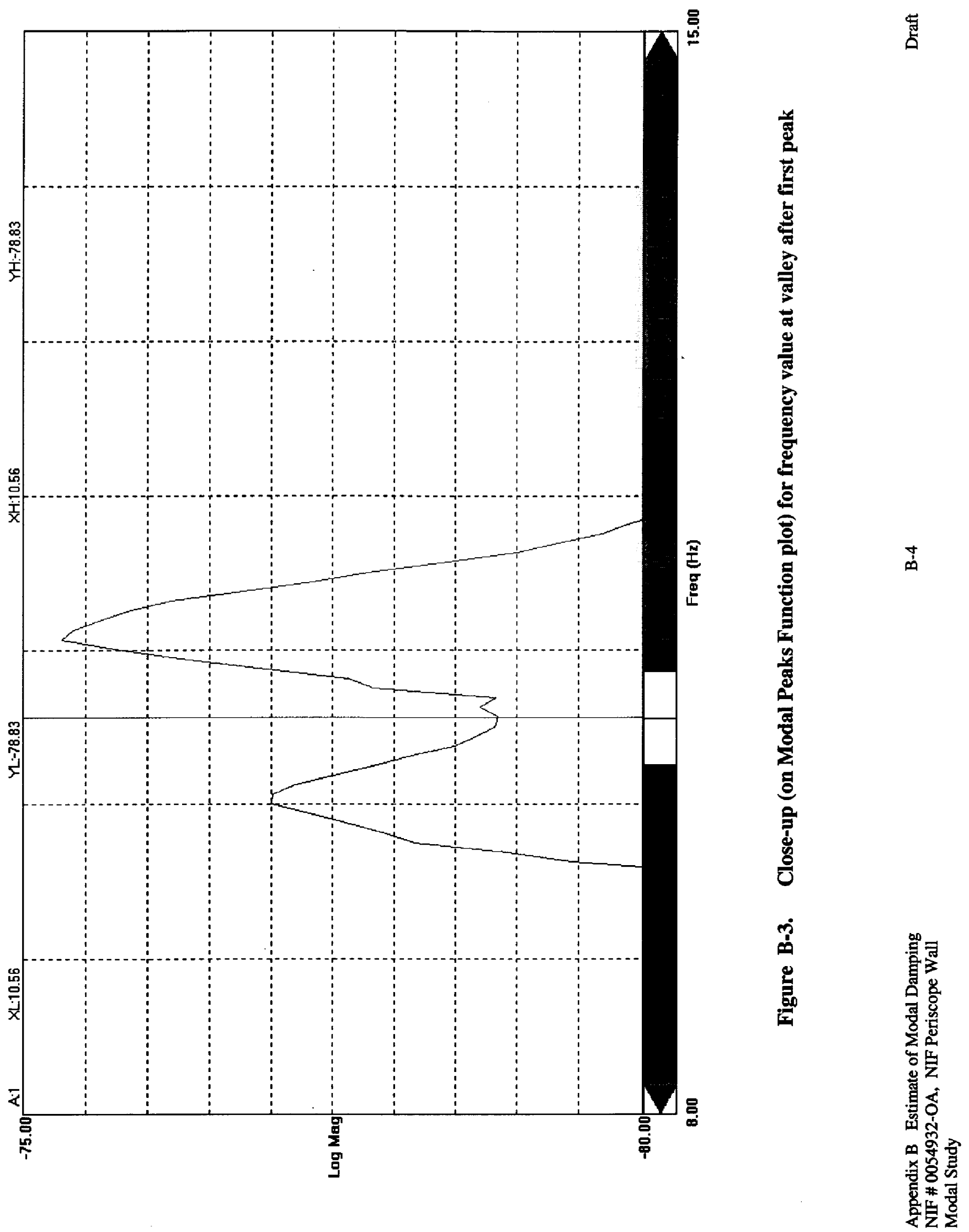



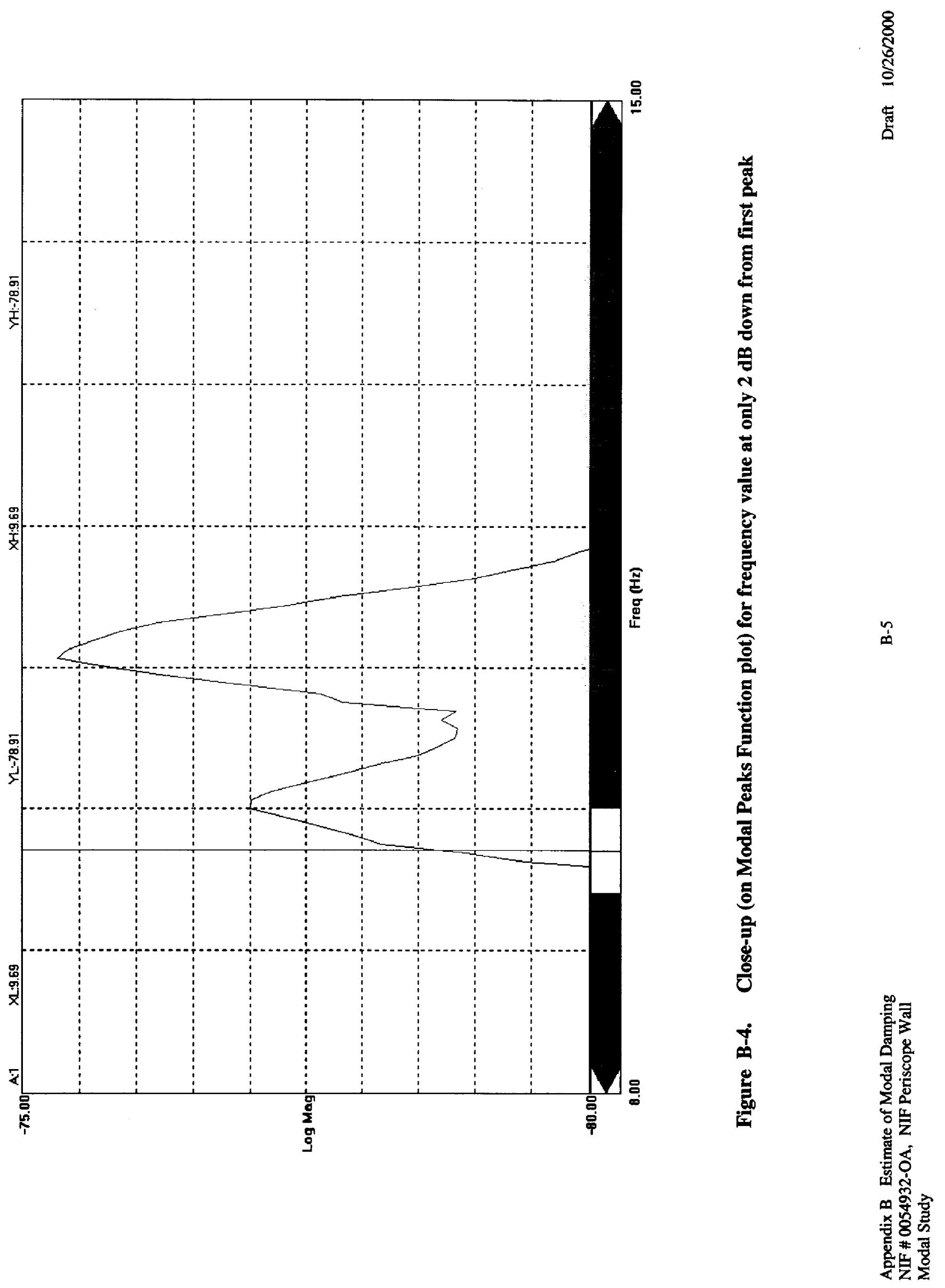


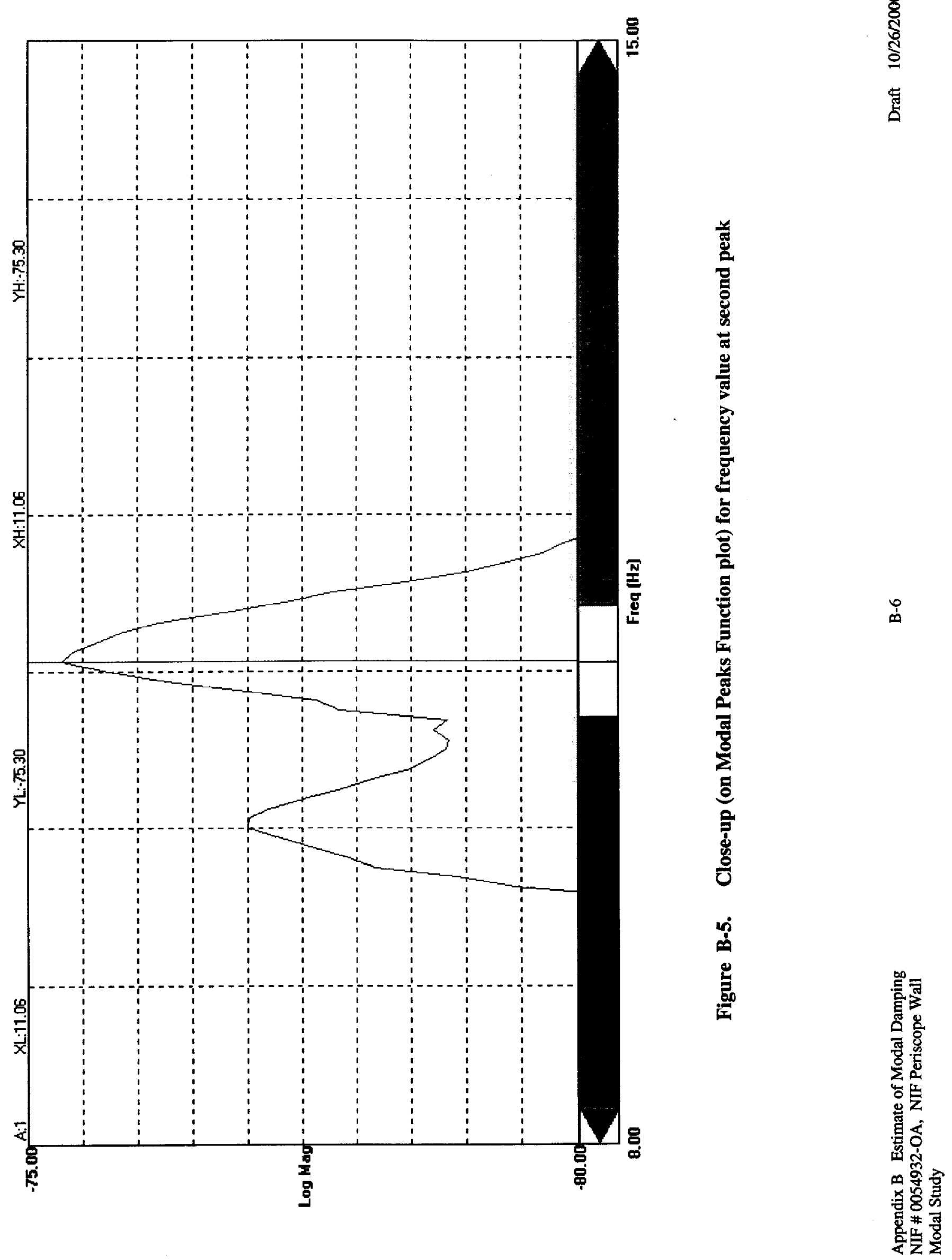



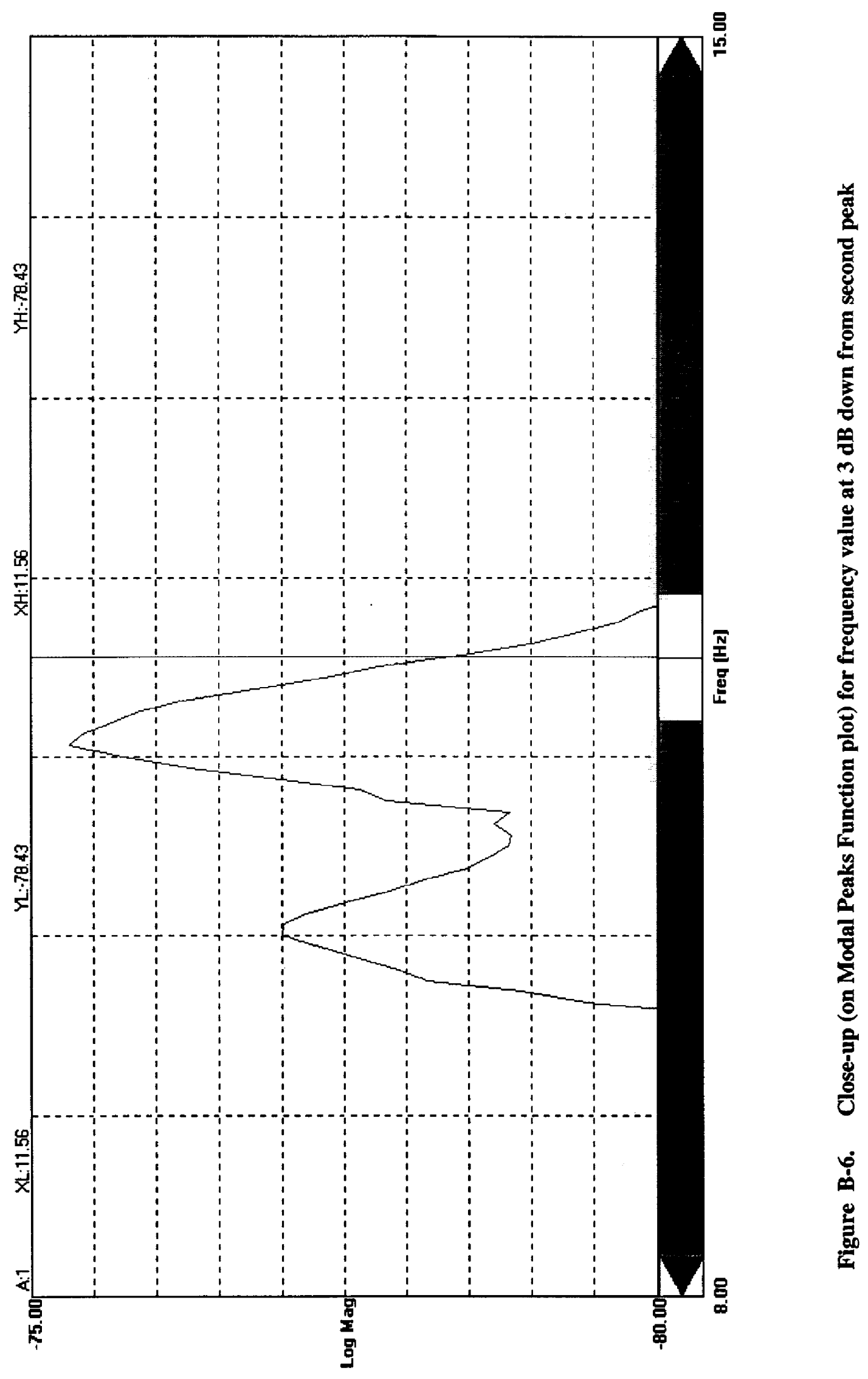

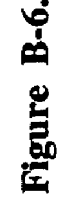

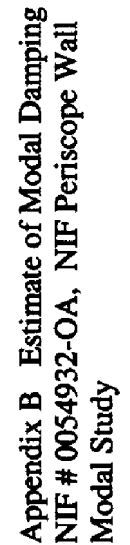




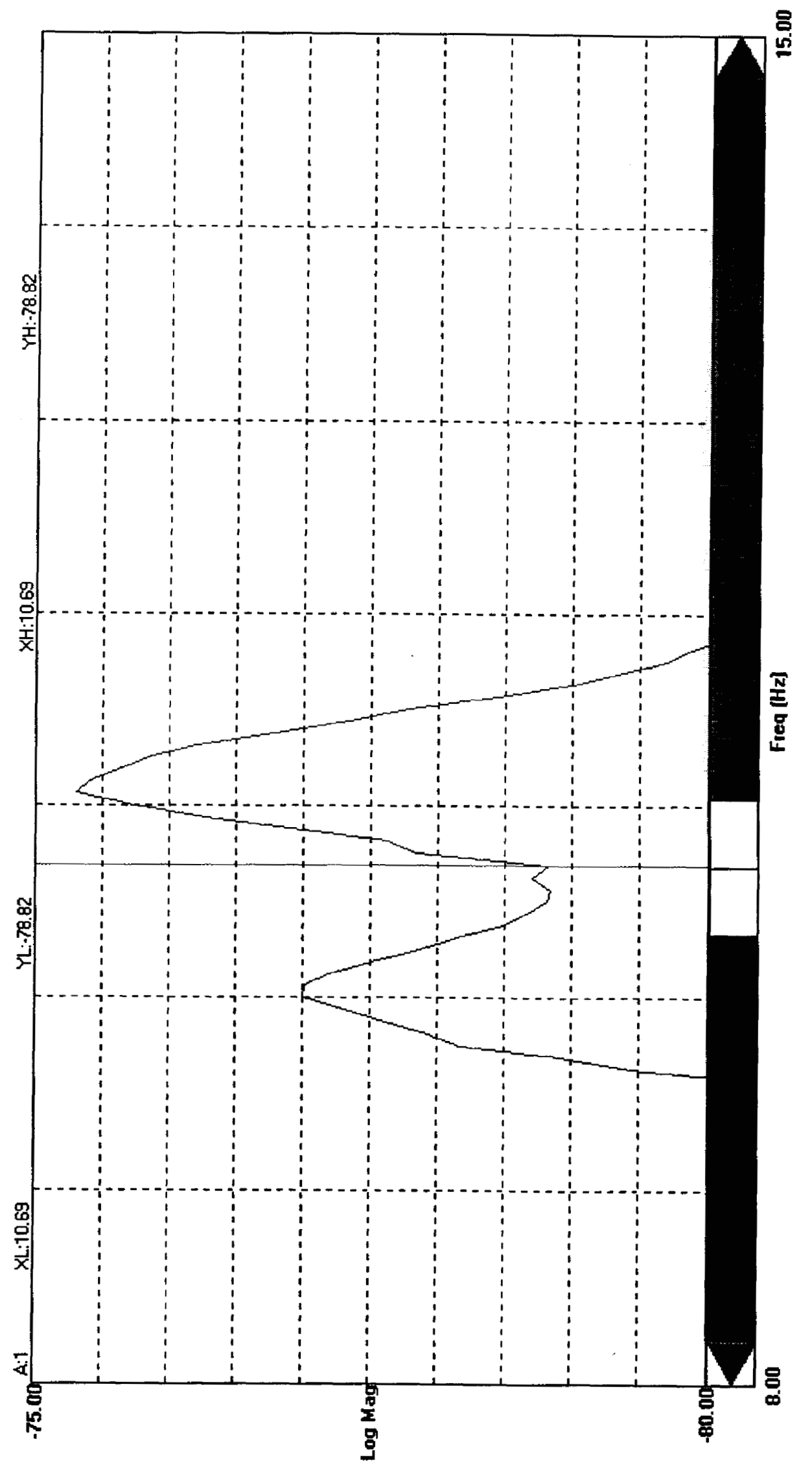

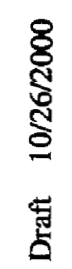

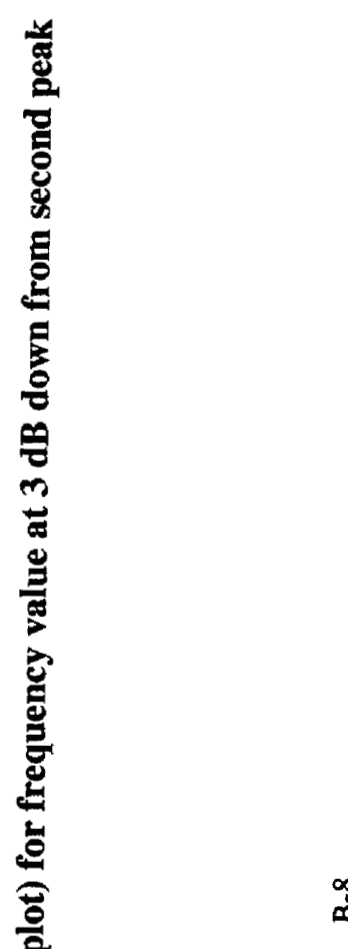

$\stackrel{\infty}{\infty}$

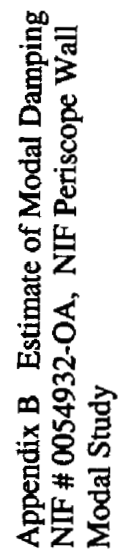




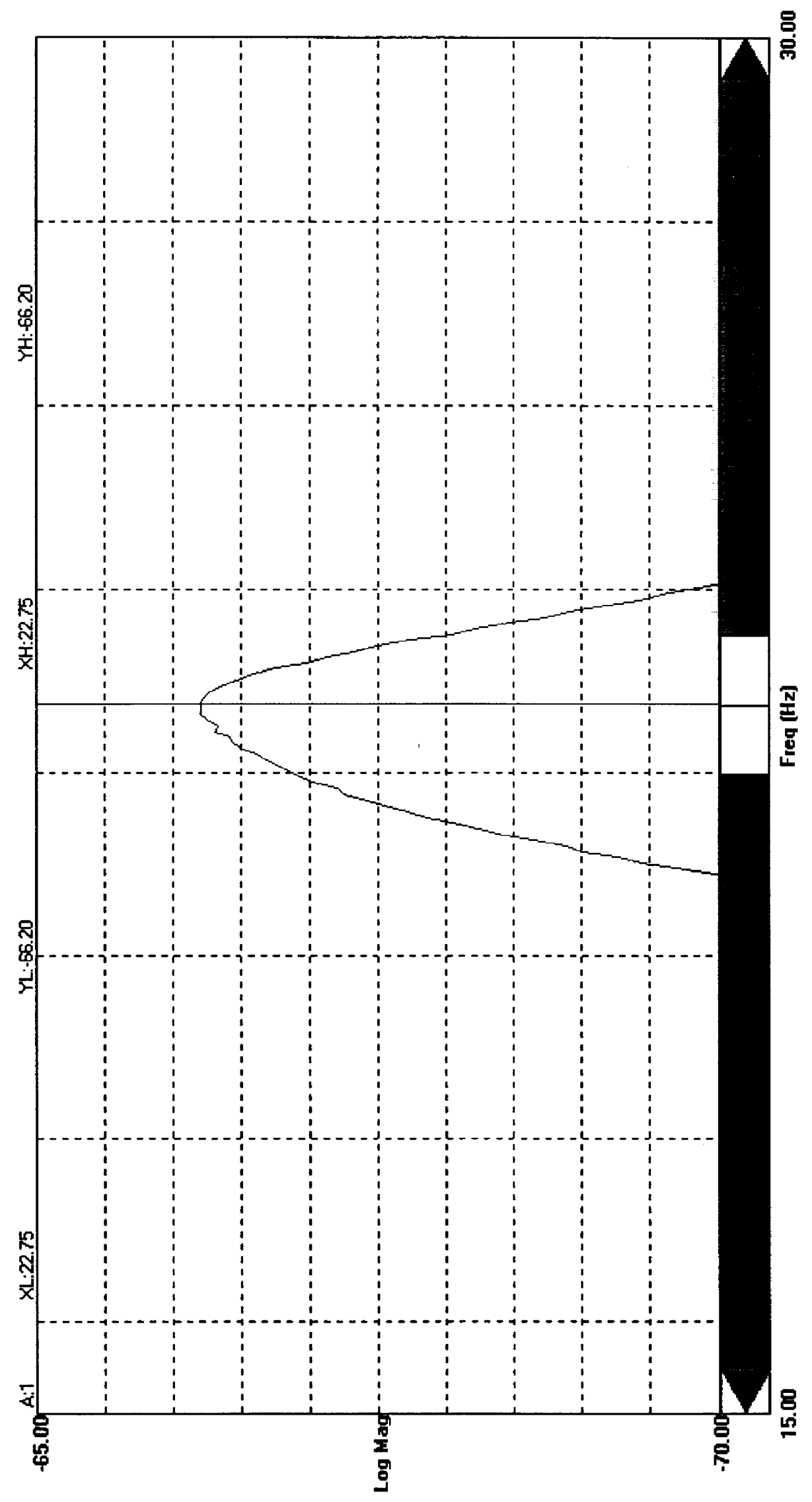

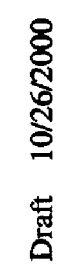

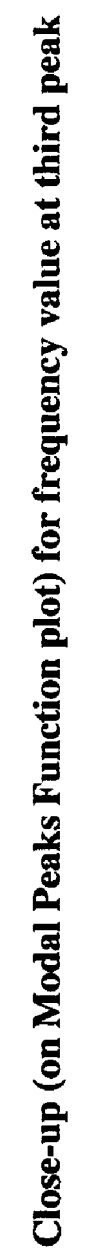

ì

营

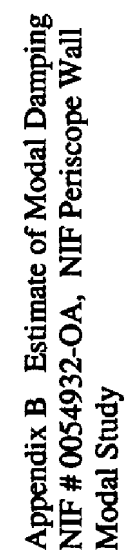




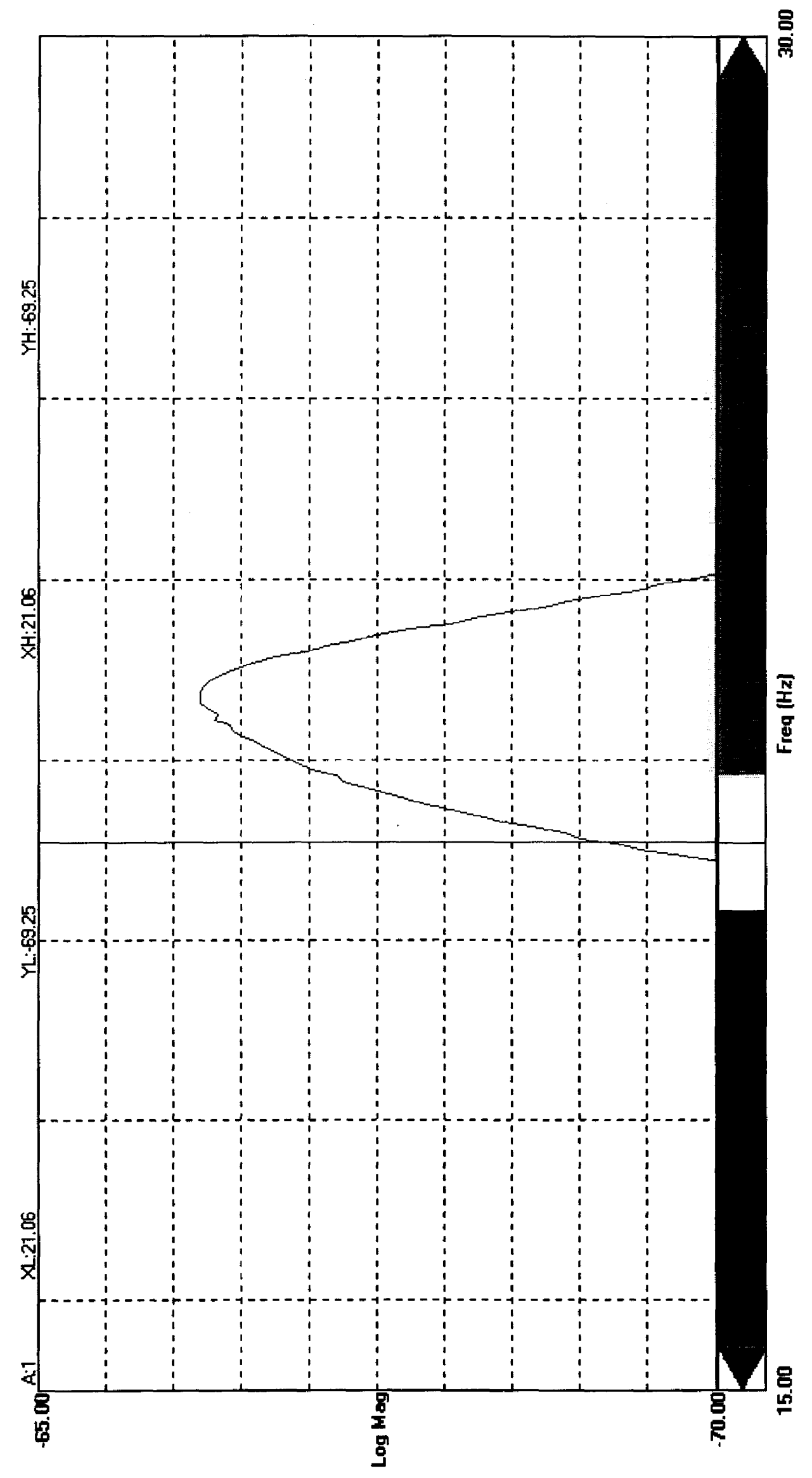

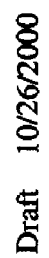

है

官

$\frac{}{\dot{1}}$

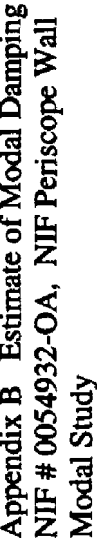




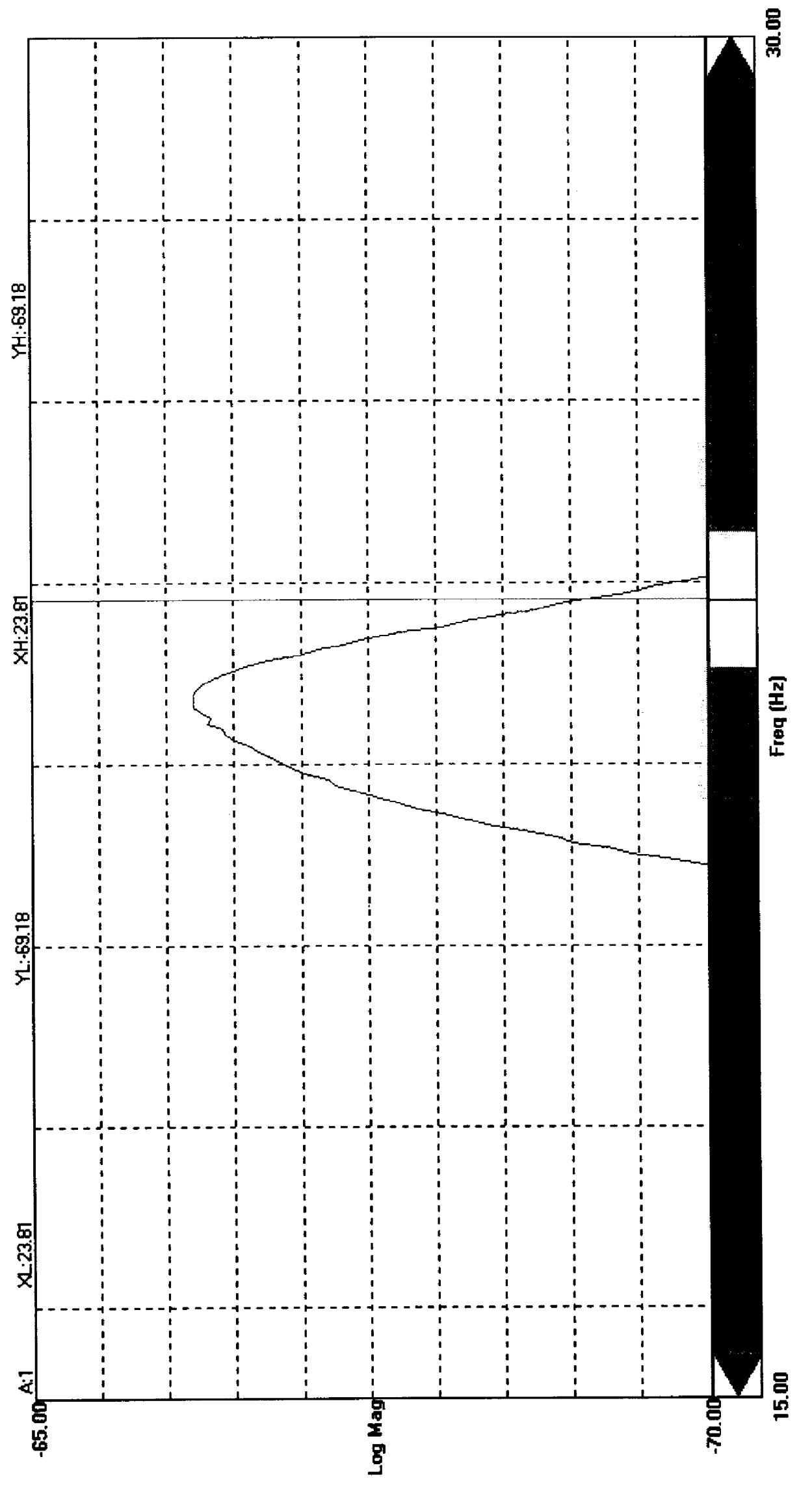

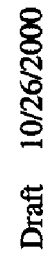

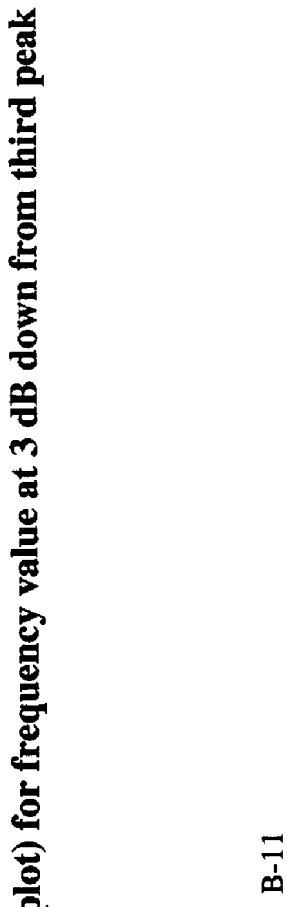

$\bar{m}$

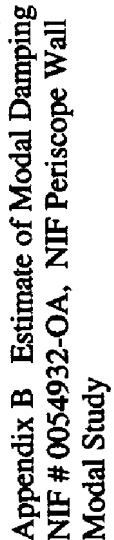




\section{Appendix C}

\section{Modal Assurance Criteria (MAC)}

A method for quantitative comparison between numerical and test results 

. 


\section{C.0 Modal Assurance Criteria (MAC) - A method for quantitative comparison between numerical and test results}

A quantitative comparison can be made between the numerical and test results using the modal assurance criteria (MAC) which estimates the degree of correlation between mode shape vectors calculated from the numerical finite element model and from the experimental modal analysis. The MAC between the $\mathrm{i}^{\text {th }}$ measured mode, $\phi_{\mathrm{m}}{ }_{\mathrm{m}}^{\mathrm{i}}$, and the $\mathrm{j}^{\text {th }}$ numerical mode, $\phi_{\mathrm{n}}^{\mathrm{j}}$, is defined as

$\operatorname{MAC}_{\mathrm{ij}}=\left(\phi_{\mathrm{m}}{ }^{\mathrm{iT}} \phi_{\mathrm{n}}{ }^{\mathrm{j}}\right)^{2} /\left[\left(\phi_{\mathrm{m}}{ }^{\mathrm{iT}} \phi_{\mathrm{m}}{ }^{\mathrm{i}}\right)\left(\phi_{\mathrm{n}}{ }^{\mathrm{jT}} \phi_{\mathrm{n}}{ }^{\mathrm{j}}\right)\right]$.

The MAC has a value between 0 and 1 . A value of 1 means that one mode is a multiple of the other. An analyst's judgement determines when two modes have 'good' correlation. This generally occurs for values greater than 0.7 .

Because the mesh density and node location of the FE model and the test model (measurement location points) are almost always different, care must be taken in selecting the element of $\phi_{\mathrm{n}}^{\mathrm{j}}$ and $\phi_{\mathrm{m}}{ }^{\mathrm{i}}$.

For the results presented in this report, the MAC between the FE solid model and the test model for the first mode is 0.9857 . In comparison, the MAC between the FE solid model and the FE shell model is 0.9983 . Similar calculations can be done for the other modes. In this case, the FE model nodes closest to the measurement points were chosen as the elements of the modal vectors. 



\section{Appendix D}

\section{Modal Test of PEPC LRU}

(conducted 6-98 in Test Stand at B-432) 



\section{D.0 Modal Test of Prototype PEPC LRU}

In June 1998, a modal test of a prototype for the NIF PEPC LRU was conducted. The modal test and analysis were requested in preparation for a Title II Design Review for the NIF PEPC LRU and associated systems.

In that prototype, there were new kinematic mounts and mock mirrors. The PEPC LRU was mounted on a test frame in B-432 High-Bay (Figure D-1). At that time, the modal test was requested in order to provide a comparison with the assumed modal properties for the kinematic mounts. Table D-1 shows the frequencies and damping for each global mode along with a brief description of the corresponding mode shapes. Figure D-2 shows the relative location of PEPC LRU's in the full Periscope Assembly in Laser Bays 1 \& 2. Figure D-3 shows the locations of the accelerometers used during the modal test. Figures D-4 through D-22 show selected views of the mode shapes for the first nine global modes.
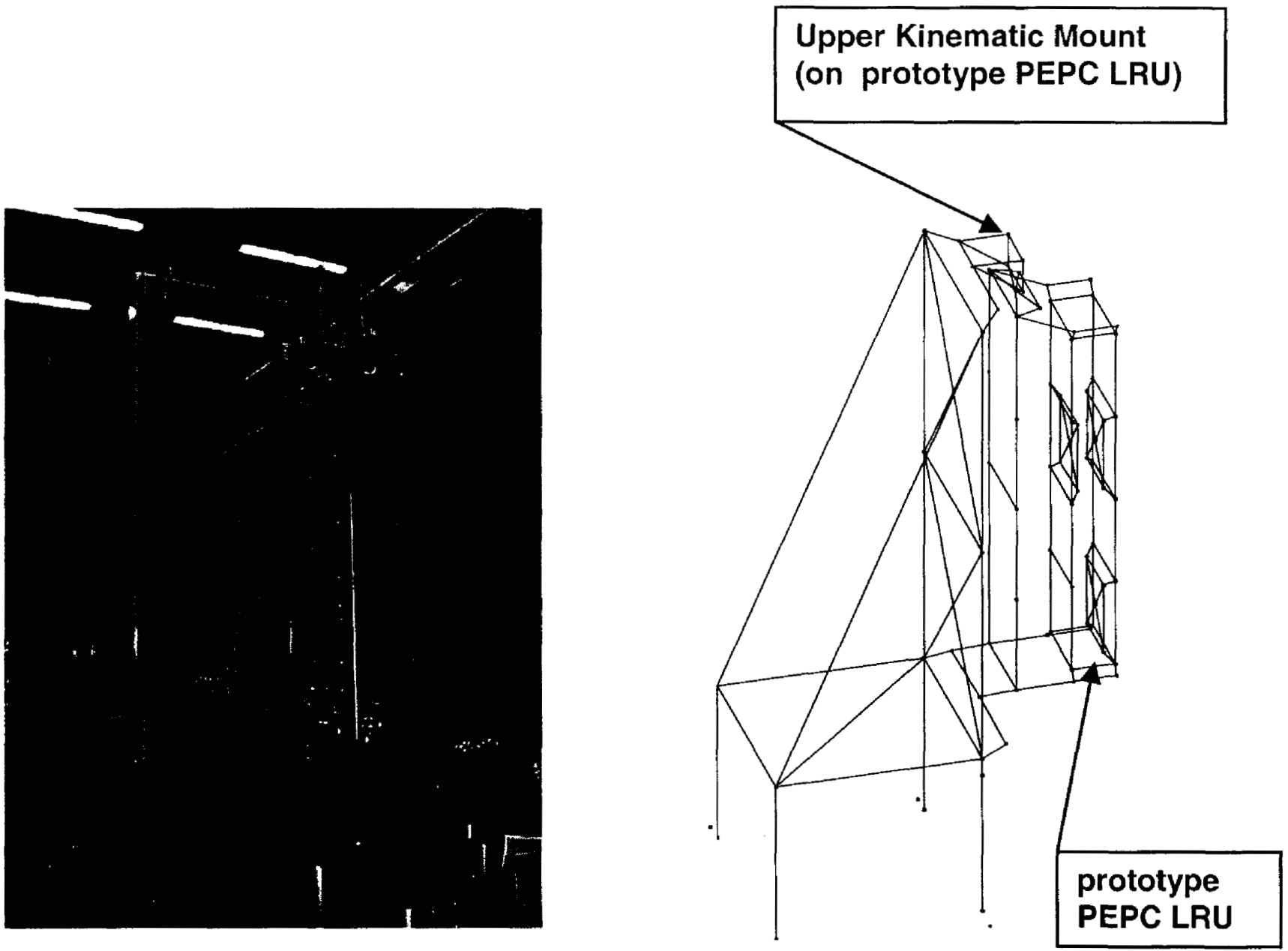

Figure D-1. A series of experimental modal tests was conducted (in June 1998) on a prototype for the NIF PEPC LRU (with its kinematic mounts and mock mirrors), on a test stand in B-432 (photo at left). 


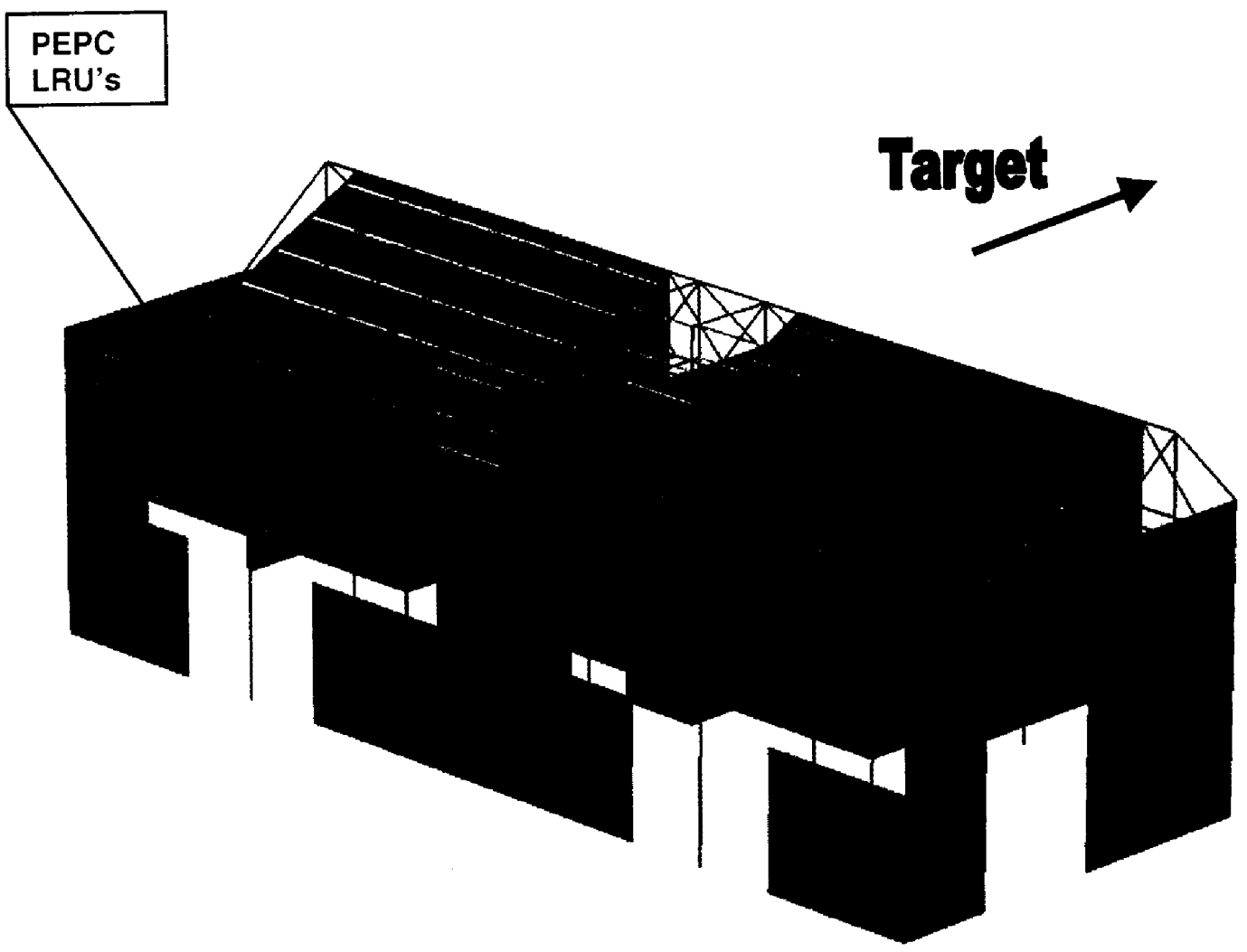

Figure D-2. View of the FEA model for the entire NIF Periscope Assembly (including PEPC LRU's and support structure)

in NIF Laser Bay 1. 
Table D-1. Summary of Frequencies \& Mode Shapes for Prototype of PEPC LRU in Test Stand

\begin{tabular}{|c|c|c|c|}
\hline $\begin{array}{l}\text { Global } \\
\text { Mode } \\
\text { No. }\end{array}$ & $\begin{array}{c}\text { Frequency } \\
(\mathrm{Hz})\end{array}$ & $\begin{array}{c}\text { Modal } \\
\text { Damping (\%) }\end{array}$ & Mode shape \\
\hline 1 & 22.6 & 0.8 & $\begin{array}{l}\text { Vertical motion (Y-dir) of PEPC LRU; with slight rigid-body } \\
\text { rotation of LRU about horiz Z-axis and about vert Y-axis; } \\
\text { Upper mock mirror (lens blank) on +z side of LRU has out-of- } \\
\text { plane rotation about horiz } x \text {-axis; }\end{array}$ \\
\hline 2 & 25.5 & 2.0 & Dominant rigid-body rotation of PEPC LRU about vert Y-axis; \\
\hline 3 & 27.8 & 1.6 & $\begin{array}{l}\text { Dominant rigid-body rotation of PEPC LRU about horiz Z-axis } \\
\text { (pivot at about the center height of LRU); }\end{array}$ \\
\hline 4 & 28.8 & 1.4 & $\begin{array}{l}\text { Dominant rigid-body rotation of PEPC LRU about horiz X-axis } \\
\text { (pivot at the lower mounts for LRU); top of LRU moves out of } \\
\text { phase with the top of test stand (in Z-dir motion); }\end{array}$ \\
\hline 5 & 36.3 & 1.8 & Dominant torsion of PEPC LRU about vertical Y-axis; \\
\hline 6 & 46.7 & 1.2 & $\begin{array}{l}\text { First Bending mode of PEPC LRU about horiz X-axis; also, } \\
\text { upper mock mirror (lens blank) on }+\mathrm{z} \text { side of LRU has out-of- } \\
\text { plane rotation about horiz x-axis (pivot about upper edge of } \\
\text { upper mock mirror; }\end{array}$ \\
\hline 7 & 50.5 & 0.9 & Moderate torsion of PEPC LRU about vertical Y-axis; \\
\hline 8 & 62.6 & 1.5 & $\begin{array}{l}\text { Bending mode of test stand about horiz X-axis near top of test } \\
\text { stand influences bending mode of PEPC LRU about horiz X- } \\
\text { axis; main portion of LRU bends out-of-phase with rest of LRU } \\
\text { frame located closer to test stand; }\end{array}$ \\
\hline 9 & 67.0 & 1.0 & $\begin{array}{l}\text { Moderate torsion of PEPC LRU about vertical Y-axis; rear part } \\
\text { of LRU frame located closer to test stand has dominant torsion } \\
\text { about vertical Y-axis; }\end{array}$ \\
\hline
\end{tabular}



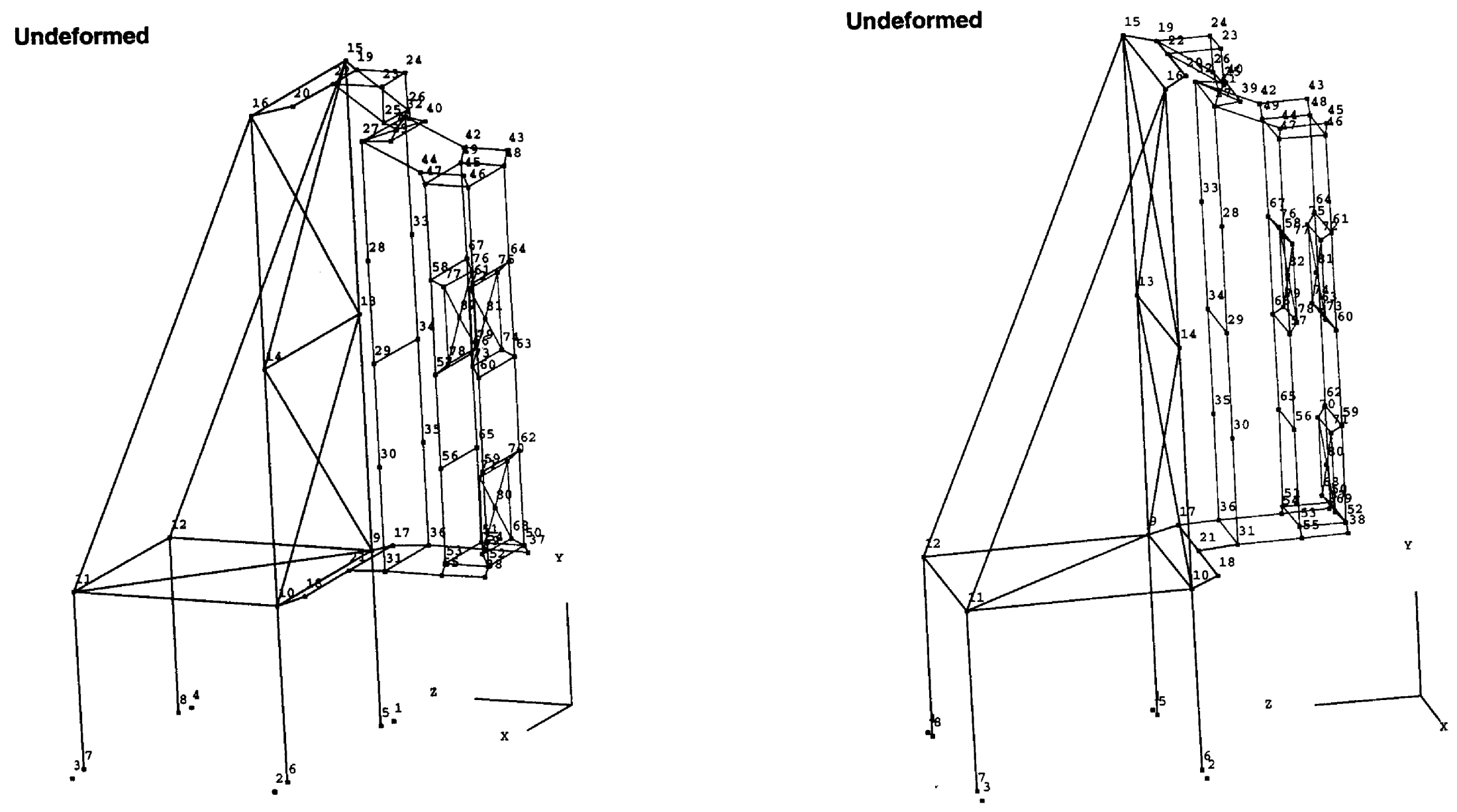

Figure D-3. Modal Test setup of of a prototype for the NIF PEPC LRU and its kinematic mounts, showing locations of sensors used during modal test. This modal test used a test stand in B-432. 


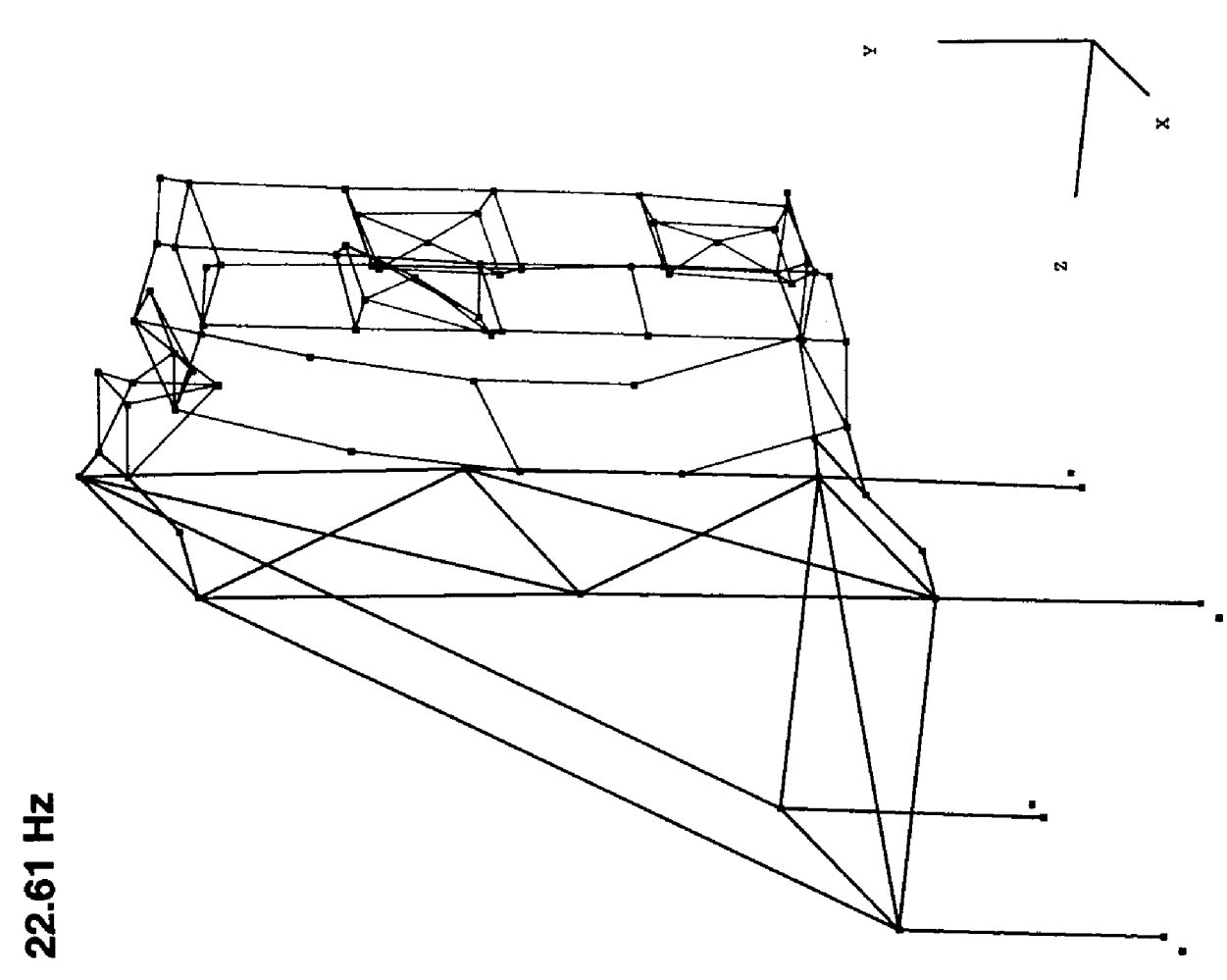

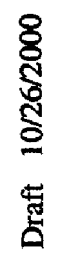

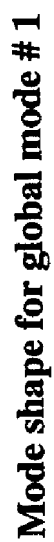

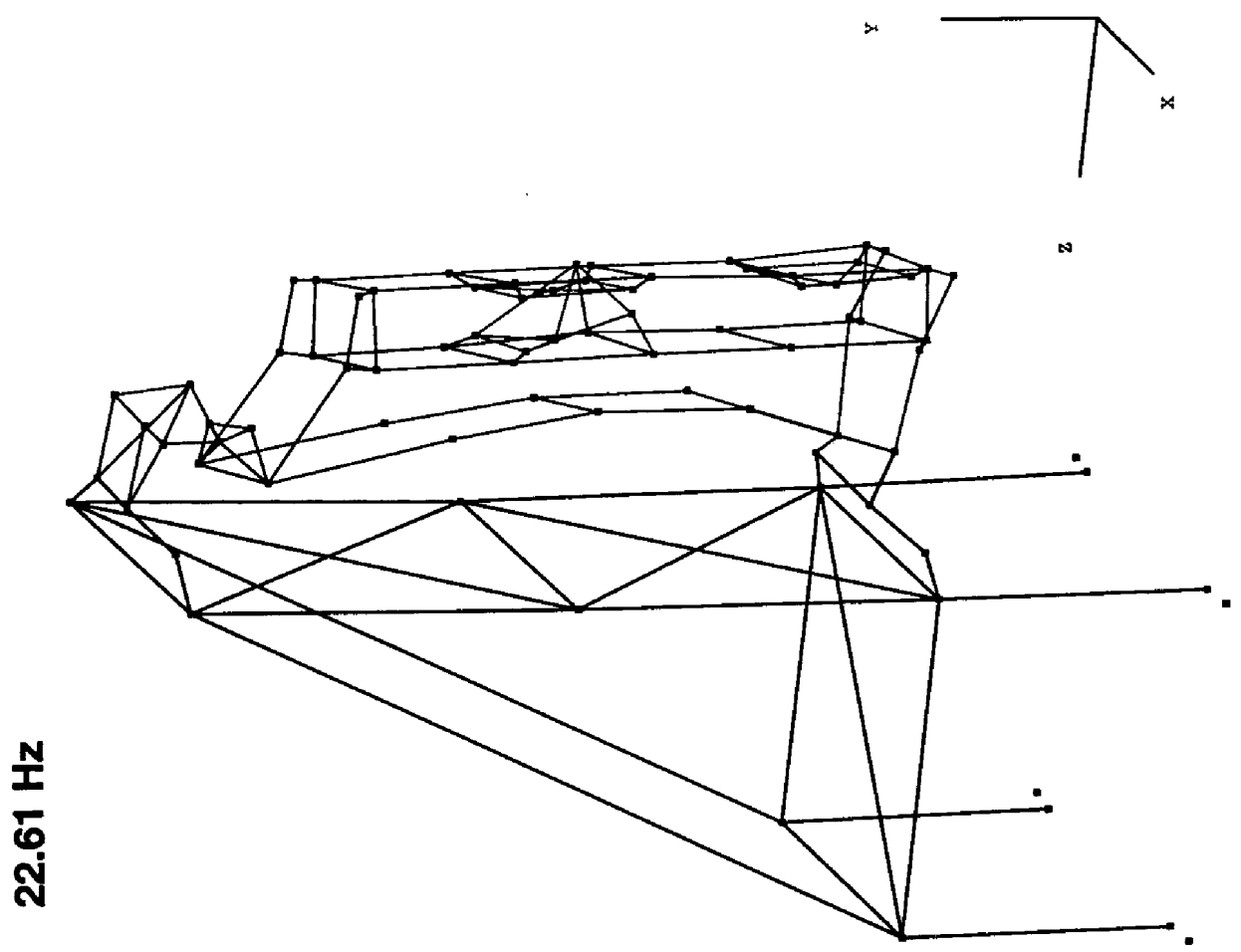

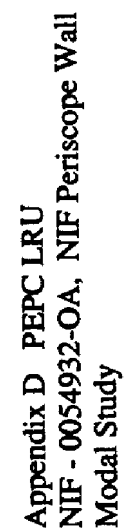




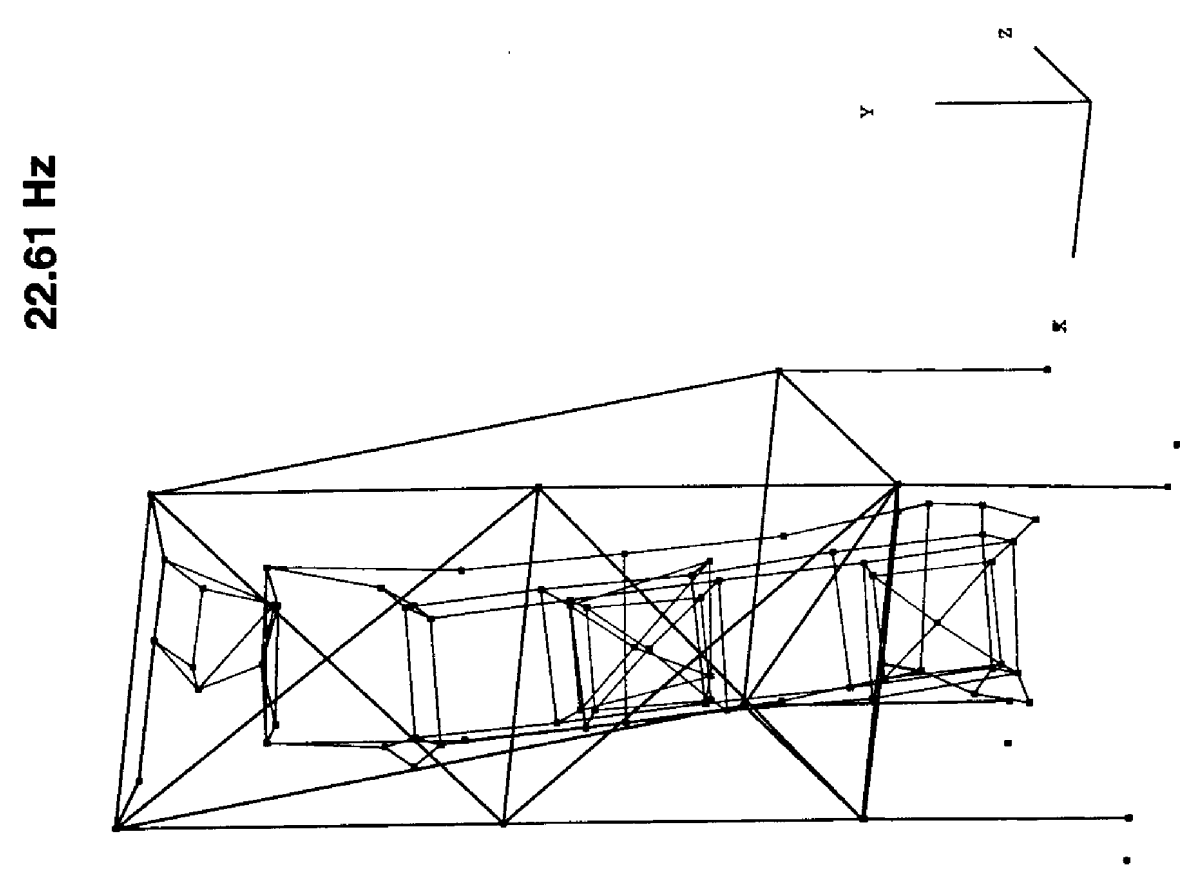

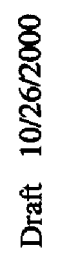

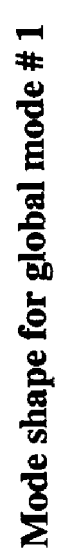

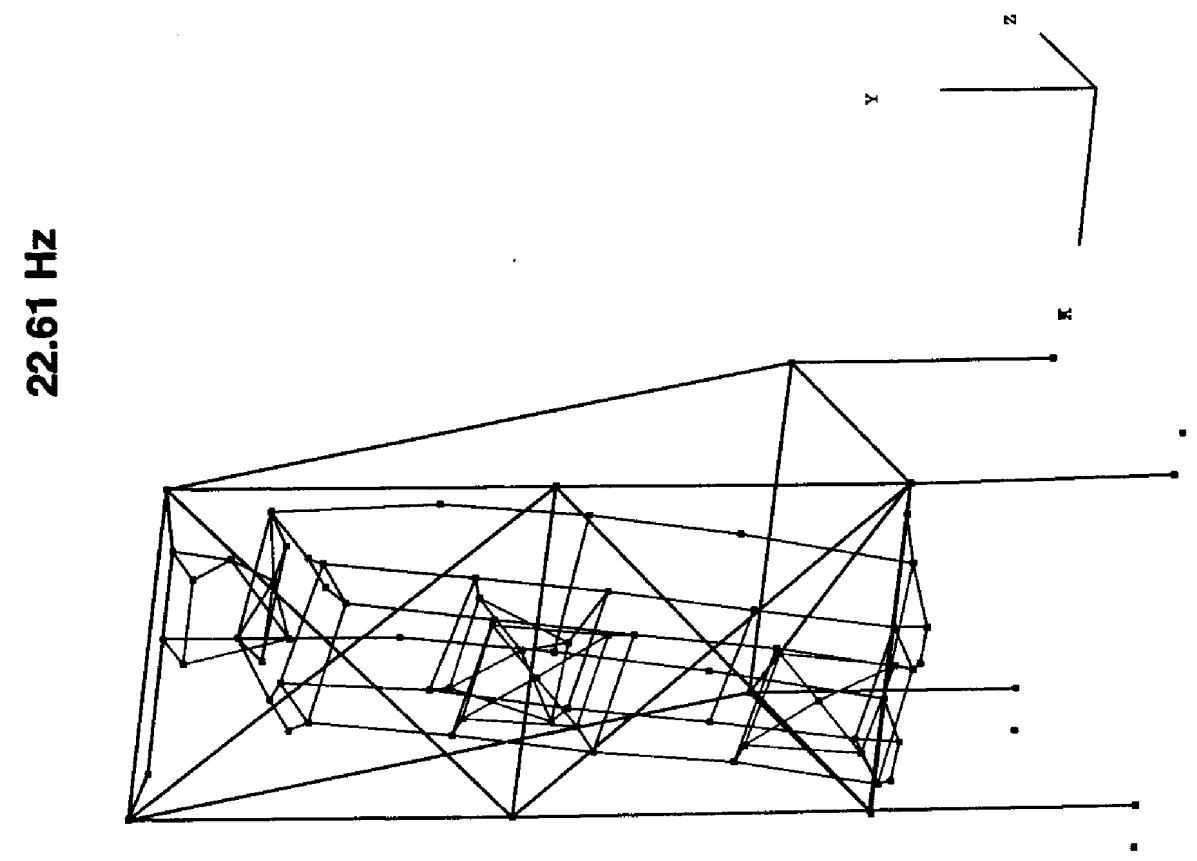

$\dot{p}$
0
0
0

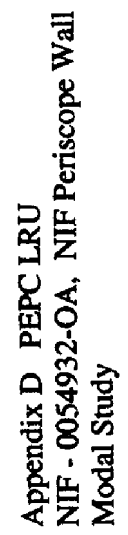



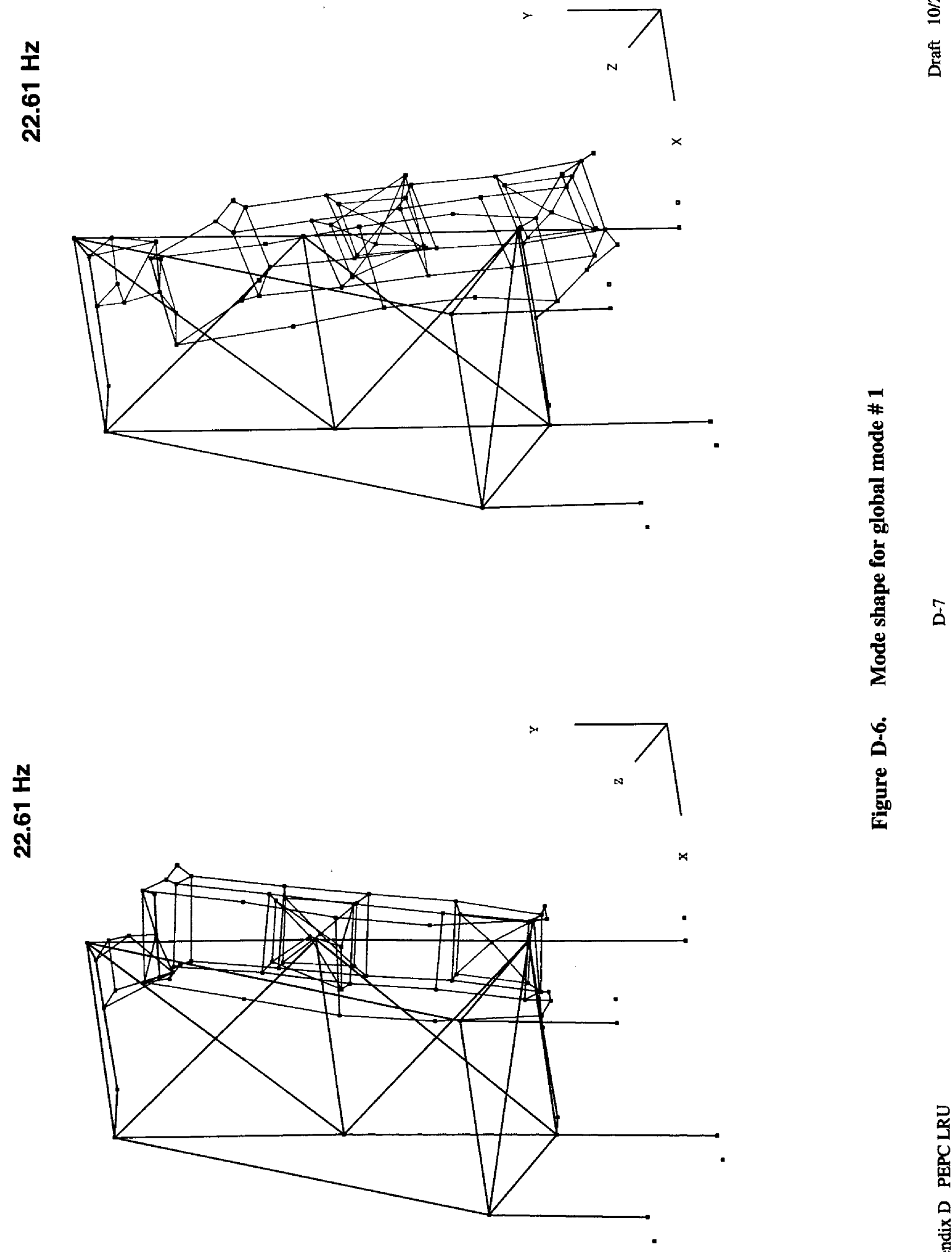

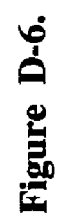

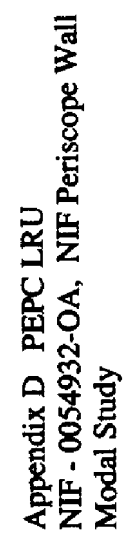


$25.52 \mathrm{~Hz}$

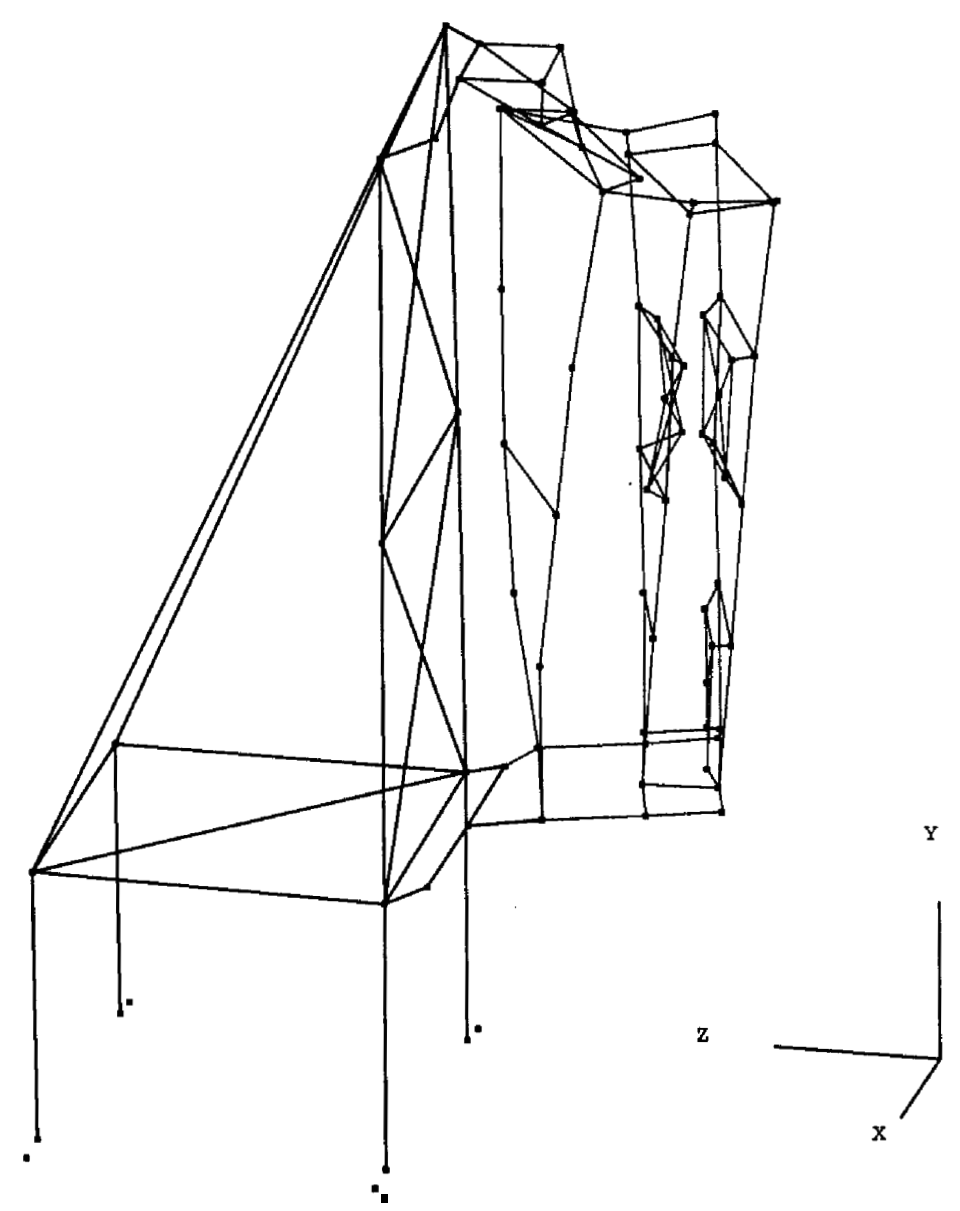

$25.52 \mathrm{~Hz}$

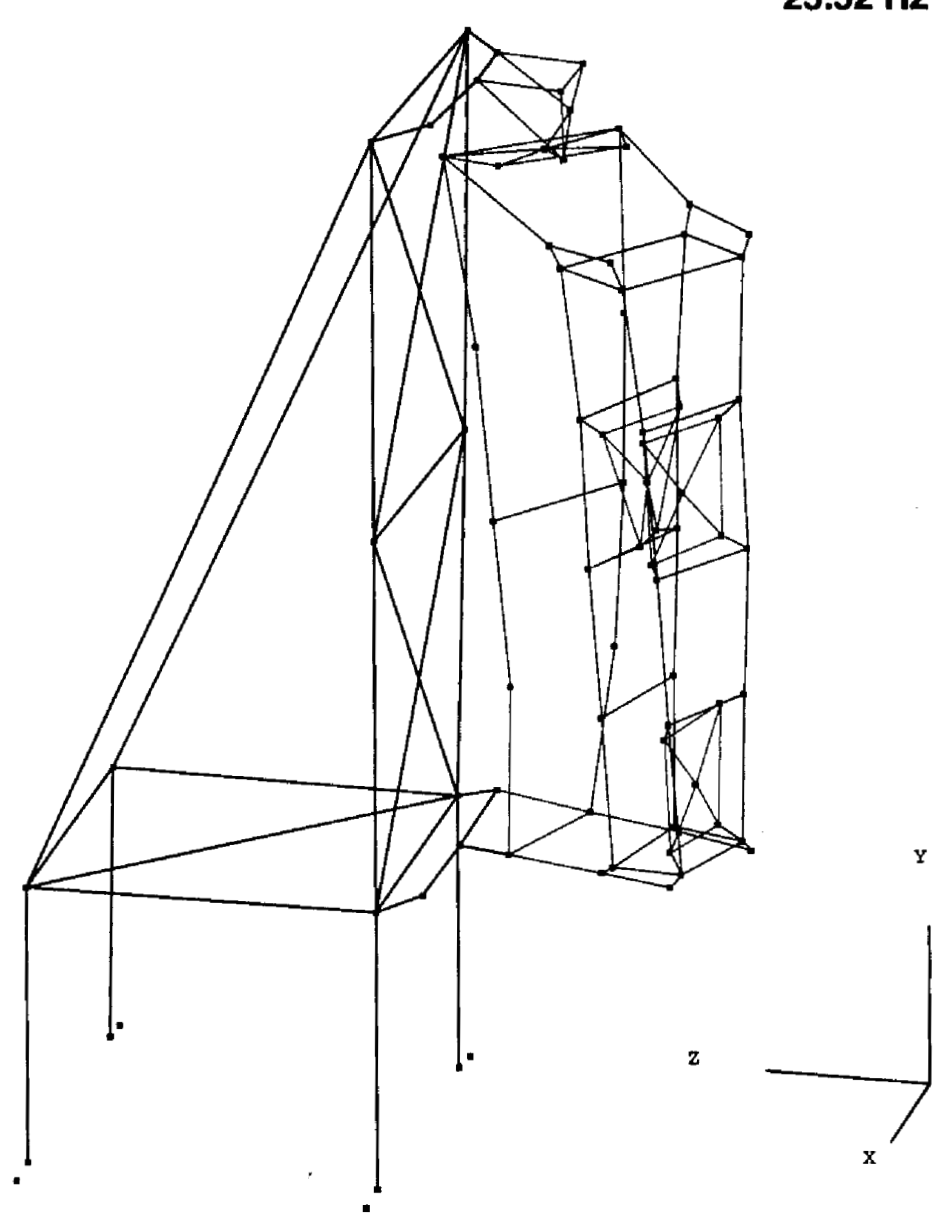

Figure D-7. Mode shape for global mode \# 2 


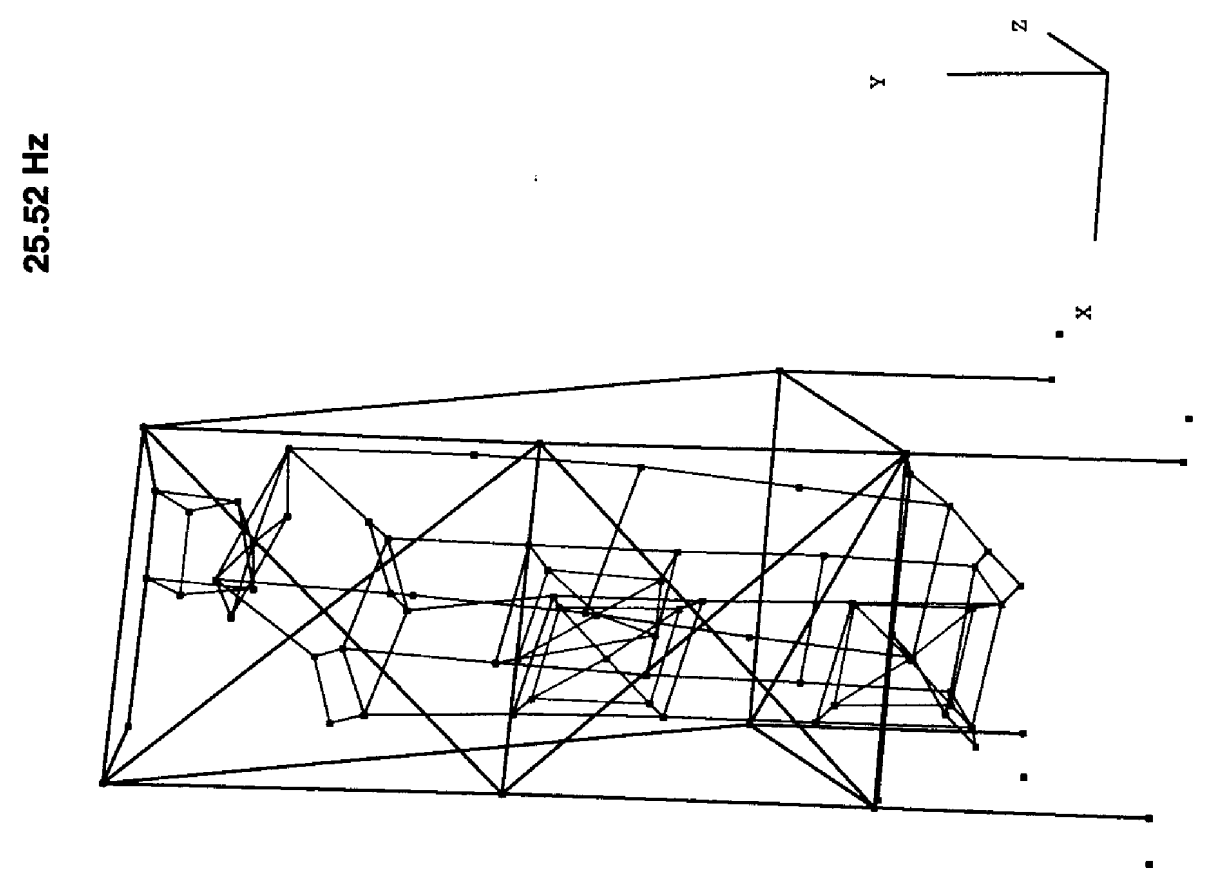

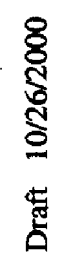

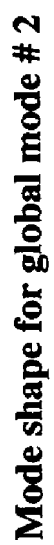

à

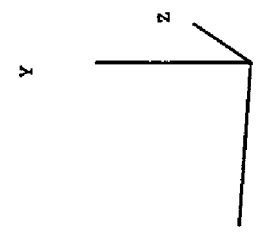

这

ำ
กิ
ำ

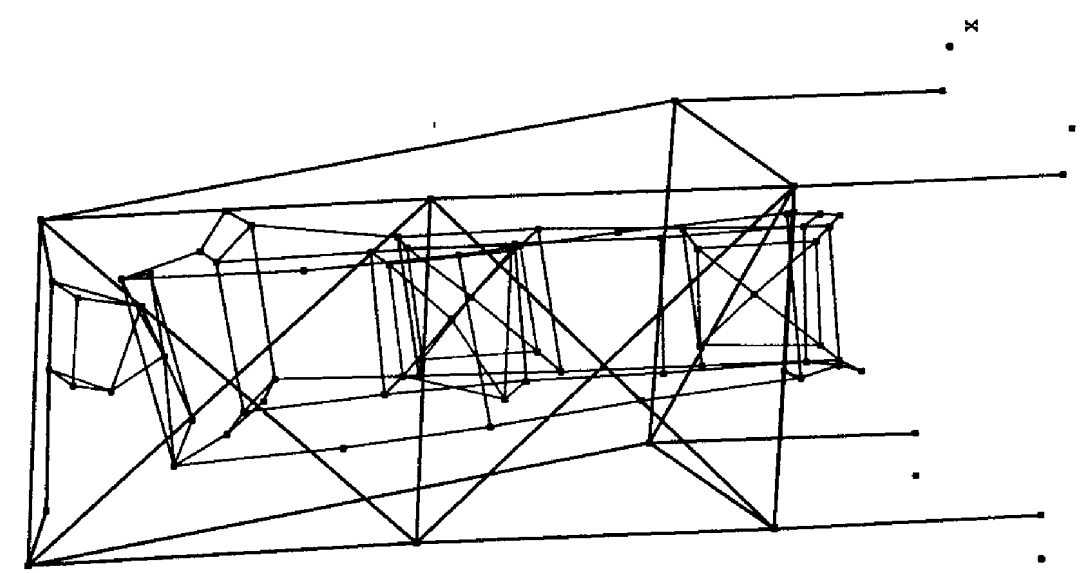

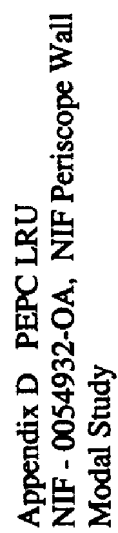




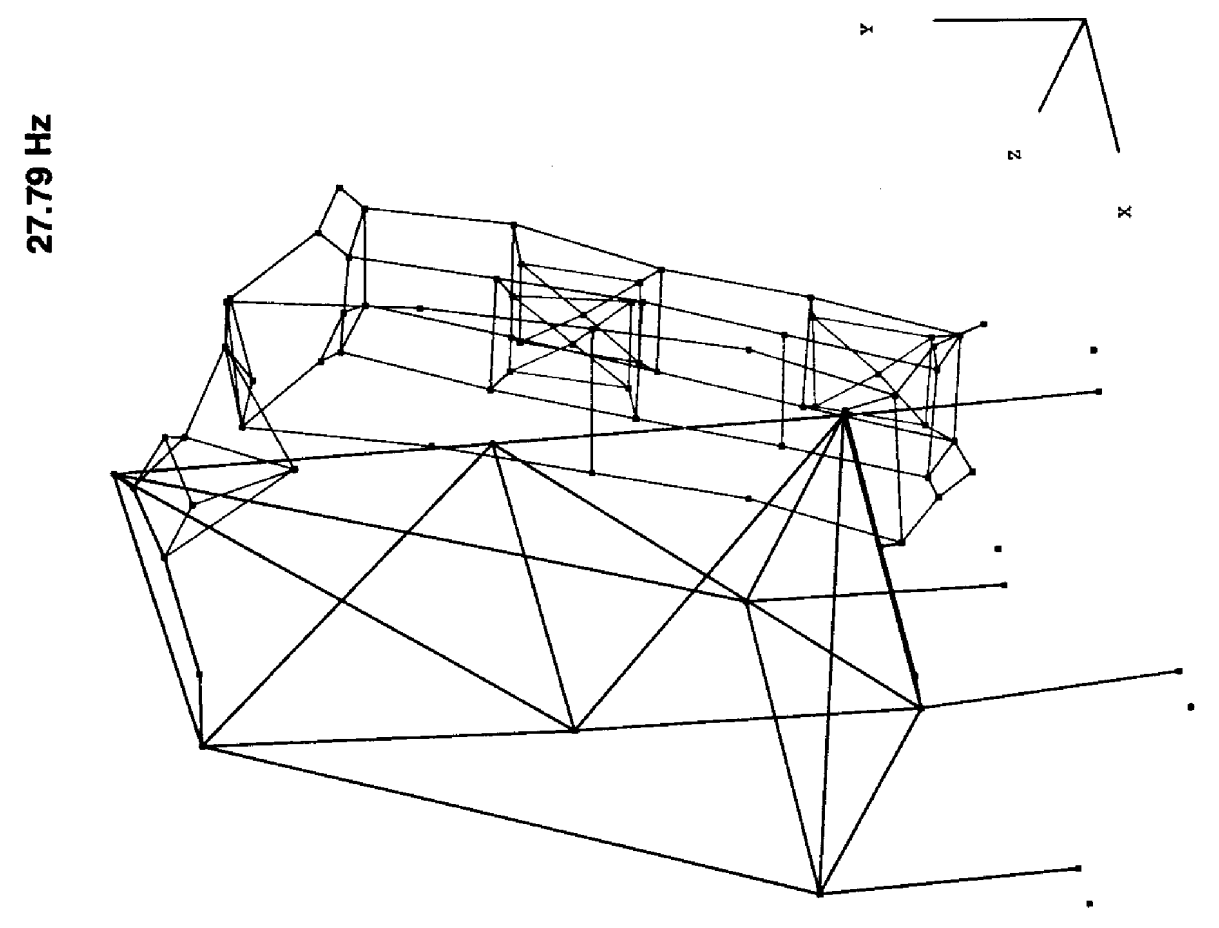

ఫ్ర్ర్ర

氙

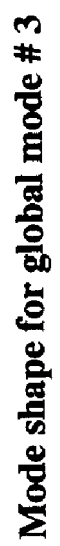

$\frac{1}{b}$

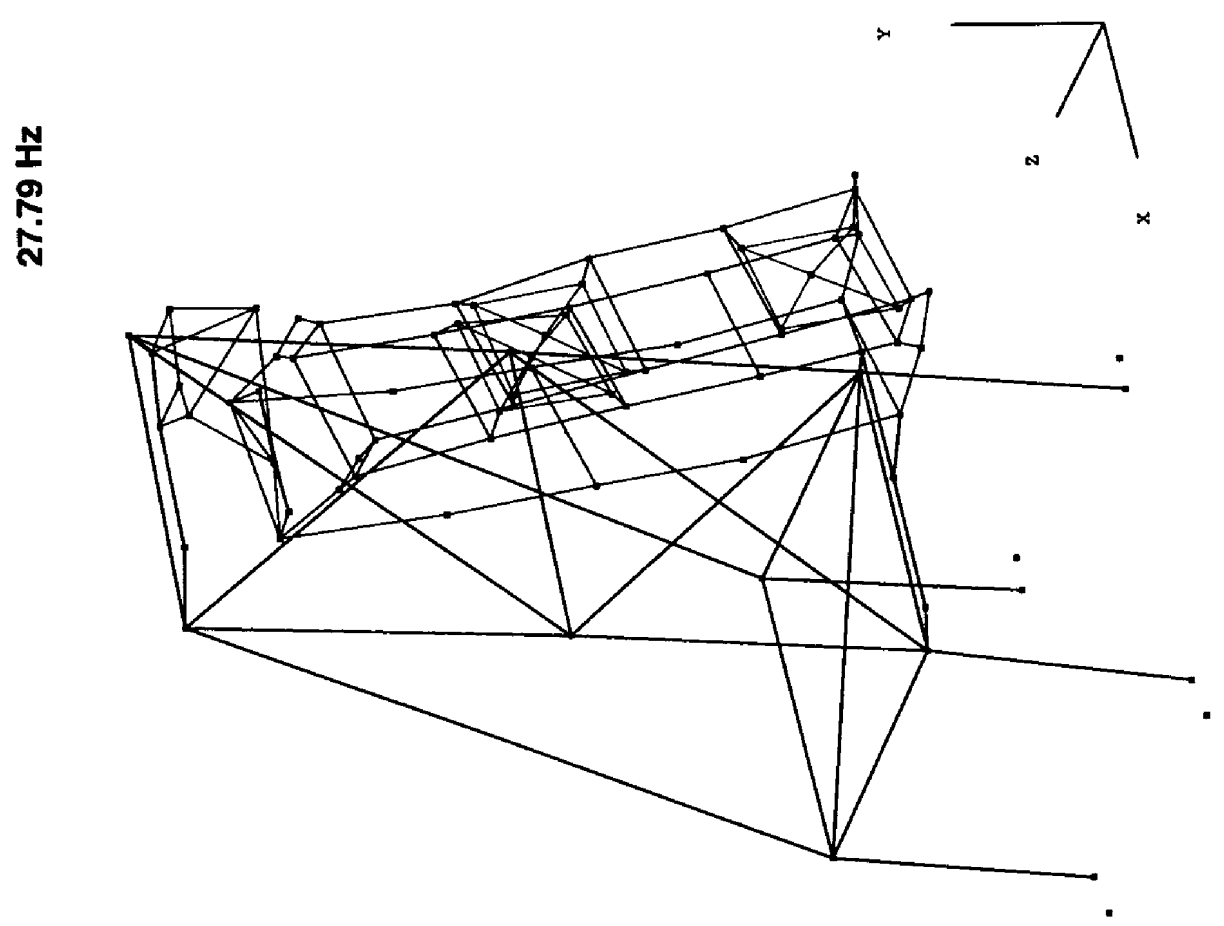

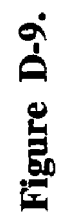

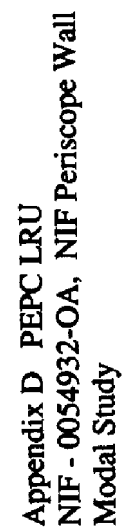




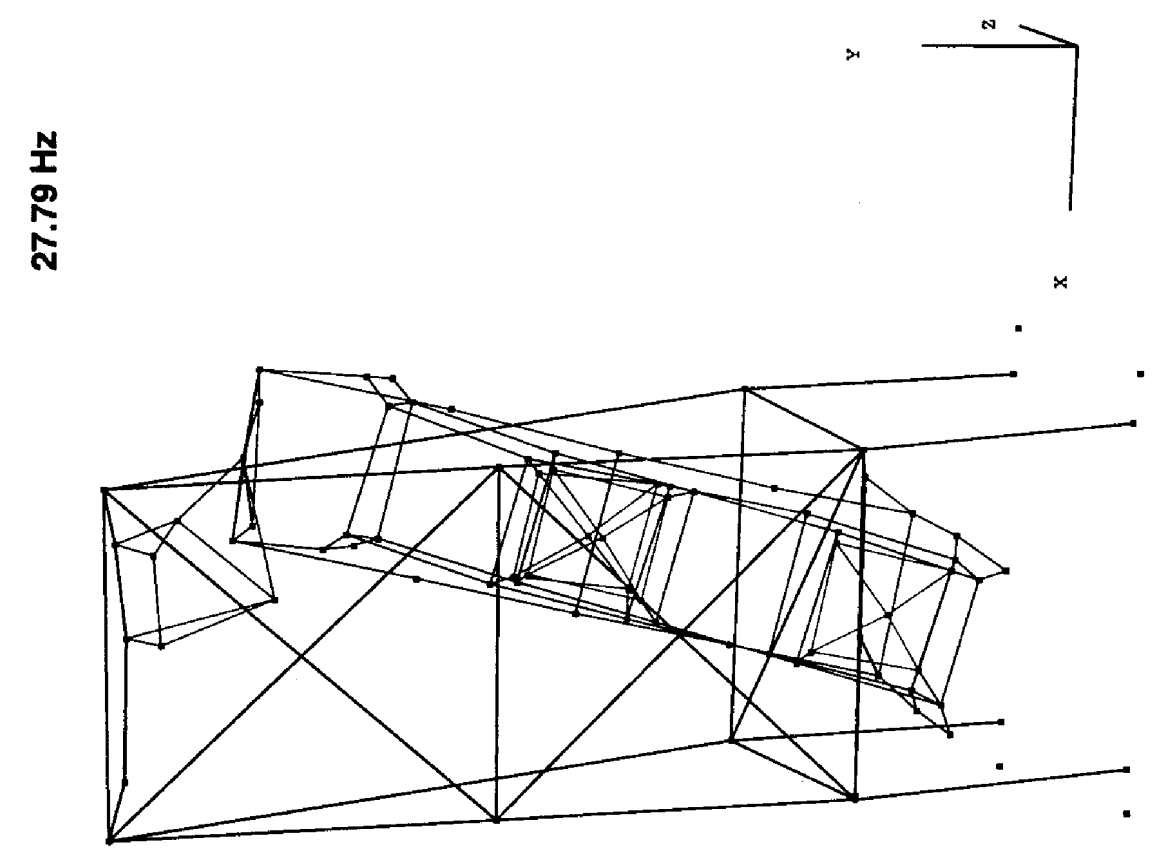

8
ญे
ญे

产

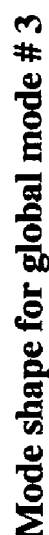

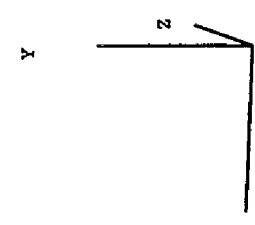

官

$\bar{a}$

$\frac{N}{N}$ 
N
T
ล

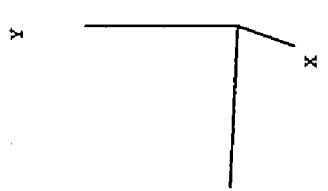

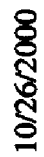

营

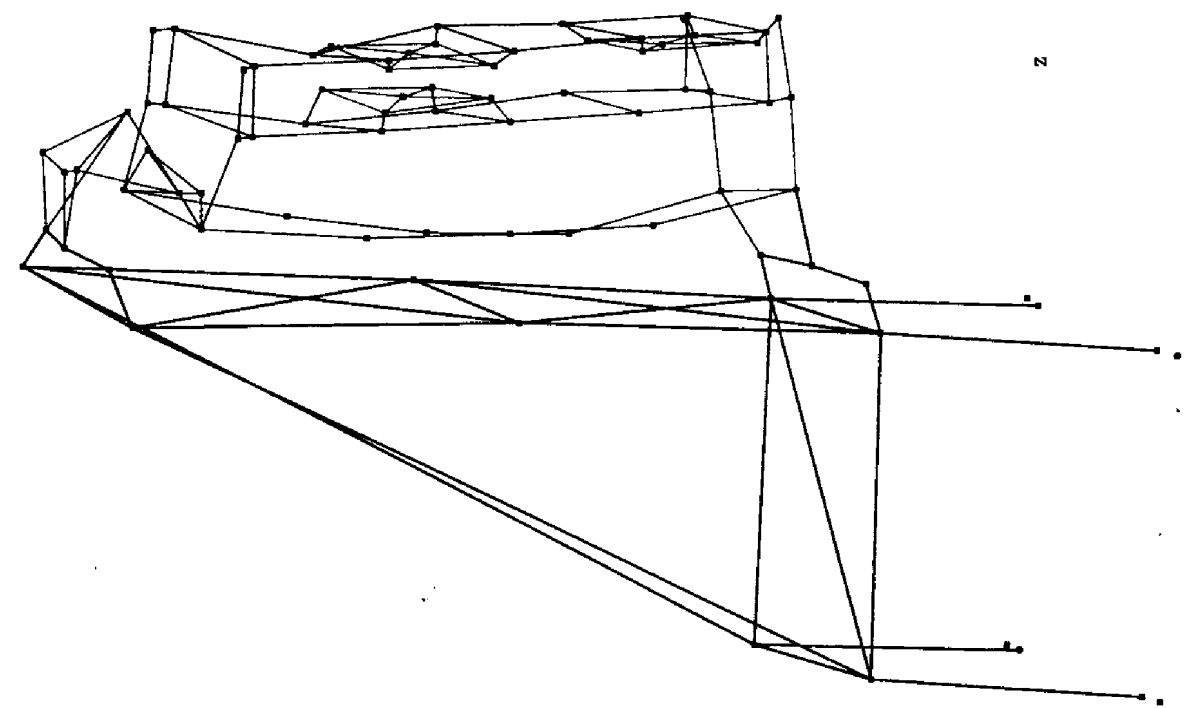

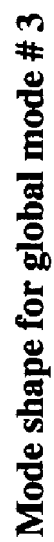

$\frac{x}{d}$

$\underset{N}{N}$

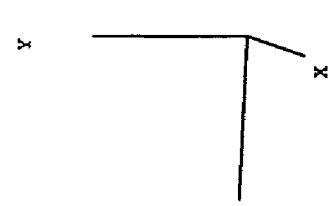

룰

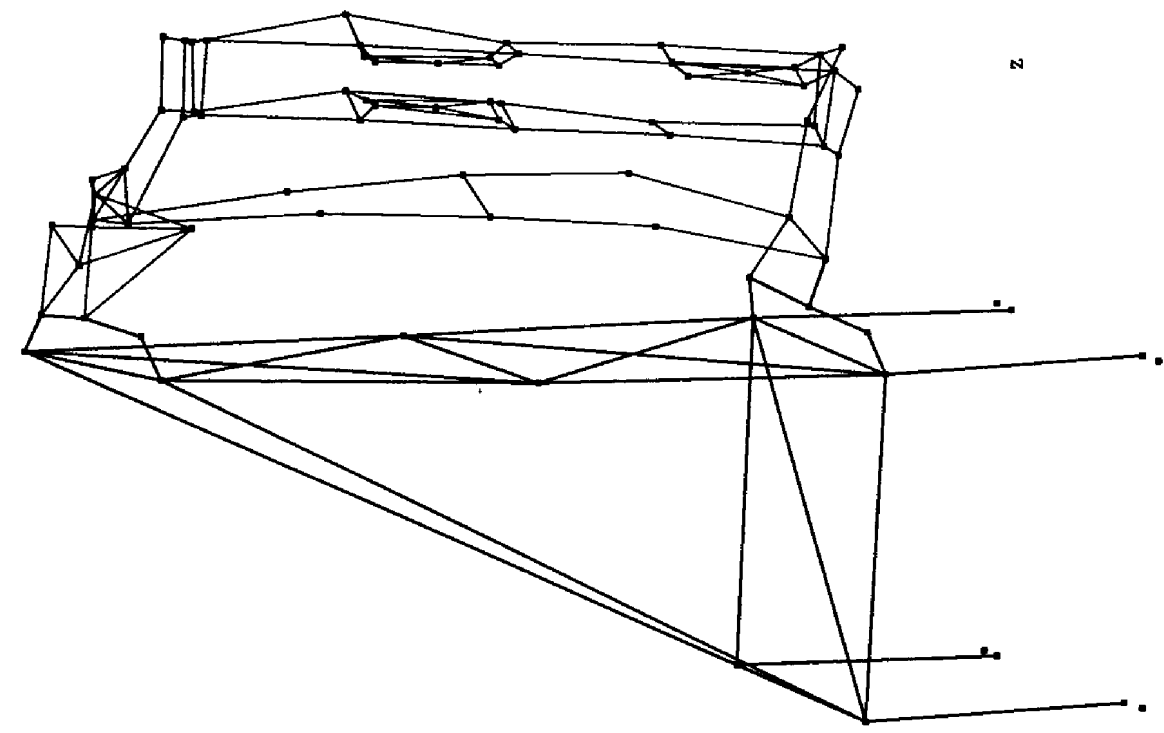




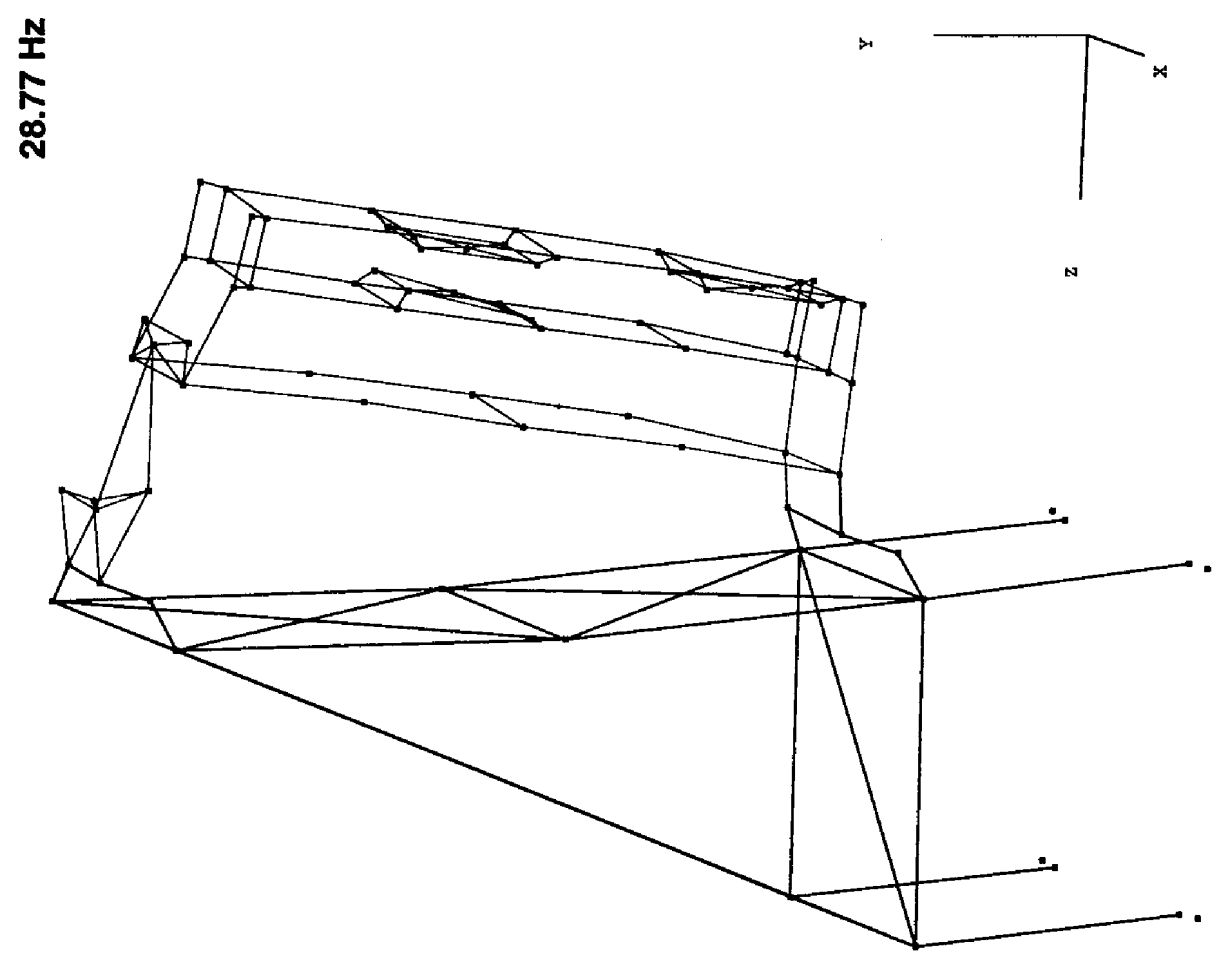

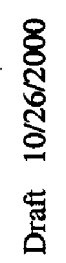

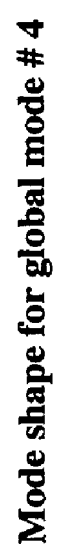

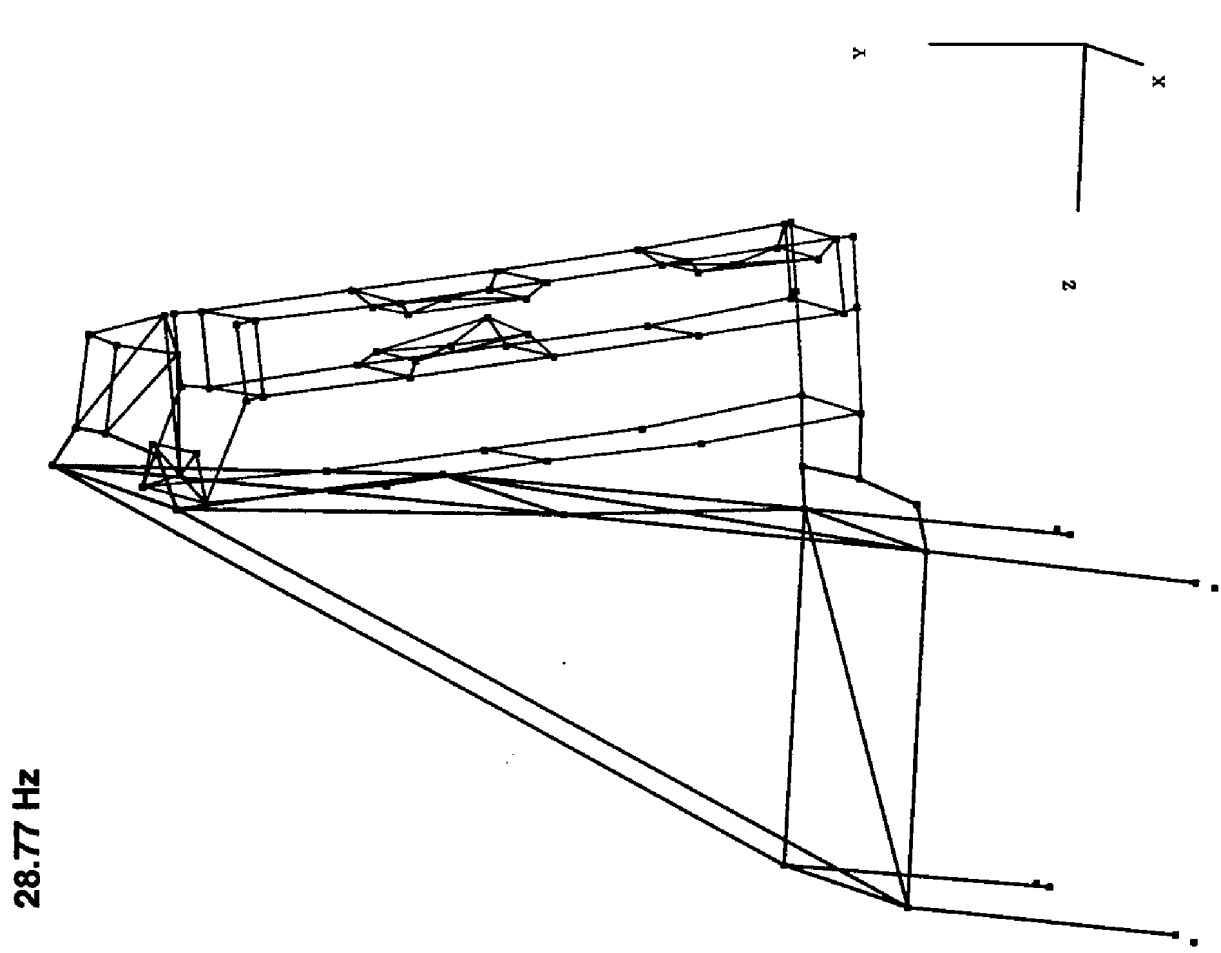

ำ 


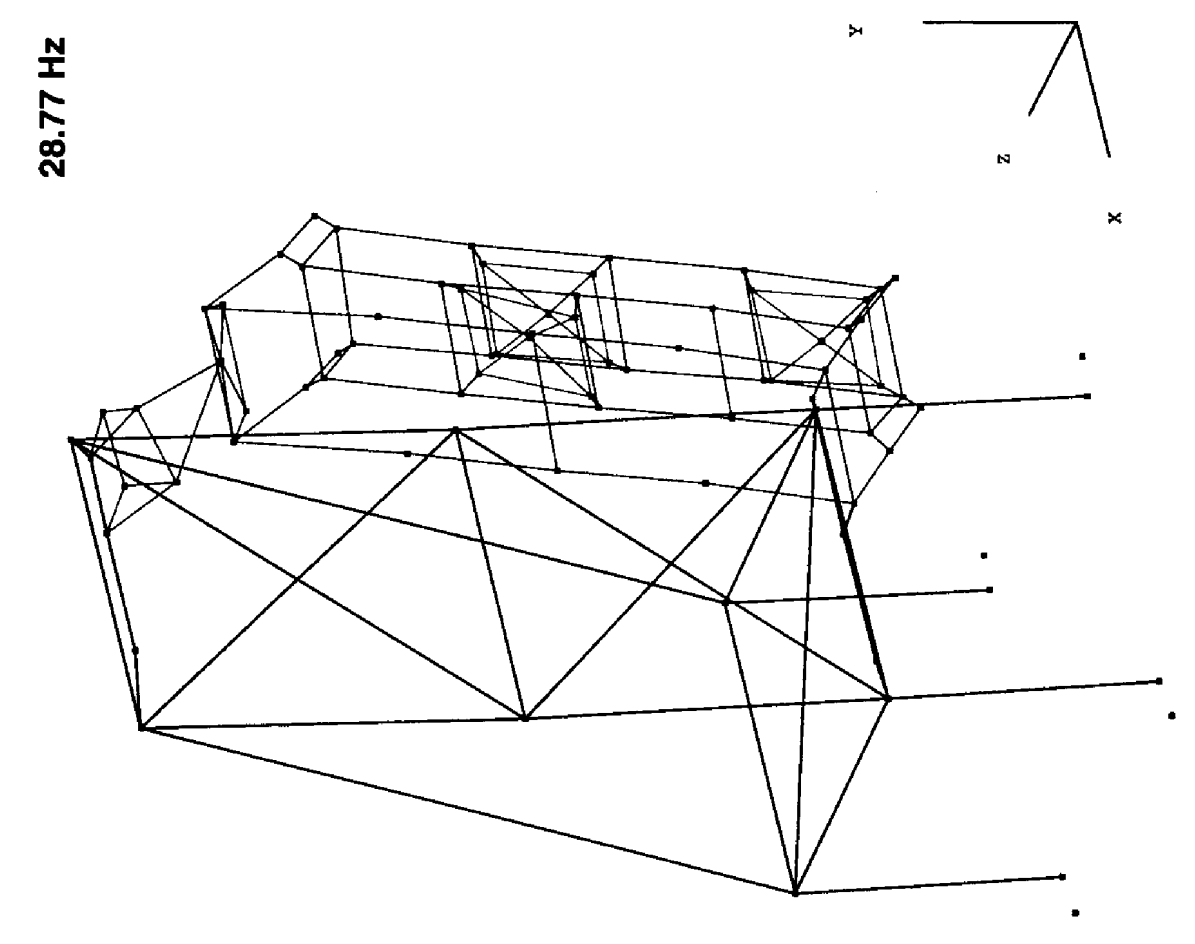

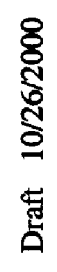

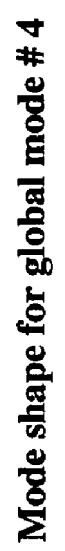

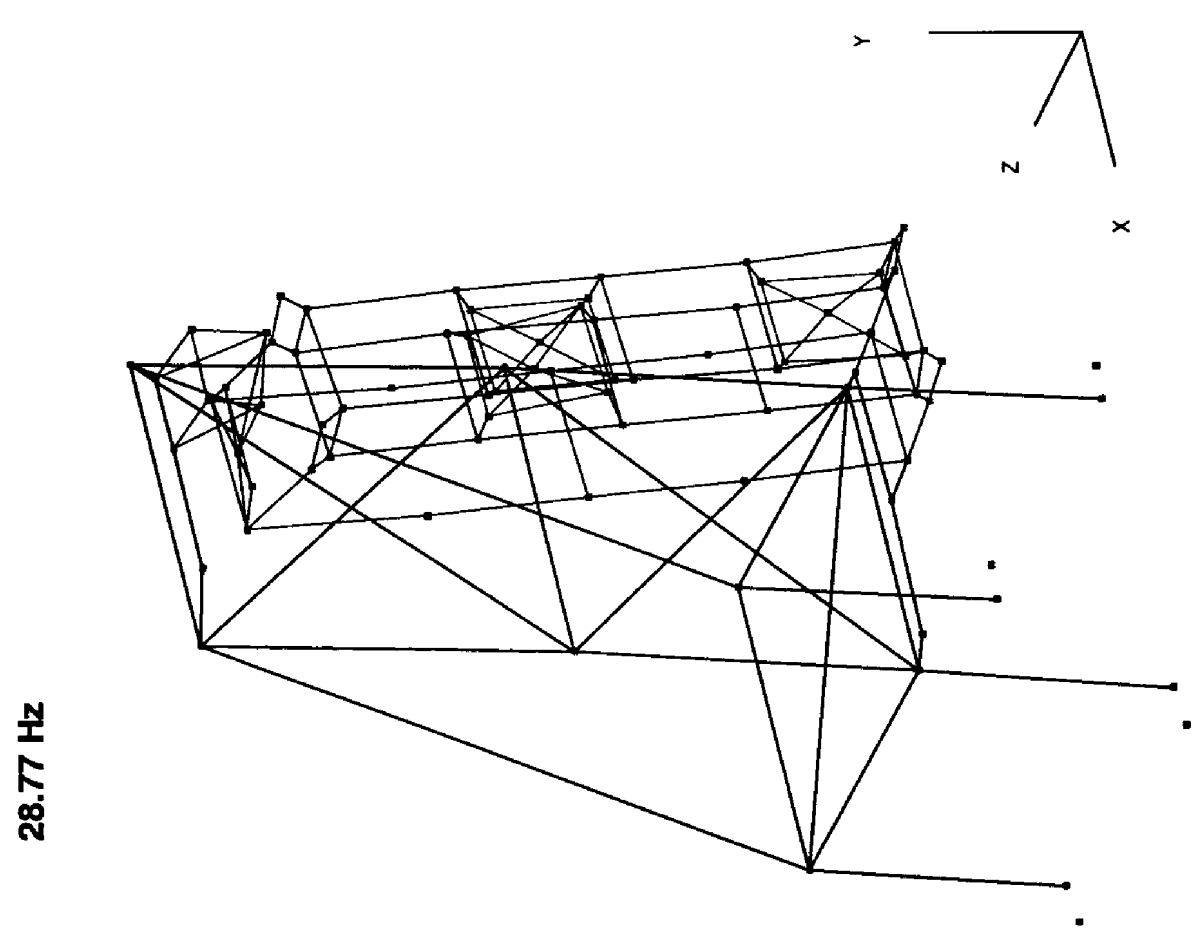

常

$\frac{ \pm}{a}$

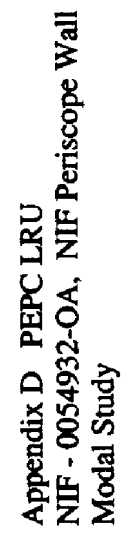


N
:
:

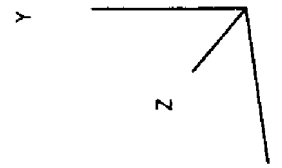

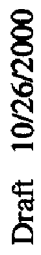

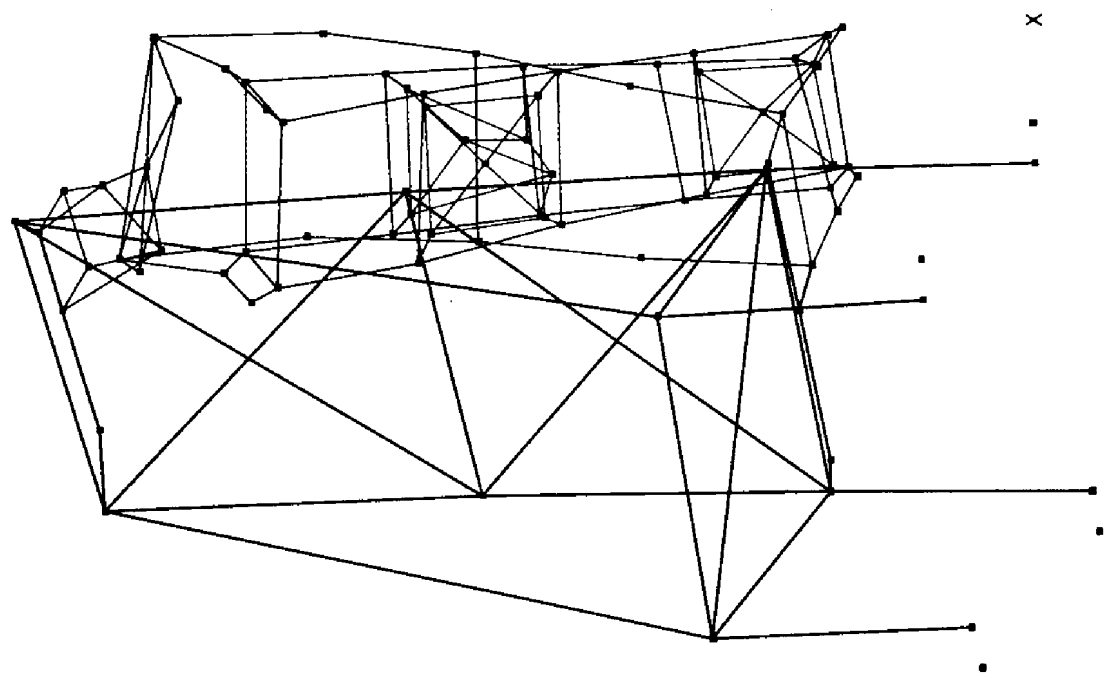

\#

$\frac{n}{0}$

N̦
ơ
0
0

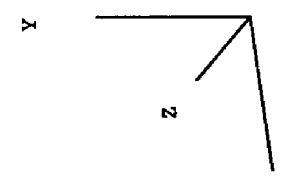

官

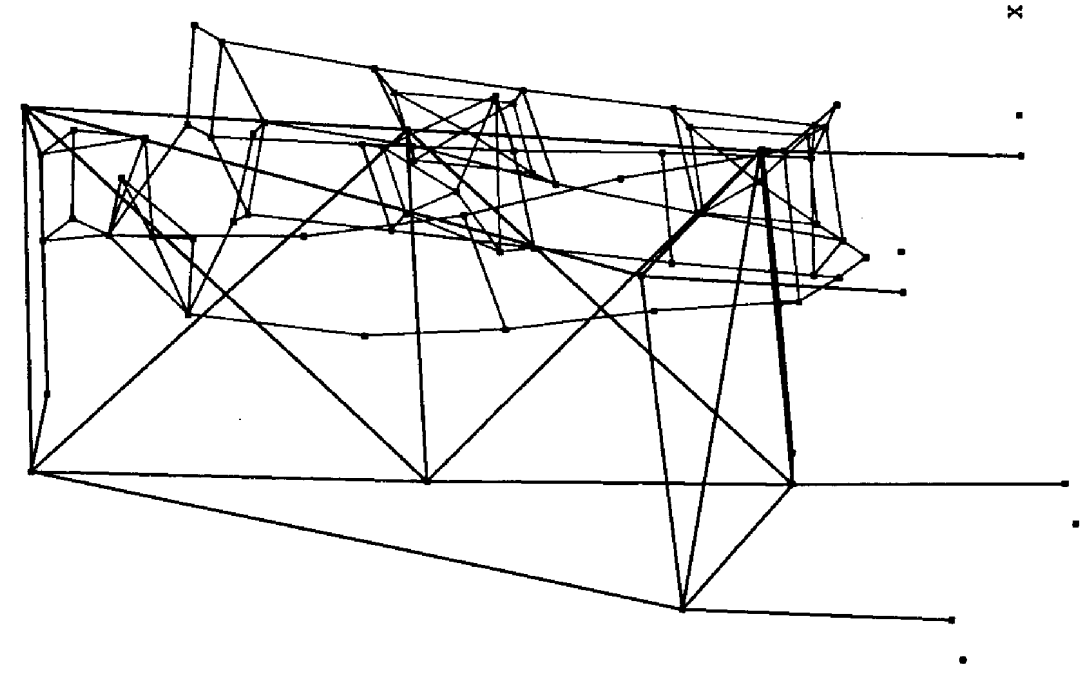



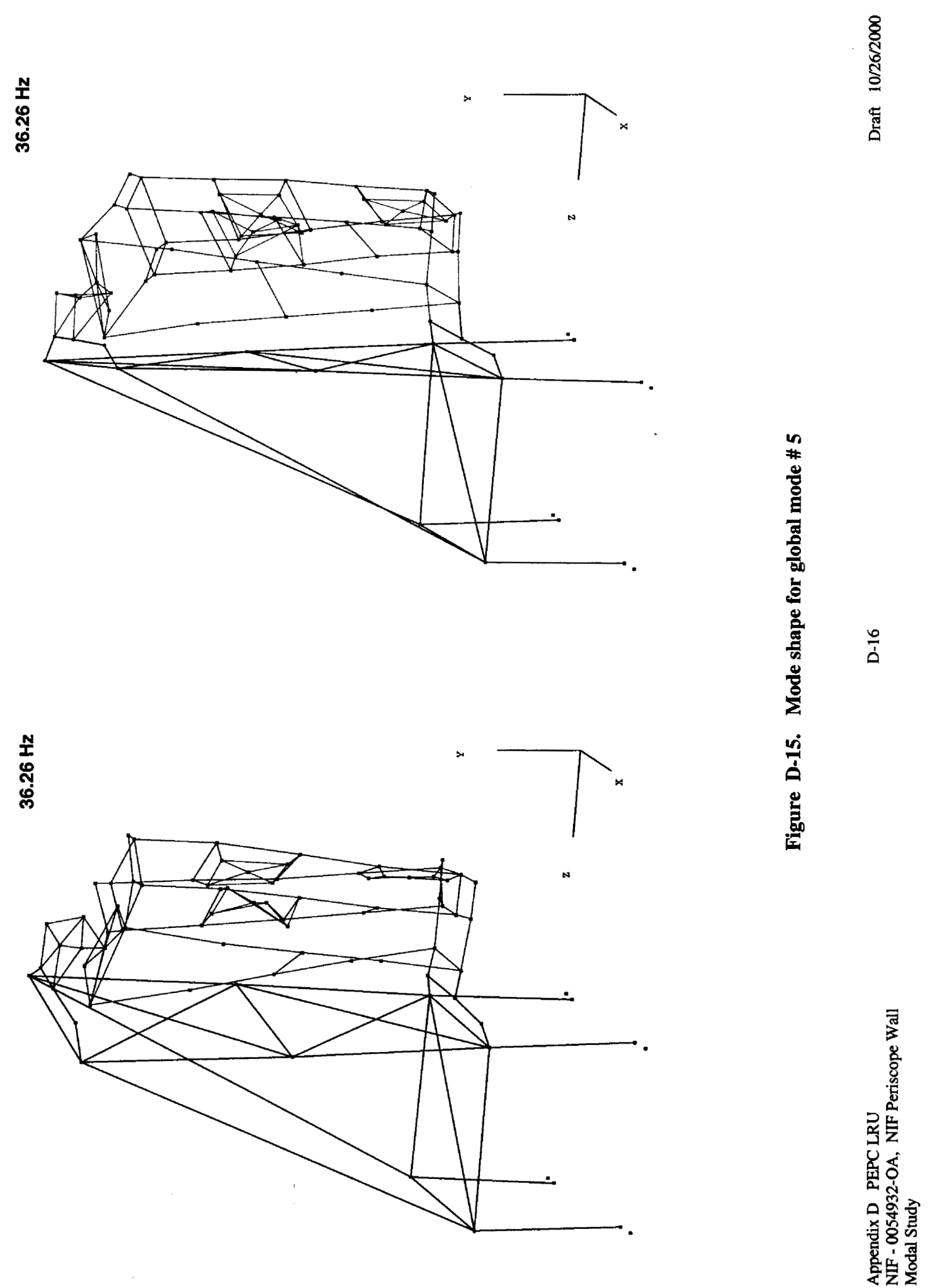

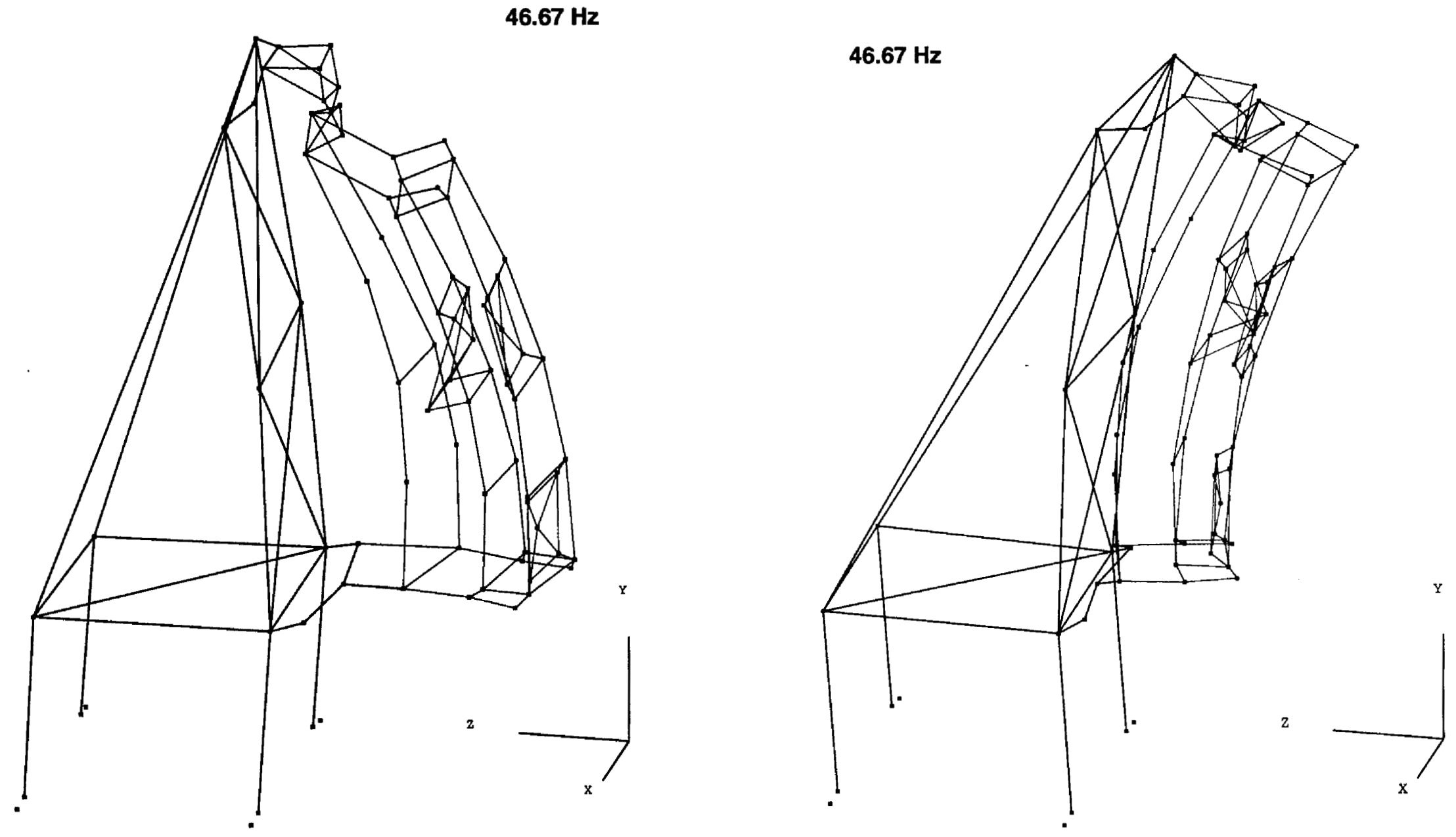

Figure D-16. Mode shape for global mode \# 6 

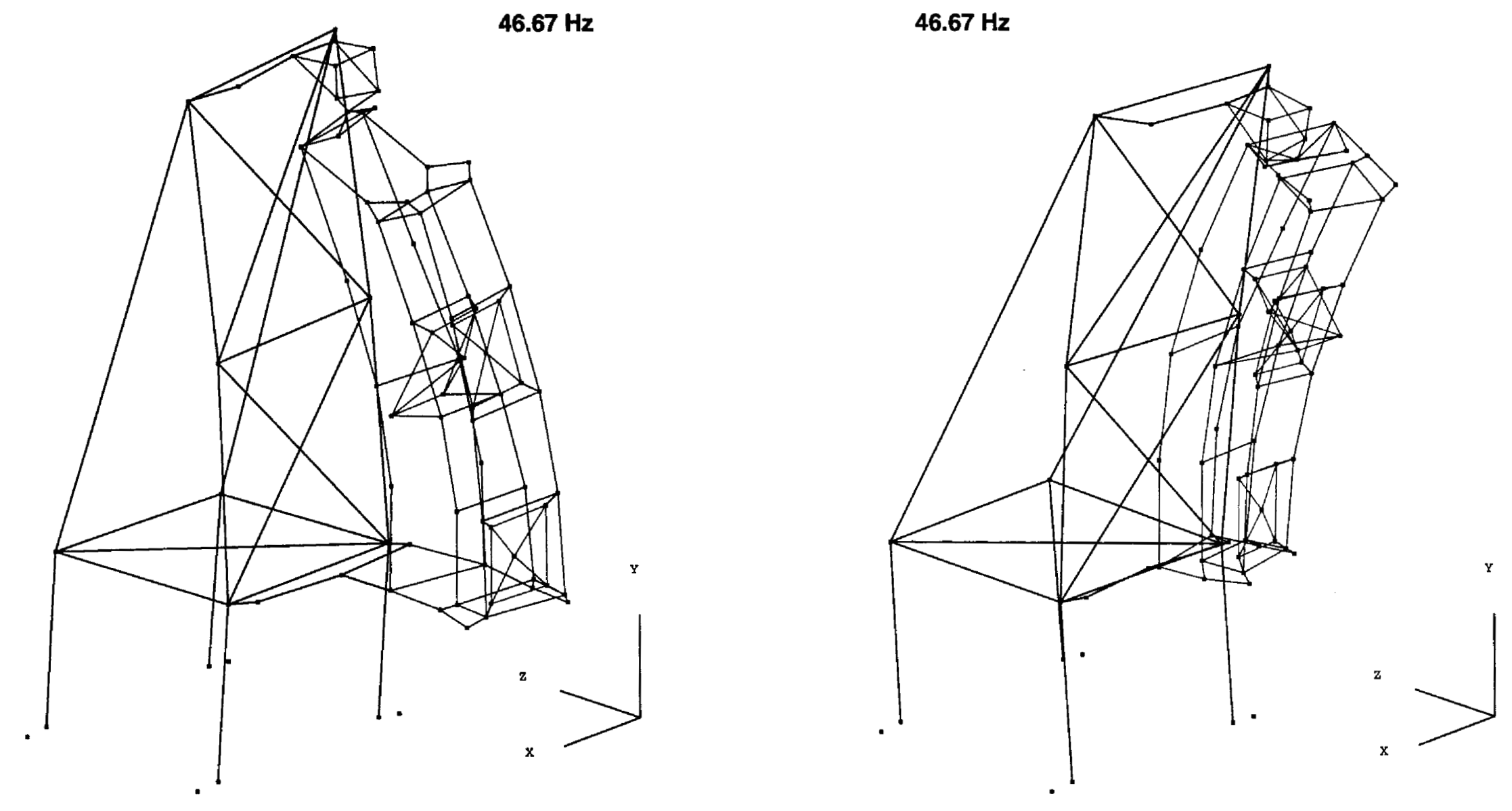

Figure D-17. Mode shape for global mode \# 6 


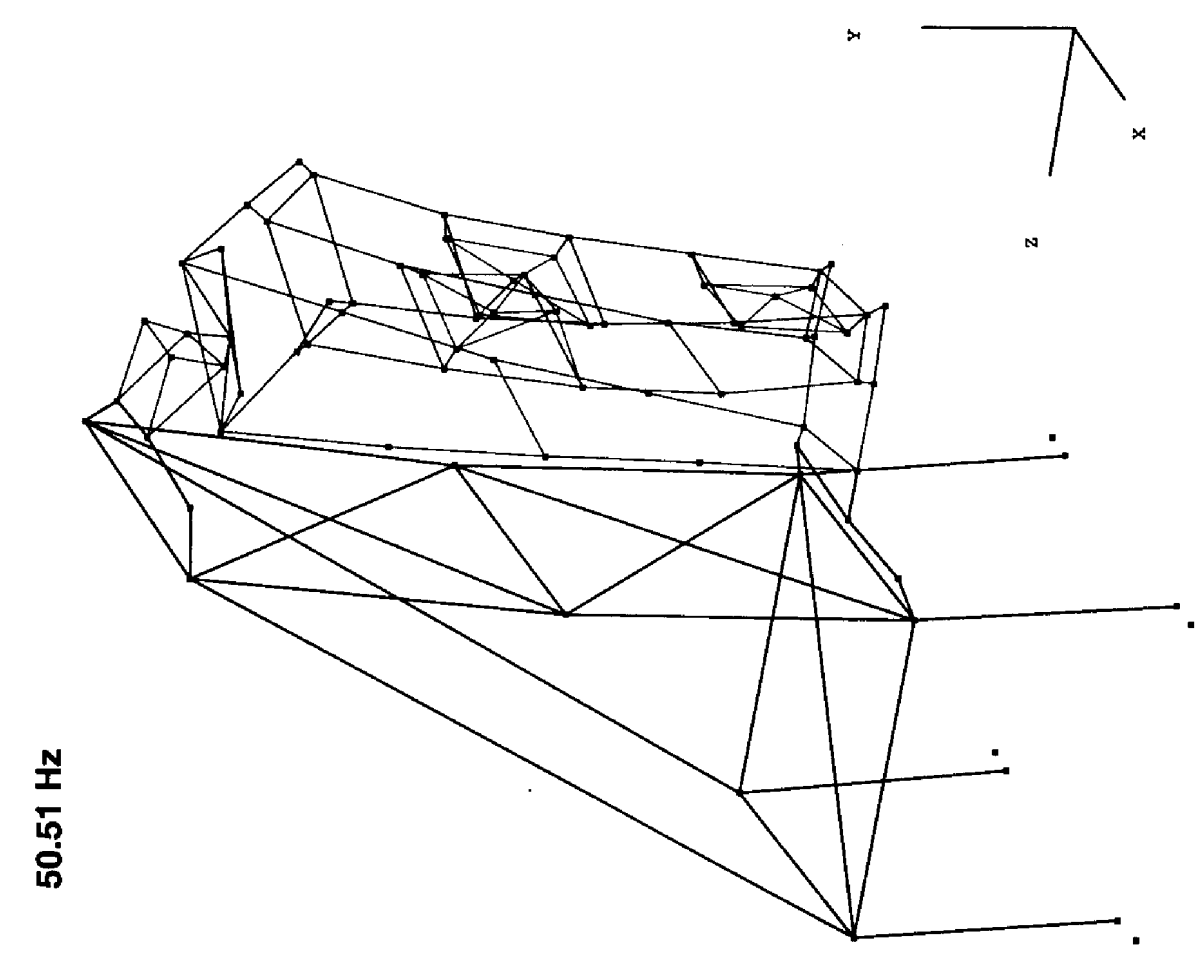

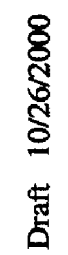

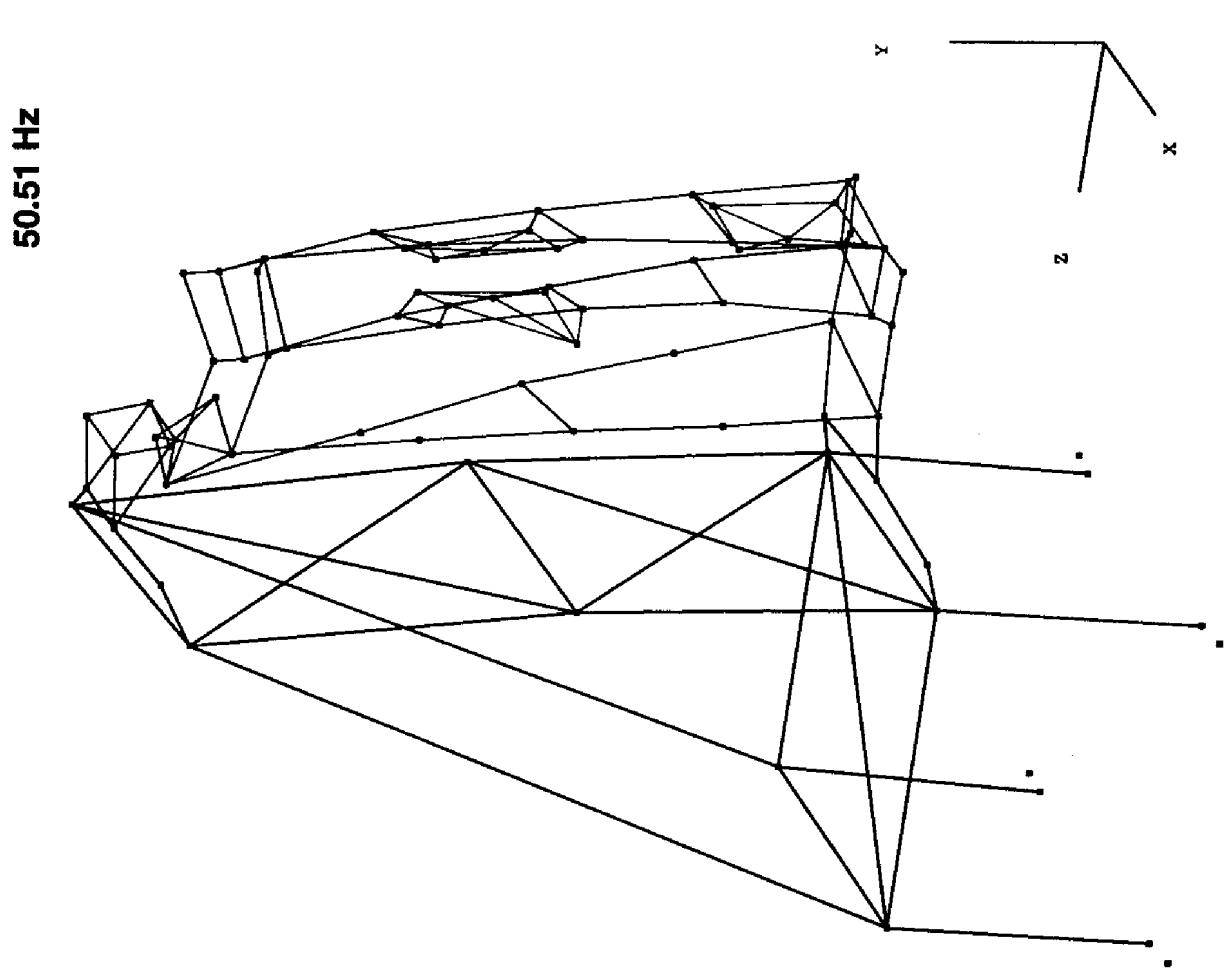

官 


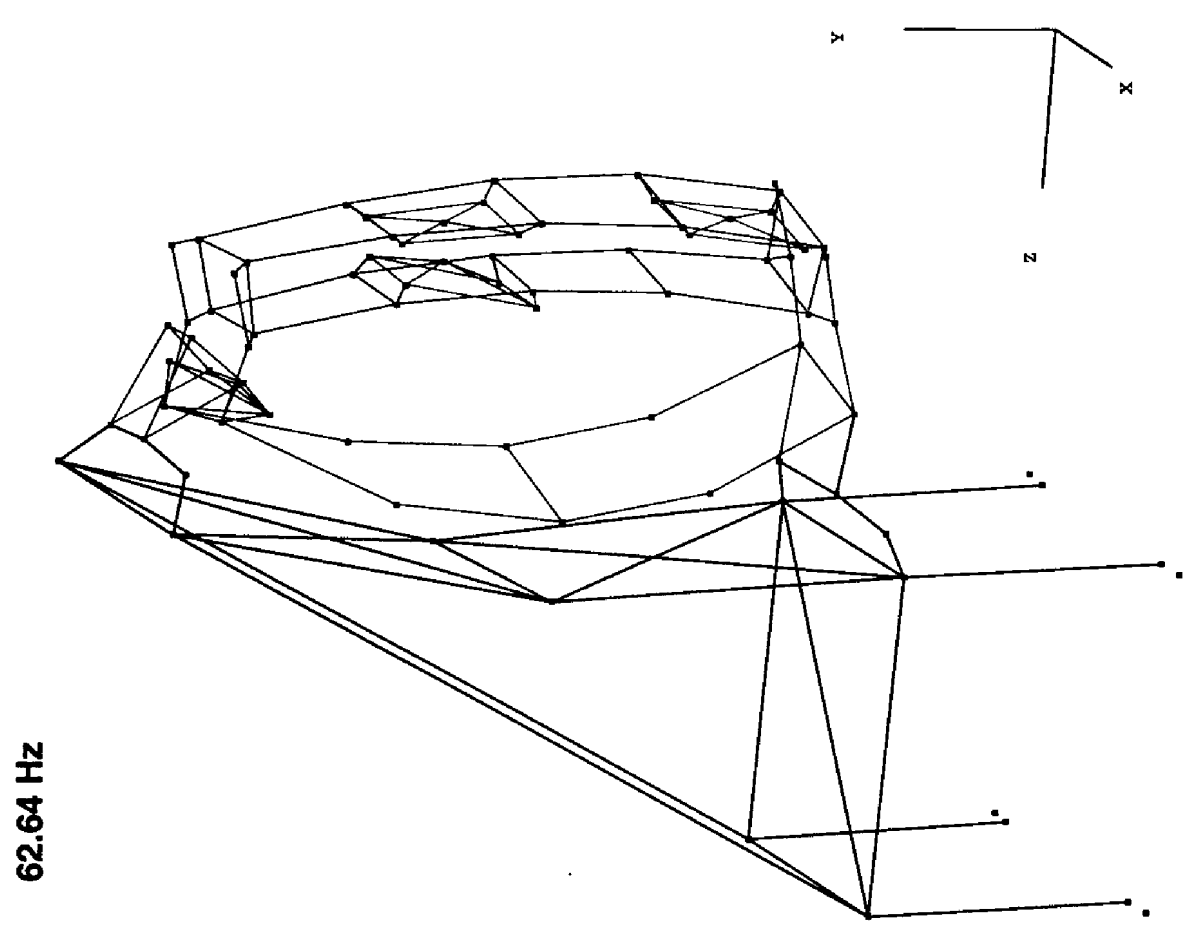

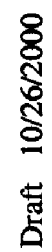

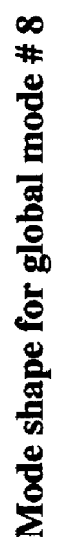

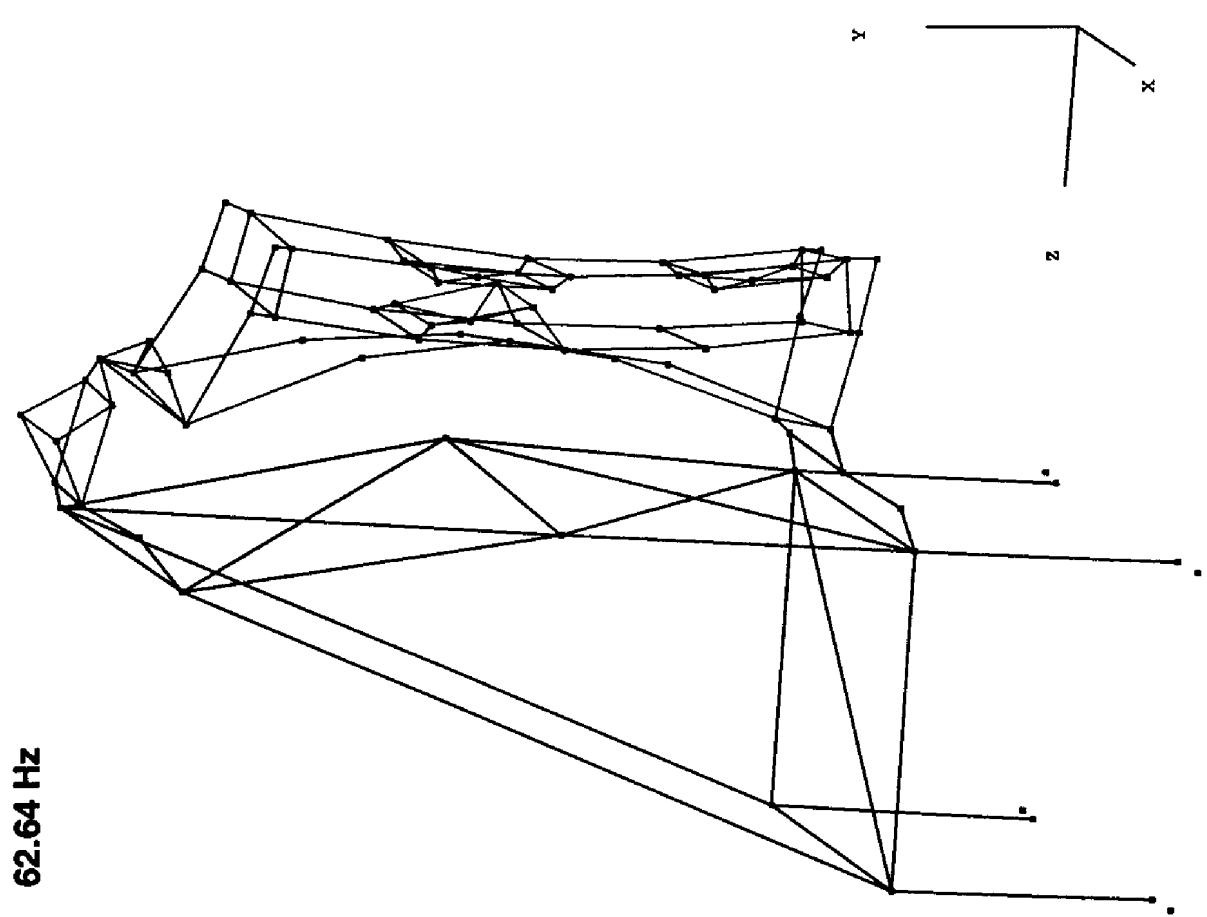

官 

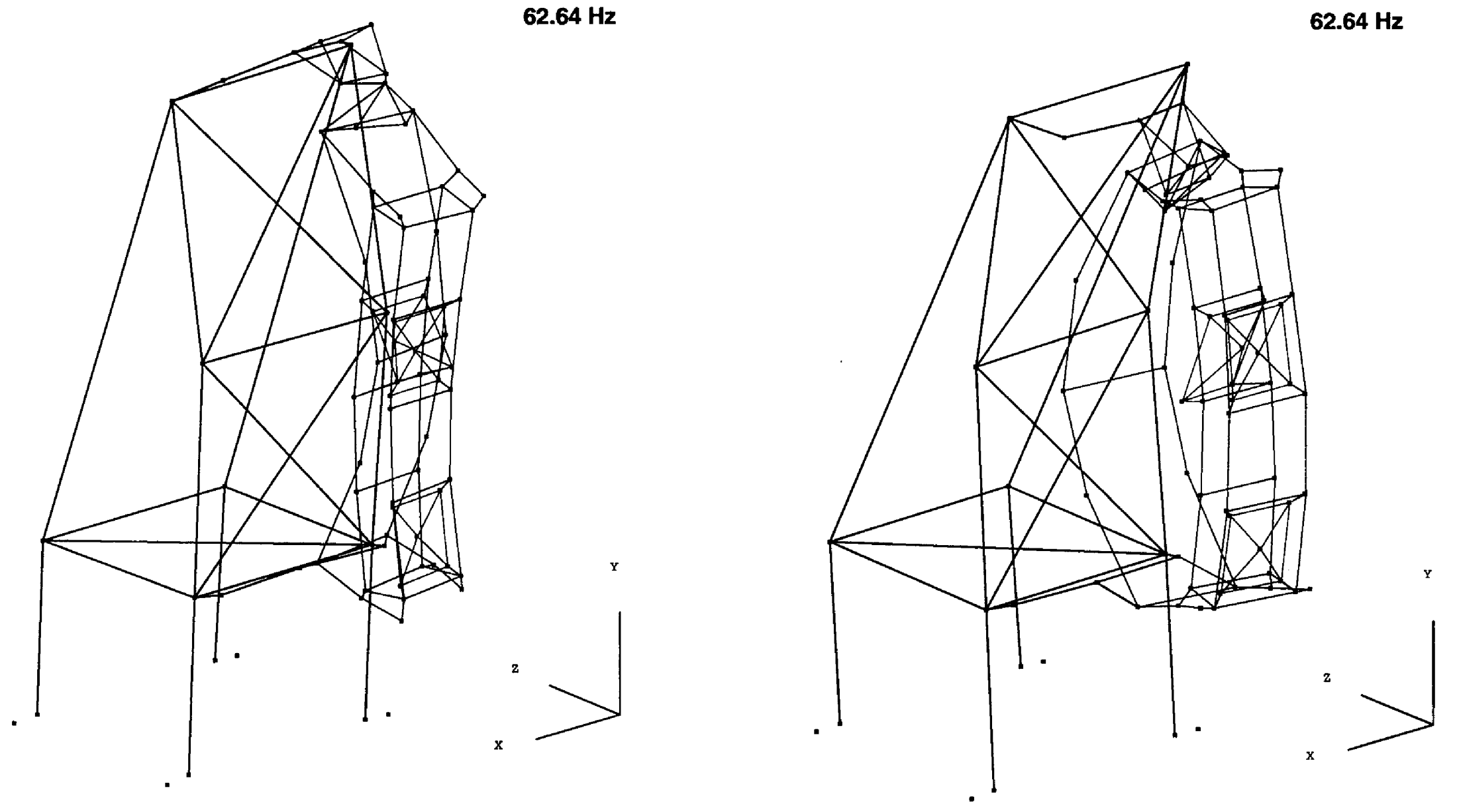

Figure D-20. Mode shape for global mode \# 8 


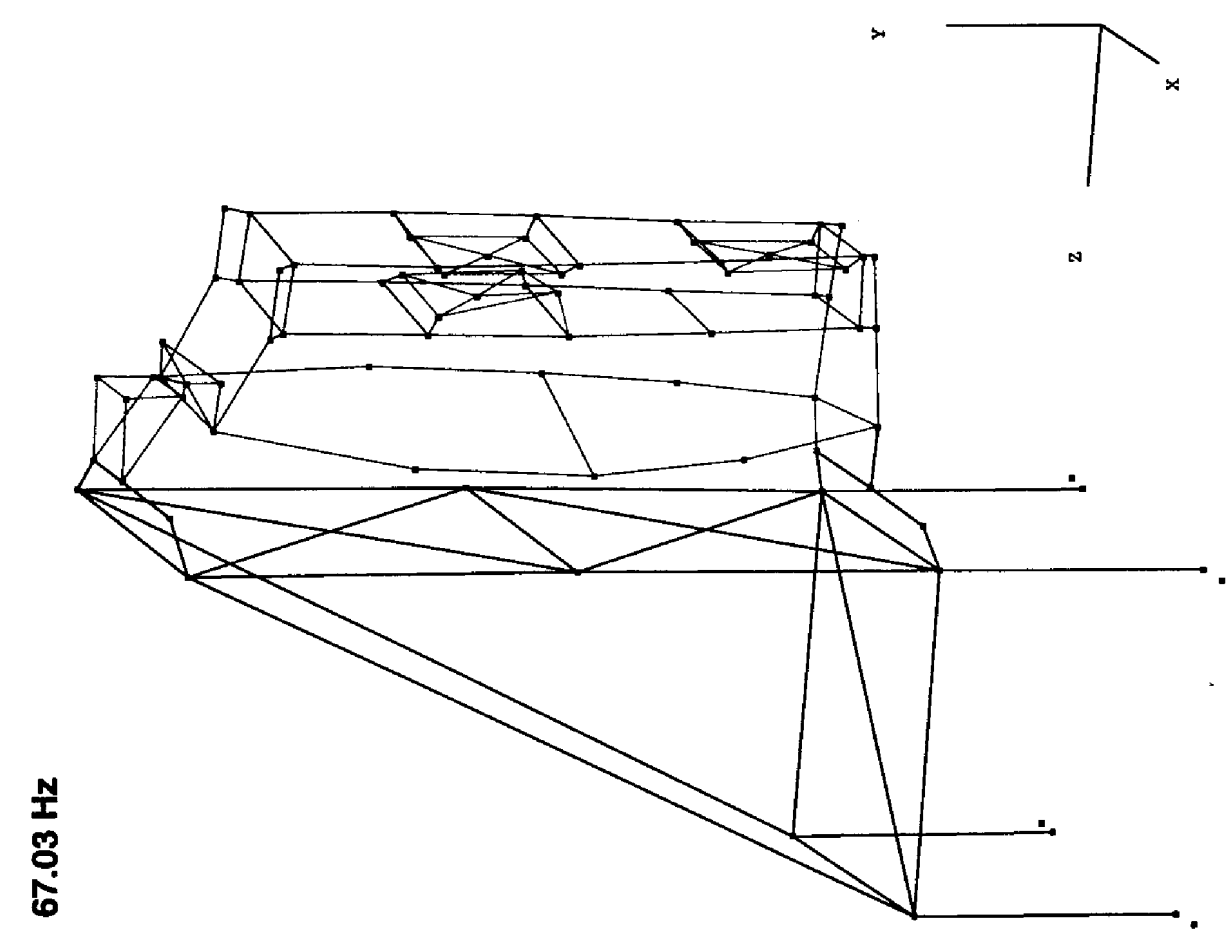

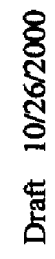

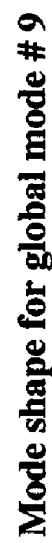

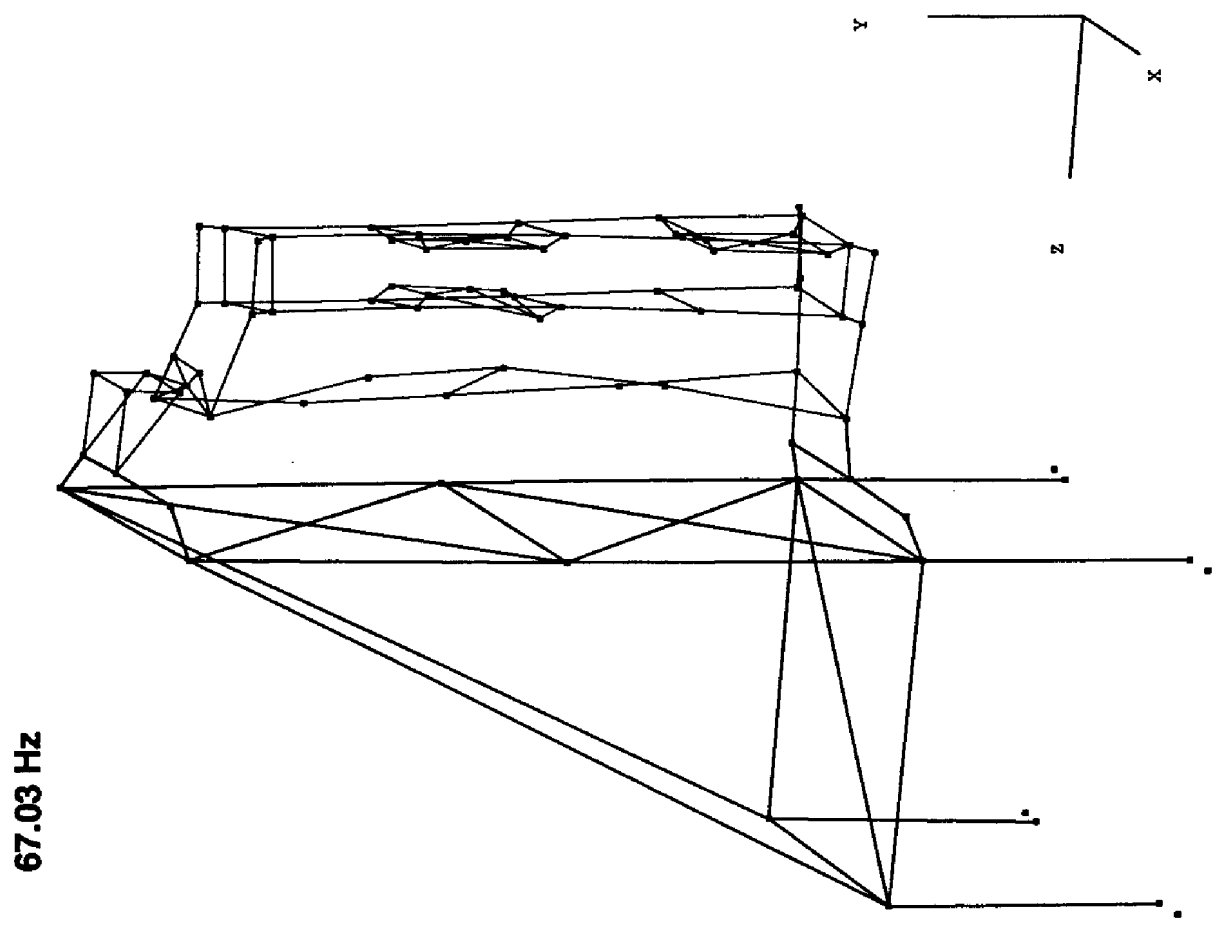

ํ. 


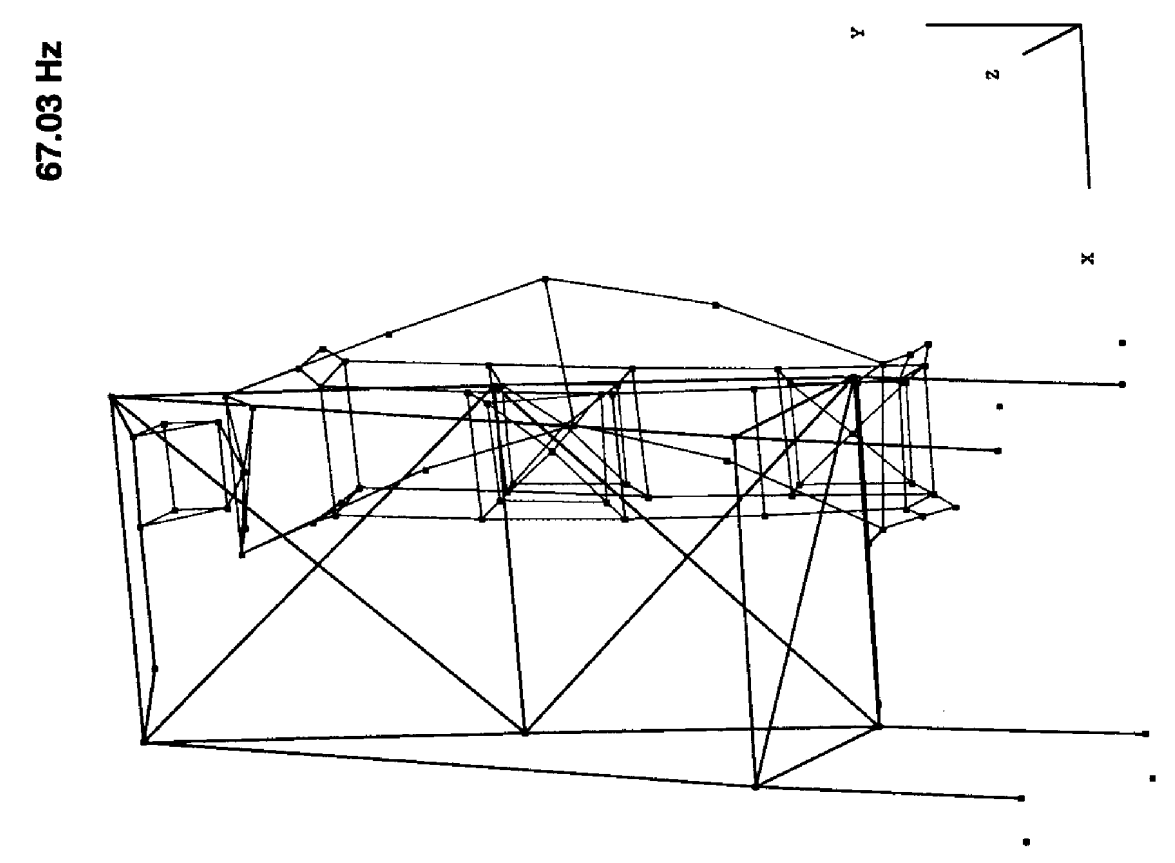

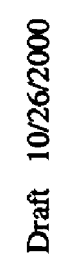

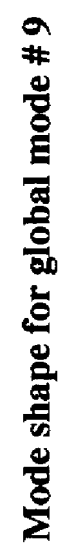

$\frac{1}{8}$

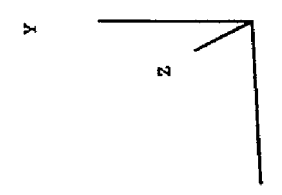

สุ่ 
University of California

Lawrence Livermore National Laboratory

Technical Information Department

Livermore, CA 94551

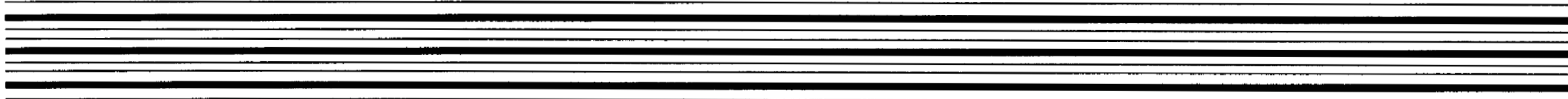

